NBSIR 84.2820 (FDA) Reference $\quad \begin{aligned} & \text { NBS } \\ & \text { Publi- } \\ & \text { cations }\end{aligned}$

\title{
Information on Polymeric Materials Used In Orthopedic Devices
}

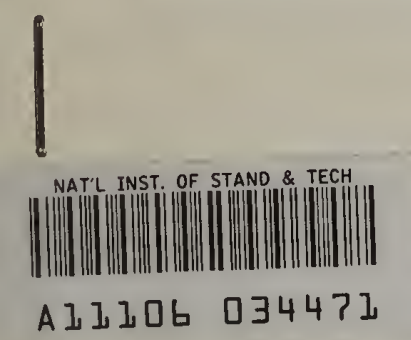

Task 80-01, NBS-Bureau of Medical Devices Interagency Agreement

January 1984

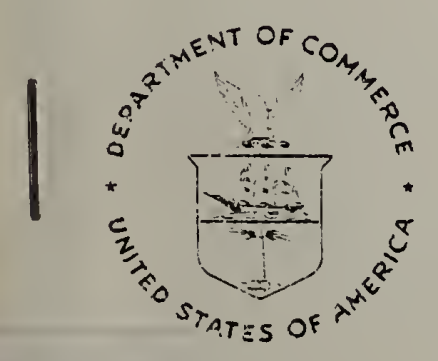
$\cdots Q C-$
100
EPARTMENT OF COMMERCE, Malcolm Baldrige, Secretary
.456 IAL BUREAU OF STANDAECS, Ernest Ambier, Director





\section{Information on Polymeric Materials Used In Orthopedic Devices}

J.M. Crissman

G.B. McKenna

Task 80-01, NBS-Bureau of Medical

Devices Interagency Agreement

January 1984

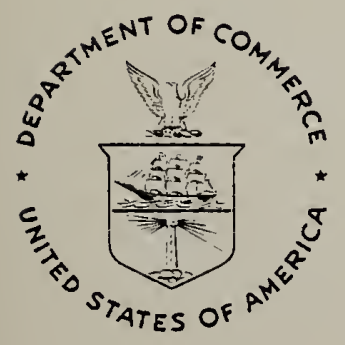

U.S. DEPARTMENT OF COMMERCE, Malcolm Baldrige, Secretary NATIONAL BUREAU OF STANDARDS, Ernest Ambler, Director 



\section{Abstract}

This report provides information on the two polymeric materials most commoniy used in the fabrication of orthopedic implants. The work was done as part of Task 80-01 NBS-FDA/BMD Interagency Agreement. The two materials described are ultra high molecular weight polyethylene UHMWPE and polymethylmethacrylate (PMMA) bone cement. The report contains information on such subjects as specifications (ASTM), raw materials characterization, processing, morphology, mechanical properties, and wear. 
This report has been prepared for the Food and Drug Administration, Bureau of Medical Devices, as part of Task 80-01 NBS-BMD Interagency Agreement.

The technical monitors for this effort were Mr. Daniel J. Chwirut of the Center for Medical Device Analysis, and Dr. James G. Dillon of the Division of Surgical and Rehabilitation Devices, Bureau of Medical Devices, Department of Health and Human Services, FDA, Washington, D.C. The principal investigator was $\mathrm{Dr}$. John $\mathrm{M}$. Crissman and the project leader was Dr. Gregory B. McKenna.

The authors gratefully acknowledge the assistance of Dr. Fred A. Khoury who provided the optical and electron micrographs concerned with ultra high molecular weight polyethylene. In addition the authors wish to thank the following publishers for permission to reporduce in this report certain figures taken from journal articles: John Wiley \& Sons, New York; Pergamon Press, Inc., Elmsford, New York; Butterworth Scientific, Ltd., Surrey, England; the American Society for Testing and Materials (ASTM), Philadelphia, PA; the Journal of Bone and Joint Surgery, Boston, MA. and United Trade Press Limited, London. 


\section{Introduction}

This report provides information on the two polymeric materials most commonly used in the fabrication of components for orthopedic implants. Specifications for both materials are listed in the American Society for Testing and Materials. Each polymer is discussed in a separate chapter with the headings and paragraph numbering system designed to be compatible with those used in the chapters prepared by Eagle Engineering, Inc., Houston, Texas describing the six metal alloys used in orthopedic implants.

The two materials to be described are ultra high molecular weight polyethylene (UHMWPE) and polymethylmethacrylate (PMMA) bone cement. UHMWPE is used in the fabrication of implant components such as acetabular cups (hip replacement) and tibial plateaux (knee reconstruction). PMMA bone cement is used to secure the implant components to bone as well as act as a space filler material in repair of diseased bones.

Since in clinical use the function of the two polymeric materials is quite different, the same information may not in all cases be available for both. Moreover, specific properties or characteristics which are important in determining performance may be different in the two cases. The properties provided are typical and should not be regarded as valid design numbers or design criteria.

A section on wear has been included in the chapter on UHivPE. Wear represents an important aspect of materials characterization and performance in applications such as orthopedic devices, yet it remains a most difficult phenomenon to quantify. As in the case of metals, the results are often contradictory and in dispute. To a large extent this is believed to be due to differences in test procedures, variations 
in specimen geometry, and the methods in which wear is evaluated and quantified. There remains a need for the development of more standardized test procedures for the determination of wear and for making quantitative comparisons of wear results. 
2. Ultra High Molecular Weight Polyethylene. . . . . . . 2-1

2.1 Trade Names and Specifications ......... . 2-1

2.1.1 Trade Names ... . . . . . . . . . 2-1

2.1.2 Specifications. . . . . . . . . 2-1

2.2 Description of Terms (ASTM Grade). . . . . . 2-1

2.3 Virgin UHMWPE Powder Requirements (ASTM Grade) . . . 2-2

2.3.1 Generic Properties. . . . . . . . . . . 2-2

2.3.2 Nongeneric Properties....... . 2-2

2.4 UHMWPE Fabricated Form Requirements (ASTM Grade) . . . 2-3

2.4.1 Compositional Requirements. . . . . . . . 2-3

2.4.2 Physical Requirements .......... 2-3

2.4.3 Mechanical Requirements ......... 2-3

2.5 Sampling (ASTM Grade). . . . . . . . . 2-4

2.6 Processing Information .......... 2-4

2.6.1 Raw Polymer Characterization. . . . . . . 2-4

2.6.1.1 Morphology . . . . . . . . 2-4

2.6.1.2 Density. . . . . . . . . . 2-6

2.6.1.3 Compaction ....... . . 2-7

2.6.1.4 Melting Behavior........ 2-8

2.6.2 Compression Molding . . . . . . . 2-8

2.6.3 Characterization of the Fabricated Form . . . 2-10

2.6.3.1 Density. . . . . . . . . . 2-10

2.6.3.2 Morphology ......... . 2-12

2.6.3.3 Machining. . . . . . . . . 2-15

2.6.3.3.1 Sawing. ........ 2- 2-15

2.6.3.3.2 Milling ........ 2- 2-16

2.6.3.3.3 Drilling. . . . . . . . 2-17

2.6.3.3.4 Turning....... 2- 2-17

2.7 Mechanical Properties. . . . . . . . . . 2-17

2.7.1 Constant Rate of Elongation . . . . . . 2-18

2.7.2 Impact Resistance .... . . . . . . . 2-19

2.7.2.1 Tensile Impact . . . . . . . . . 2-19

2.7.2.2 Izod Impact. . . . . . . . . . . 2-19

2.7.3 Creep and Recovery. . . . . . . . . . . . 2-20

2.7.3.1 Short Time Creep and Recovery at

Small Deformations...... 2-20

2.7.3.2 Long Tjme Creep at Smali Deformations. . 2-28

2.7.3.3 Creep at Large Deformations. . . . . . 2-33

2.7.4 Stress Relaxation........ . . 2-37

2.7 .5 Fatigue . . . . . . . . . . . 2-40 
2.8 Wear . . . . . . . . . . . 2-44

2.8.1 Types of Wear . . . . . . . . . 2-44

2.8.2 Methods for Wear Testing . . . . . . 2-45

2.8.3 Wear Rate Measurements . . . . . . 2 2-45

2.8.4 Wear Rate Data . . . . . . . . 2-48

2.9 Effects of High Energy Radiation ....... 2-53

2.9.1 Density and Crystallinity. ...... 2-54

2.9.2 Melting Behavior........ 2- 2-56

2.9.3 Tensile Yield Stress....... . 2-58

2.9.4 Tensile Yield Point Elongation.... 2-60

2.9.5 Tensile Modulus . . . . . . . . 2-60

2.9 .6 Impact Strength ......... 2- . 2-62

2.9.7 Surface Hardness . . . . . . . . . . 2-62

2.9 .8 Creep ............ 2- . . 2-64

2.9.9 Stress Relaxation ....... 2-68

2.9.10 Fatigue ............ 2-. 2-68

2.9.11 Effect of Radiation on Wear.... 2-69 
2. ULTRA HIGH :HOLECULAR WEIGHT POLYET'HYLENE (UHMWPE)

2.1 Trade Names and Specifications

2.1.1 Trade Naliles 1

UHMWPE used in the manufacture of surgical implants is marketed under the names and designations $1900^{2}$ and Hostalen RCH $1000 c^{3}$.

\subsubsection{Specifications ${ }^{4}$}

The principal specifications for 1 inear UHMWPE powder intended for use in surgical implants, and fabricated forms, are those contained in ASTM F-648-80, Standard Specification for ULTRA-HIGH-MOLECULAR-WEIGHT POLYETHYLENE POWDER AND FABRICATED FORM FOR SURGICAL IMPLANTS $[1]^{5}$.

\subsection{Description of Terms (ASTM Grade)}

2.2.1 generic property- that property which is determined solely by the chemical composition and structure of the virgin polymer. 2.2.2 virgin polymer powder - the form of UHMUNE as obtained from the manufacturer and prior to fabrication into a bulk shape.

2.2.3 fabricated form any buIk shape of UH!WPE, fabricated from the virgin polymer powder, used during the process of fabricating surgical implants prior to packaging and sterilization.

Certain commercial materials are identified in this report in order to specify them adequately. In no case does such identification imply recomriendation or endorsement by the National Bureau of Standards.

${ }^{2}$ Registered Trademark - Hercules Inc., Wi Tmington, Delaware.

${ }^{3}$ Registered Trademark - American Hoechst Corporation, Somerville, New Jersey. ${ }^{4}$ Reprinted, with permission from the Annual Book of ASTM Standards. Copyright, ASTM, 1916 Race Street, Philadelphia, PA 19103.

5 Numbers in brackets denote references to the literature found at the end of this section. 


\subsection{Virgin UHMWPE Powder Requirements (ASTM Grade)}

\subsubsection{Generic Properties:}

2.3.1.1 The virgin polymer shall be a linear homopolymer of e thylene.

2.3.1.2 The molecular weight of the polymer powder shall be indicated by determining either the relative solution viscosity or the flow value. The relative solution viscosity shall not be less than 1.95. The prescribed method for the determination of the relative solution viscosity is ASTM 01601 . The flow value shall not be less than $0.2 \mathrm{MPa}$ when determined by ASTM F-648 Annex A2.

\subsection{2 itongeneric Properties:}

2.3.2.1 The polymer powder shall not contain extraneous matter such as dirt, lint, silica and discoloring materials of diameter greater than 300 um. When viewing a sample prepared in accordance with section 7.1 .2 of ASTM F648-30, the concentration of visible particles of extraneous matter shall not be greater than 10 per $400 \mathrm{~cm}^{2}$.

2.3.2.2 The concentration of trace elements in the polymer powder shall not exceed:

$\begin{array}{cc}\text { Element } & \text { ppm, max } \\ \text { A1 } & 50 \\ \text { Ti } & 300 \\ \text { Ca } & 100 \\ \text { Cl } & 90\end{array}$

2.3.2.3 The content of any other trace element shall not exceed $10 \mathrm{ppm}$.

2.3.2.4 Total trace elements shall not exceed 550 ppm.

2.3.2.5 All powder shall pass a Ho. 16 (1.18mm) sieve. 


\subsection{UHMWPE Fabricated Form Requirements - (ASTM Grade)}

\subsubsection{Compositional Requirements:}

2.4.1.1 No stabilizers or processing aids are to be added to the virgin polymer powder during manufacture of a fabricated form. 2.4.1.2 The surface of a fabricated form shall not contain particles of residue of diameter greater than $300 \mu \mathrm{m}$. The concentration of the visible particles shall not be greater than 10 particles per $400 \mathrm{~cm}^{2}$.

\subsubsection{Physical Requirements:}

2.4.2.1 The fabricated form sha11 be fused to the extent that light patches larger than $300 \mu \mathrm{m}$ in diameter sha11 not be observed.

2.4.2.2 The density of the fabricated form shall be within the range from 0.930 to $0.944 \mathrm{~g} / \mathrm{cm}^{3}$.

\subsubsection{Mechanical Requirements:}

2.4.3.1 UHMWPE in fabricated form from which surgical implants are made shall meet the requirements listed in Table 2.4.3.1.

Table 2.4.3.1 UHMWIPE Fabricated Form Requirements

$\quad$ Property
Tensile strength at $23^{\circ} \mathrm{C}$
Ultimate
Yield
Elongation
Ultimate
Yield
Elongation
Ul tiliate
Yield
Elongation
Izod impact strength
Deformation under load

Hardness
Fabricated Form Type

molded, machined molded, machined nolded, macninied extruded, machined extruded, machined extruded, machined compression molded compression molded compression molded

all types

a 11 types

al1 types
ASTM Test Method Requirement, min

0638 (Speed C)

$34 \mathrm{YPa}(5000 \mathrm{psi})$

$21 \mathrm{MPa}(3000$ psi)

$300 \%$

$300 \%$

$21 \mathrm{MPa}(3000 \mathrm{psi})$

$200 \%$

$27 \mathrm{MPa}$ (4000 psi)

$19 \mathrm{i:Pa}$ (2800 psi)

$350:$

$0256\left(A_{1}\right) \quad$ nonbreak

$0621(A)(7$ ipa $2:$ deformation

(1000 psi) for after 90-min

$24 \mathrm{~h})$

o 2240(Shore 0) recovery

60 


\subsection{Sampling (ASTM Grade)}

2.5.1 Where applicable, the requirements for each lot of powder and fabricated form by sampling sizes and procedures shall be done according to ASTM Method 01898 Standard Recommended Practice for SAMPLING OF PLASTICS.

\subsection{Processing Information}

\subsubsection{Raw Polymer Characterization}

\subsubsection{Morphology}

UHMWPE polymer, in its as polymerized (i.e., nascent) state consists of fine particles. The particles are irregularly shaped and vary in size from approximately 80 to $330 \mu \mathrm{m}[2,3]$. Scanning electron micrographs showing one example of the nascent UHMWPE powder are presented in Figure 2.6.1.1. The surfaces of the particles are highly convoluted and appear to be composed of clusters of minute spheres. Whereas portions of the surface of the particle are relatively smooth, others exhibit a highly porous appearance. At higher magnification the gaps or voids in the porous regions can be seen to be bridged by thin fibrils which are 50 to $100 \mathrm{~nm}$ in diameter. The various origins of fibrils in nascent polyolefins have been reviewed by Marchessault et al [4]. The particle size distributions for the different commercial powders have been found, from sieve analysis, to have roughly log normal distributions [3]. 


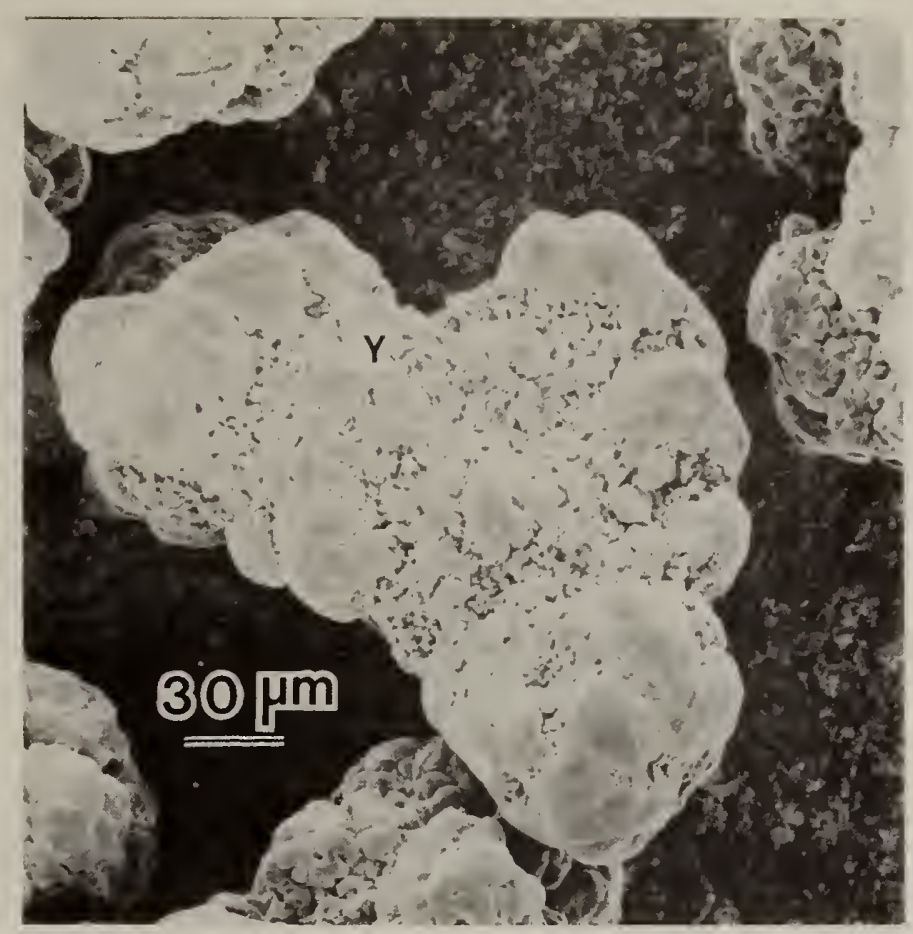

(a)

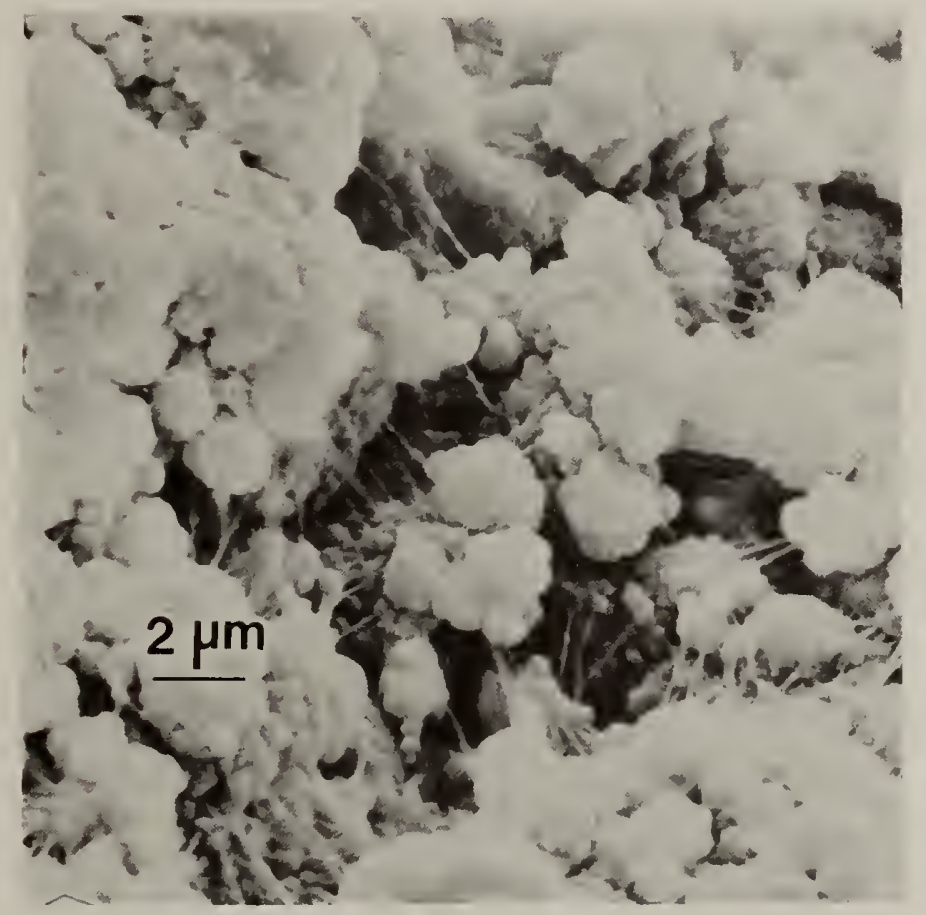

(b)

Fig. 2.6.1.1 (a) Scanning electron micrograph of a particle of raw UHMWPE. (b) The region to the right of the area $y$ shown at higher magnification. Note the fibrils bridging the gaps or voids in the porous regions. (From reference [2]). 



\subsubsection{Density}

The density of nascent UHiWWPE powder can be determined by one or more of several different methods described in ASTM D792 [5], ASTM B212 [6], ASTM B331 [6], and ASTM B527 [6]. Table 2.6.1.2 lists typical values of the density as determined by each method.

Table 2.6.1.2 Typical Values of Density for UHMWPE Powders Used in the Fabrication of Surgical Implants. 1

\begin{tabular}{llc}
\hline Measure of Density & Density $\mathrm{g} / \mathrm{cm}^{3}$ & Method of Determination \\
\hline theoretical & $0.945-0.964$ & ASTM D792 \\
apparent & $0.34-0.40$ & ASTM B272 \\
green ${ }^{2}$ & $0.76-0.82$ & ASTM B331 \\
tap & $0.41-0.47$ & ASTM 6527 \\
\hline
\end{tabular}

$1_{\text {Data taken from reference [3] }}$

${ }^{2}$ For a compaction pressures greater than $100 \mathrm{MPa}$. 
In processing, the apparent density is used to determine the tooling size and storage volume. The apparent density is determined to a large extent by particle size, size distribution, and morphology. Tap density refers to the packing possible when the barriers to interparticle movement are overcome.

\subsubsection{Compaction}

The compressibility of a polymer powder can be represented as a compaction efficiency, or "densification parameter" (DP), defined by:

$$
D P=\frac{\text { green density - apparent density }}{\text { theoretical density - apparent density }}
$$

The densification parameter increases with increased compaction pressure and, in the case of UHMWP $\cong$ powders, reaches a plateau value at pressures above about $100 \mathrm{MPa}[3,7]$. Therefore, there appears to be no particular advantage in using compaction pressure greater than 100 to $200 \mathrm{MPa}$. The maximum DP attainable for UHMWPE powders ranges from about 0.66 to $0.80[3]$.

\subsubsection{Melting Behavior}

It is typical of crystallizable polymers such as polyethylene that their melting temperatures are dependent upon their previous thermal and mechanical histories, and are lower than the equilibrium melting point, i.e. the melting point of an ideal extended chain crystal of the polymers $\left(\sim 19 \mathrm{~K}, \sim 146^{\circ} \mathrm{C}\right)[9]$. UHMWPE powders, as polymerized, exhibit a very high degree of crystallinity. Based upon specific enthalpy of fusion measurements obtained from differential scanning calorimetry [2 3$]$, the percent crystallinity $(x)$ is found to be in the range $x=60-78$, and the inelting point of the crystals is in the range $413 \mathrm{~K}-415 \mathrm{~K}\left(140^{\circ} \mathrm{C}-143^{\circ} \mathrm{C}\right)$. This feature of UHM!!PE refiects 
the favorable crystallization conditions present during polymerization. Upon melting and subsequent recrystallization, the percent crystallinity drops into the range $x=51-63$, depending on the particular polymer being used and the rate at which it is cooled from the melt. Upon remelting the melting point drops into the range $408 \mathrm{~K}-417 \mathrm{~K}\left(135^{\circ} \mathrm{C}-138^{\circ} \mathrm{C}\right)$ depending on how rapidly the polymer is cooled following the first melting.

\subsubsection{Compression Molding}

Because of its high molecular weight and very high melt viscosity, UHMWPE is not easily processed by conventional techniques such as injection molding and extrusion. Processing techniques are further restricted by the requirements in ASTM F648 that no stabilizers or processing aids can be added to the virgin polymer powder. Fabricated forms of UHMWPE polymer are most commonly produced by compression molding of the powder. The finished prosthesis is either machined from a block or sheet of previously compression molded material, or, in some cases, is direct press molded from the powder. The latter process is more difficult requiring uniform temperature control during both heating and cooling, and if the shape of the piece is complex, the pressure during cooling may not be evenly distributed over the whole of the piece.

Each manufacturer of UHMWPE powder $[9,10]$ has a recommended procedure for compression molding of the powder. ${ }^{5}$ A list of several of the more important procedures is provided below.

${ }^{5}$ One manufacturer of UHMWPE supplies the polymer in sheet form only when it is intended for use in surgical implants. 


\section{Procedures for Compression Molding UHMWPE}

1. The mold cavity should have adequate depth to accomodate a powder charge approximately 2.5 to 3 times the thickness of the final piece.

2. The powder should be cold pressed at a pressure of from 10-20 MPa (1450-2900 psi) for a period of from 1-10 minutes. This step is important in order to expel most of the entrapped air from the powder. The cold pressing step can be done either prior to heating of the press or during the early stages of heating with the platens already at temperature.

3. After cold pressing the pressure is reduced into the range 2-5 $\mathrm{MPa}$ (290-715 psi) during heating. The press is heated to a temperature between $200^{\circ} \mathrm{C}$ and $220^{\circ} \mathrm{C}$ and held at that temperature for sufficient time to insure that all the material is in the molten state.

4. A pressure in the range from $10-20 \mathrm{MPa}(1450-2900 \mathrm{ps} i)$ is again applied and maintained during cooling. Insufficient pressure during cooling may result in cavities inside the piece and sink marks on the surface.

5. The rate at which the mold is cooled will be determined by the value of density desired for the molded form (see Section 2.6.3). Water cooling of the platens at a rate as high as $20^{\circ} \mathrm{C}$ per minute cooling of the platens under ambient conditions will generally yield a density in the range $0.930-0.940 \mathrm{~g} / \mathrm{cm}^{3}$. 


\subsubsection{Characterization of the Fabricated Form}

\subsubsection{Density}

The density of the fabricated form will depend upon both the rate at which piece is cooled during molding and the particular UHMWPE being used. Subsequent heat treatment may increase or decrease the density. Examples of the density variability which can be found in molded UHMMUPE are given in Table 2.6.3.1.

Table 2.6.3.1 Density (p) and Percent Crystallinity $(x)$ of compression molded UHMWIPE Prepared under Varied Thermal Histories (From Reference [12])

\begin{tabular}{lll}
\hline UHMWPE & Dens jty & at\% \\
Polymer & $\mathrm{g} / \mathrm{cm}^{\mathrm{a}}$ & Crystallinity
\end{tabular}

\begin{tabular}{lll}
\hline 1 (Quenched) $^{\mathrm{b}}$ & 0.923 & 51 \\
1 (Slowly Cooled) $^{\mathrm{c}}$ & 0.935 & 59 \\
1 (Annealed) $^{\mathrm{d}}$ & 0.942 & 63
\end{tabular}

$\begin{array}{lll}2 \text { (Quenched) }^{b} & 0.925 & 52 \\ 2 \text { (Slowly Cooled) }^{c} & 0.941 & 63 \\ 2 \text { Annealed) }^{d} & 0.953 & 71\end{array}$

a - Measured at $23^{\circ} \mathrm{C}$ in a water athanol density gradient colurin.

$b$ - Obtained by reheating a sheet of the slowly cooled polymer to $200^{\circ} \mathrm{C}$ between chromed photographic plates followed by submersion into ice water.

$c$ - Cooled in the press at a rate of $\sim 1^{\circ} \mathrm{C}$ per minute.

d- Annealed under an $\mathrm{N}_{2}$ Atmosphere at $130^{\circ} \mathrm{C}$ for 72 hours followed by $135^{\circ} \mathrm{C}$ for 48 hours. 
The two UHMW polymers represent different lots of material obtained from the same manufacturer. Polymers 1 and 2 had manufacturer specified intrinsic viscosities* of $\approx 25$ and $\approx 13$ deciliters per gram, which based on the manufacturers method for estimating molecular weight from dilute solution viscosity measurements, correspond to molecular weights of approximately $4 \times 10^{6}$ and $2 \times 10^{6}$ respectively. Both lots of polymer satisfy the requirements contained in Section 4.1.2.1 of ASTM F-648 $\left(n_{\operatorname{Rel}}>1.95\right)$ for UHMWPE used in surgical implants. Note, however, that both quenched samples and one of the annealed samples have densities which are not within the range specified in Section 5.2.2 of ASTM F-648. ( $\left(0=0.930-0.944 \mathrm{~g} / \mathrm{cm}^{3}\right)$

*The deterinination of the intrinsic viscosity of UHMAISPE from dilute solution viscosity measurements is subject to a number of problems and uncertainties which have been discussed in detail by Wagner and Dillon [13]. 


\subsubsection{Morphology}

Unlike conventional low molecular weight polyethylenes, compression molded UHMWPE retains a memory of the particulate nature of the raw polymer powder. An example of this phenomenon is shown in Figure 2.6.3.2.1. This "grain memory" persists even in samples for which the dwell temperature in the melt is as much as $90^{\circ} \mathrm{C}$ above the melting point. Since the mechanical properties of the molded form will be influenced by the effectiveness of the compaction and fusion of the raw polymer particles, it is important that the dwell temperature in the melt be sufficiently high to achieve the optimium fusion of the powder particles, but without serious degradation of the polymer. For most molding operations a dwe 11 temperature in the range from $200-220^{\circ} \mathrm{C}$ is recommended.

Further examination of the bulk polymer reveals (Figure 2.6.3.2.2) that there are substantial variations in fine structure in each cross-section as evidenced by the differences in the size of the birefringent structural units from one region to another. In some regions the birefringent units are barely visible and the corresponding areas exhibit a fine grainy appearance under the polarizing microscope. Under normal conditions used to mold UHMIIPE large well developed spherulites are not observed. However, rotation of the sample about the microscope axis while keeping the crossed polarizer and analyzer fixed, indicates that some of the larger birefringent units are incipiently spherulitic or axialetic in character. The absence of well developed spherulites is likely a consequence of a high nucleation density with the result that evolving spherulites impinge upon their nearest neighbors before attaining 'mature' shapes. 


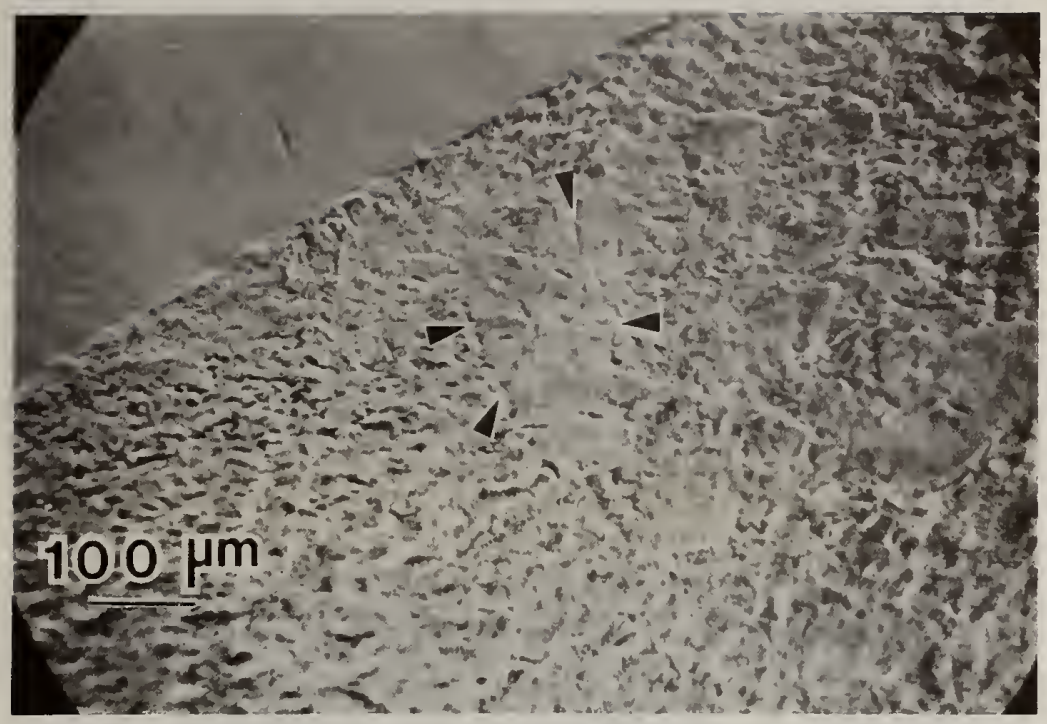

Fig. 2.6.3.2.1 Low magnification micrograph taken in a light microscope (using transmission phase contrast optics) showing a cross-section of a sheet of LHMWPE molded at $200^{\circ} \mathrm{C}$. (MW $\approx 4 \times 10^{6}$, cooling rate in the press $\approx 1^{0} \mathrm{C}$ per minute). Markers point to some of the boundaries between the original raw polymer particles. (From reference 11 ) 



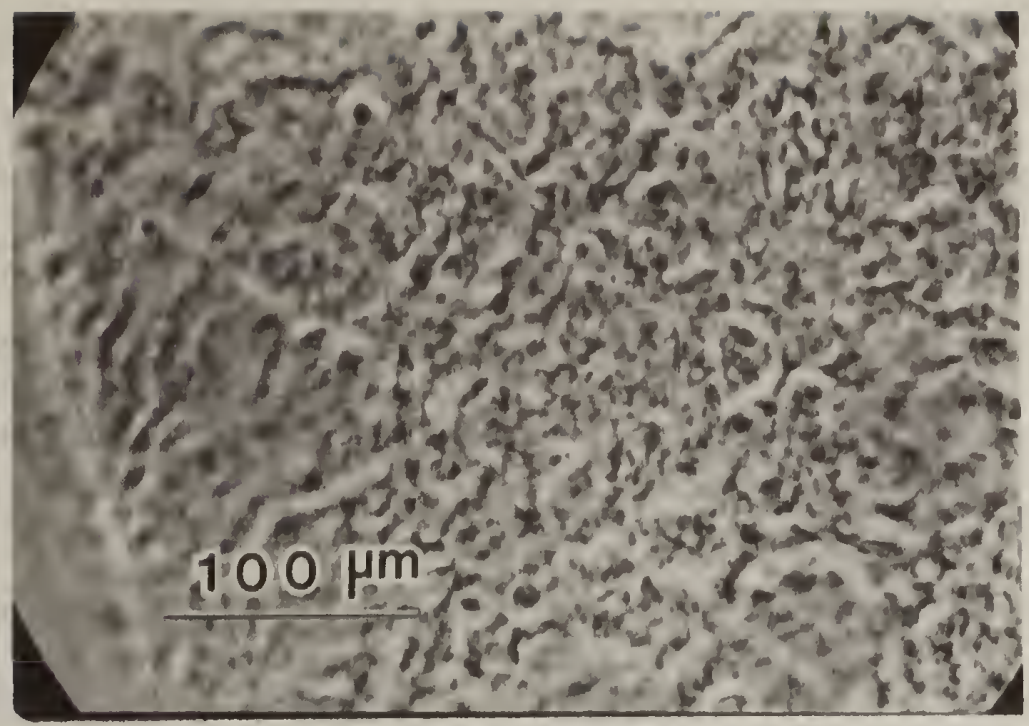

(a)

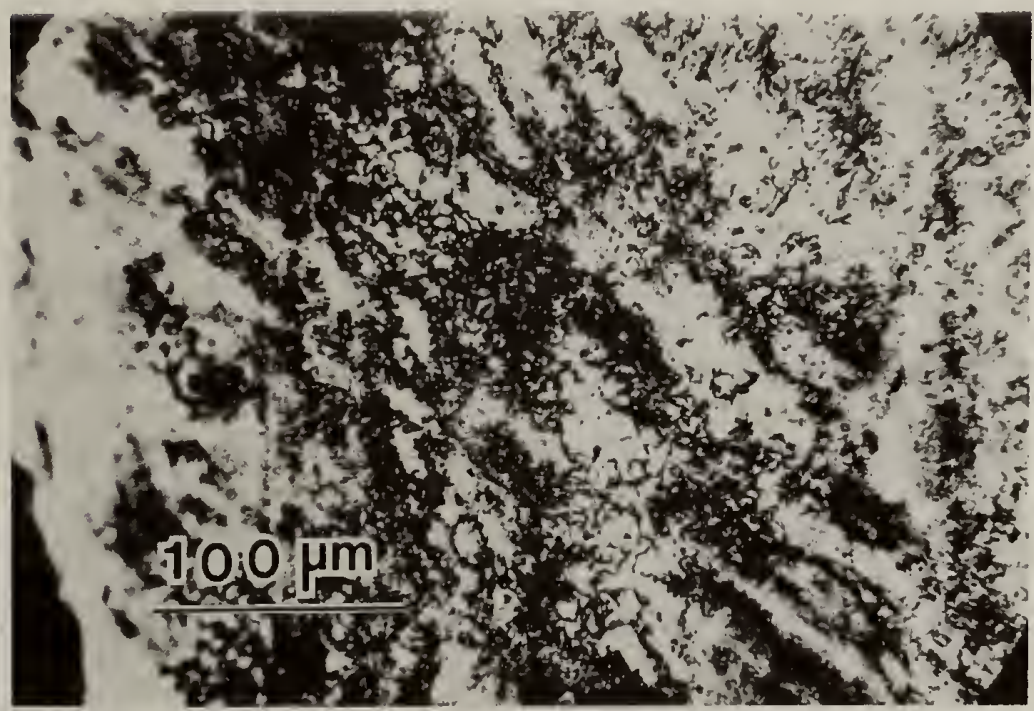

(b)

Fig. 2.6.3.2.2 Light micrographs of an area in a cross-section of a sheet of UHMWPE (Mw $\approx 4 \times 10^{6}$ ) molded at $200^{\circ} \mathrm{C}$. (a) Phase contrast optics, (b) crossed polarizer and analyzer. Note the variation in the sizes of the birefringent structures in (b). The fine variations in contrast in (a) are associated with the birefringent structures in the sample. (Frorn reference 11) 



\subsubsection{Machining}

Molded shapes of UHMWPE can readily be sawed, turned, planed, milled, or drilled using equipment designed for fabricating metals and wood $[8,14]$. To obtain high quality machined surfaces sharp tools should always be used. In many applications normal tool steel is adequate, but stellite or carbide tipped metal cutting tools are recommended. The optimum cutting speed is in the range from 250 to $1500 \mathrm{~m} / \mathrm{min}$. The lower cutting speeds do not cause significant heat buildup and sticking, whereas water cooling or dilute water soluble-oil lubrication is reauired when cutting at the higher speeds.

\subsection{Sawing}

UHINWPE shapes can be cut with standard power tools which have sharp, wide-spaced teeth. Band saws are particularly applicable since the blade carries off the heat. To prevent the saw blade from becoming jammed, the teeth should have a slight amount of set. When using circular saws, Tungsten carbide blades are recominended. The higher the cutting speed the better the surface finish will be, provided significant heat buildup does not occur.

Table 2.6.3.3.1 provides recommended settings and speeds for sawing Uitill.PE.

Table 2.6.3.3.1 - Recommendations for Sawing UHMWPE Fabricated Forms ${ }^{a}$

\begin{tabular}{lcc}
\hline & Band Saw & Circular Saw \\
\cline { 2 - 3 } Clearance & 15 & 15 \\
Angle, degrees & $5-2$ & $0-5$ \\
Angle, cegrees & Harnd & Hand \\
Feed, cm/rev. & $915-1840$ & $315-2745$ \\
Cutting speed, ir/min & $.30-7.0$ & \\
Tooth pitch, cin & \\
\hline
\end{tabular}

${ }^{a}$ From reference 14 


\subsection{Milling}

Semifinished forms of UHMWPE can be milled on any standard or high speed top milling machine. To assure the most efficient removal of chips, milling tools should be graduated to allow for good tool clearance. Cutting speeds of from 180 to $540 \mathrm{~m} / \mathrm{min}$ are recommended, with a feed rate of approx imately $0.025 \mathrm{~cm} / \mathrm{rev}$. L. . .3.3.3 Orilling

Drilling of UHMWPE $c$ an be done on a lathe, milling machine, or drill press. With al lowances for good chip removal, local overheating can be largely avoided. If cool ants, such as compressed air, water, or dilute soluble oil are not used, the drill should be removed from the hole frequently to clean out the chips and prevent overheating. A set of specifications for drilling UHWWPE is given in Table 2.6.3.3.3.

Table 2.6.3.3.3 Specifications for Orilling UHWWPE Fabricated Forms ${ }^{a}$

\begin{tabular}{|c|c|c|c|c|c|}
\hline $\begin{array}{l}\text { Hole } \\
\text { Diameter, } \\
\text { cm. }\end{array}$ & $\begin{array}{l}\text { Angle of } \\
\text { Point, } \\
\text { degrees }\end{array}$ & $\begin{array}{c}\text { Clearance, } \\
\text { degrees }\end{array}$ & $\begin{array}{l}\text { Helix, } \\
\text { degrees }\end{array}$ & $\begin{array}{l}\text { Feed, } \\
\mathrm{cm} . / \text { rev. }\end{array}$ & $\begin{array}{l}\text { Cutting } \\
\text { speed, } \\
\mathrm{m} / \mathrm{min}\end{array}$ \\
\hline $\begin{array}{l}<2.03 \\
2.03-4.06 \\
>4.06\end{array}$ & $\begin{array}{r}60 \\
120 \\
140\end{array}$ & $\begin{array}{l}15-20 \\
12-15 \\
12-15\end{array}$ & $\begin{array}{l}0 \\
0 \\
0\end{array}$ & $\begin{array}{l}.02 \\
.02 \\
.038\end{array}$ & $\begin{array}{r}75 \\
75 \\
100\end{array}$ \\
\hline
\end{tabular}




\subsection{Turning}

UHMWPE can be turned without difficulty on conventional wood - or metal-working lathes. Cooling is generally only required for large depth of cut. With feeds of from .0045$.0127 \mathrm{~cm} / \mathrm{rev}$. surface speeds up to $180 \mathrm{~m} / \mathrm{min}$. are applicable.

\subsection{Mechanical Properties}

Table 2.7 lists the fabricated form requirements contained in ASTin F-648 for the mechanical properties of UHMWPE used in surgical implants. The minimum requirements listed are, for the most part, based on relatively short time tests. However, the mechanical properties of semicrystalline polymers such as UHMWIPE are highty time dependent. The measured property may be quite sensitive to the rate of straining or the environment. In such cases, data obtained by these tests should not be considered reliable for applications in which the load-time scale or environment is greatly different from that of the test method. For engineering design purposes, tests should be done over a broad load-time scale (including impact and creep) and range of environment. In addition, the time dependent mechanical properties of semicrystalline polymers are influenced by structure or morphol ogy related features such as degree of crystallinity, orientation, spherul ite size, and texture, all features which are determined by both the polymer chemistry and processing.

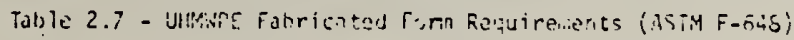

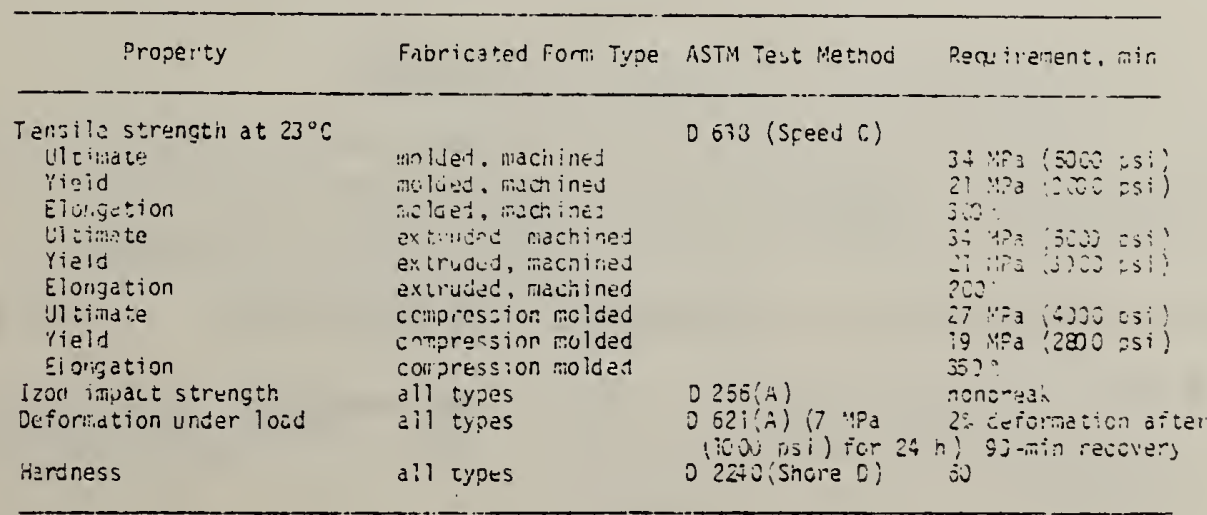




\subsubsection{Constant Rate of Elongation}

Uniaxial tensile stress-strain curves typical of UHMINPE are shown in Figure 2.7.1. Nith LPE refers to normal molecular weight linear polyethylene. UHMWPE materials in general have lower vield strengths but higher ultimate tensile strengths than do IMW polyethylenes. In the post yield region UHAWWE does not exhibit the phenomenon of macroscopic necking but does exhibit strain-hardening. The maximum stretch ratio $(\lambda)$ attainable in UHMWIPE is in the range $6-8$, whereas in NMW PE stretch ratios of 25 or greater can be attained.

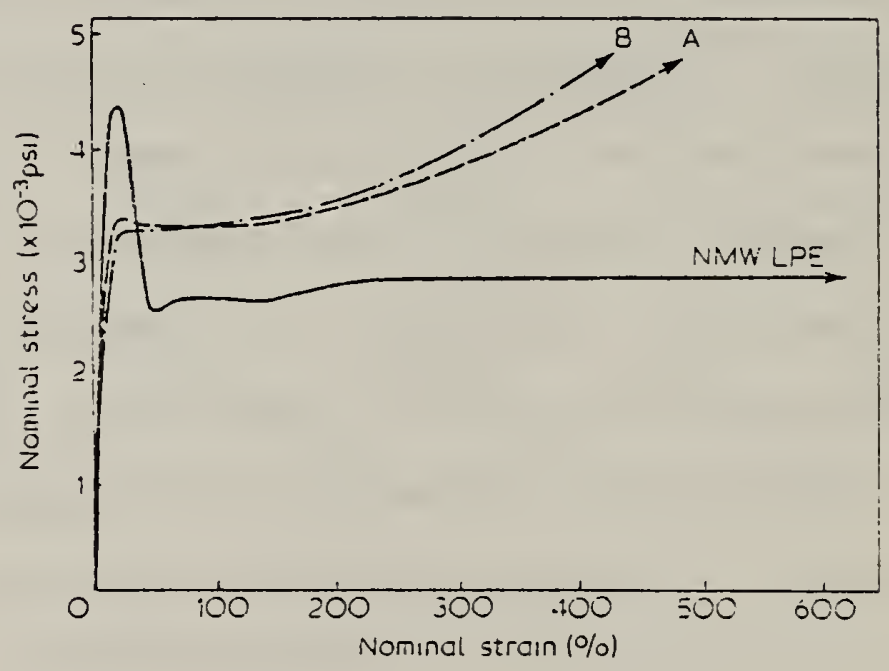

Fig. 2.7.1 Uniaxial tensile noninal stress-strain curves for UHMU.PE-A $\left([n] \approx 19.8 \mathrm{~d}_{\ell} / \mathrm{g}\right)$, UHPWPE-B $([n] \approx 14.8 \mathrm{~d} / \mathrm{g})$, and MMM PE $\left(\eta_{W} \approx 207,000\right)$. The data were obtained in accordance with ASTM 0638. 1 psi $=6.895 \times 10^{3} \mathrm{~Pa}$. [From Bhateja, Polymer, 22, 23 (1981). Reprinted by Dermission of Butterworth] \& Co., Ltd. (]) ]. 


\subsubsection{Impact Resistance.}

Impact resistance refers to the ability of a material to withstand flexural or tensile shock. The methods of measurement involve the determination of the energy required to rupture specimens having standardized geometries.

\subsubsection{Tensile Impact}

Tensile impact can be determined using ASTM D1822,

Standard Method of Test for TENSILE-IMPACT ENERGY TO BREAK PLASTICS AND ELECTRICAL INSULATING MATERIALS [5]. The tensile impact strength of UHMWPE is reported to be in the range 2100-3000 $\mathrm{kJ} / \mathrm{m}^{2}[8,16]$.

\subsubsection{Izod Impact}

Izod impact resistance can be determined using ASTM D256, Standard Method of Test for IMPACT RESISTANCE OF PLASTICS AND ELECTRICAL INSULATING MATERIALS [5]. Figure 2.7.2.2 shows the notched impact strength ( $V$-notch) of UHMIVPE as a function of temperature $[8,17]$.

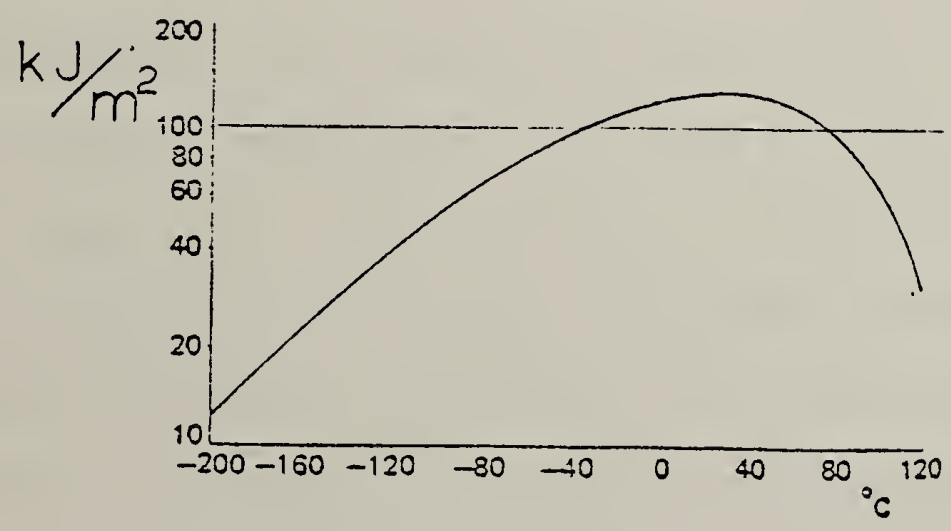

Fig. 2.7.2.2 Notched Impact Strength of UHMNPE as a function of temperature. (From reference 17) 


\subsubsection{Creep and Recovery}

The ability of a material to resist creep and to recover after deformation represents an important aspect of durability and lifetime. In the case of semicrystalline polymers such as UHMWPE the creep behavior can vary significantly depending upon the time scale of the experiment, the magnitude of the applied stress, and the temperature. The description of the creep and recovery behavior is divided into the three following subsections:

(1) Short time creep and recovery at small deformations.

(2) Long time creep at small deformations.

(3) Creep at large deformations.

Short times refer to experiments in which the duration of the creep is less than $10^{5}$ seconds ( 1 day). Small deformations refer to experiments in which the maximum creep strain is less than about 3 percent.

\subsubsection{Short Time Creep and Recovery at Small Deformations}

Tensile creep and recovery curves for UHMMPE ( ${ }_{w} \approx 4 \times 10^{6}$, $\rho=0.935 \mathrm{~g} / \mathrm{cm}^{3}$ ) are shown in Figure 2.7.3.1.1 [21]. In this type of experiment a constant tensile load is applied for a time $t_{1}$ at which time the load is removed and the strain during recovery is determined as a function of time. The time $t=0$ for the recovery corresponds to the time at which the load is removed. The dashed lines represent the strain during recovery which is predicted from viscoelasticity theory [20] assuming a superposition principle of the form

$$
\varepsilon_{R}(t)=\Sigma_{C}\left(t+t_{1}\right)-\Sigma_{C}(t),
$$


where $\varepsilon_{R}(t)$ is the strain during recovery at a time $t$ after a creep experiment of duration $t_{\eta}$, and $\varepsilon_{c}\left(t+t_{\eta}\right)$ and $\varepsilon_{c}(t)$ are the strains at time $t+t$, and $t$ during a creep experiment.

Figure 2.7.3.1.2 presents recovery data from a series of experiments in which the applied stress is the same in each case, but the duration of the creep, $t_{\eta}$, is varied. The dashed lines have the same meaning as in the previous figure. While at the very early times during recovery the predicted and experimental values of strain are in good agreement, at the longer times approaching $t=t_{\eta}$, significant deviations occur. The strain during recovery does not continue to decrease toward zero as predicted by equation (1), but tends to plateau to a finite value. Even for very small deformations and short times under load, UHMWPE exhibits "plasticity," i.e., the material retains a permanent set after creep. Figure 2.7.3.1.3 shows similar creep and recovery data for UHMWPE at $38^{\circ} \mathrm{C}$ and an applied stress of $4 \mathrm{MPa}$. Creep curves at four different temperatures are shown in Figure 2.7.3.1.4. 


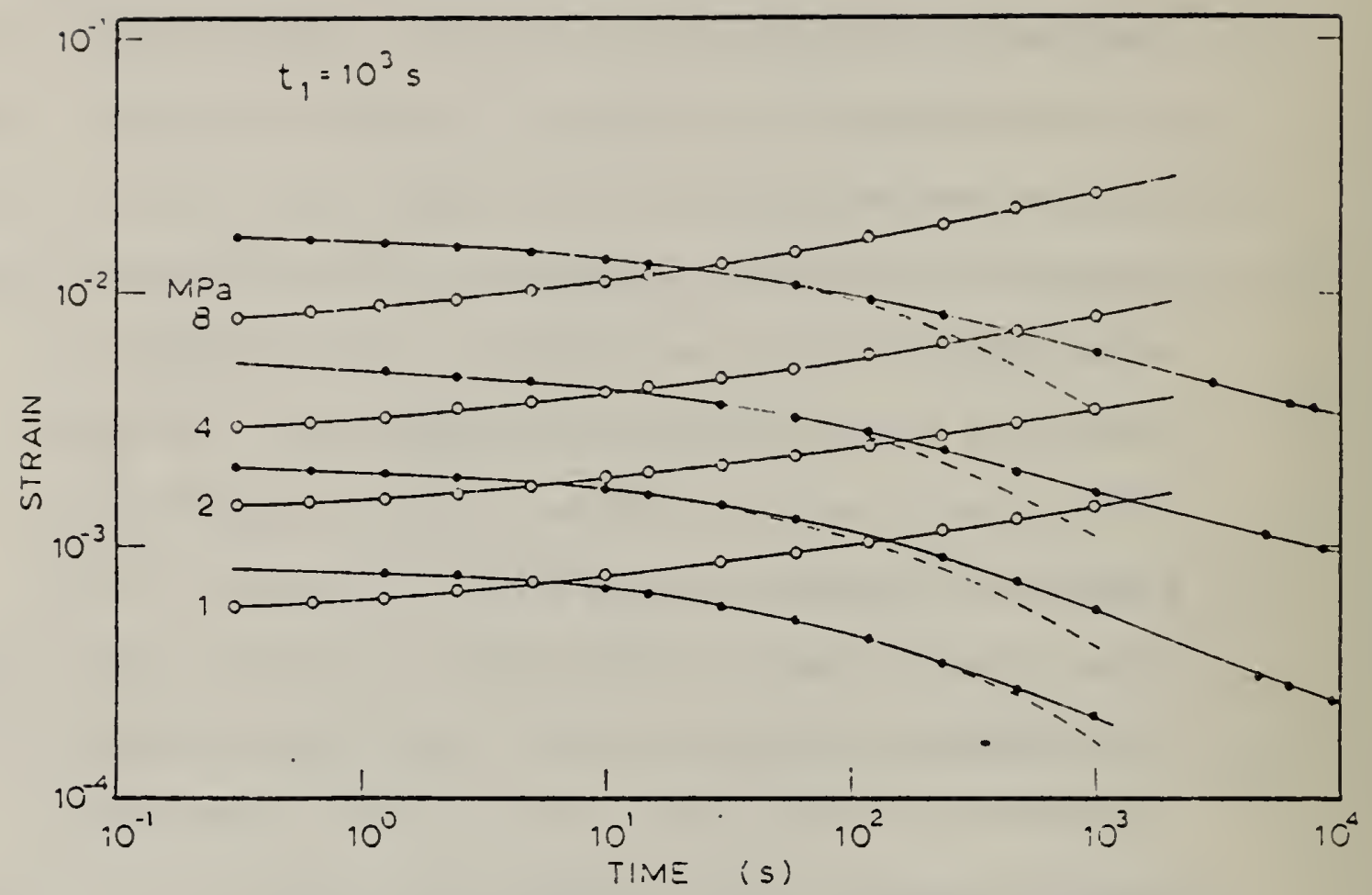

Fig. 2.7.3.1.1 Creep strain in uniaxial extension (open circles) and strain during recovery (filled circles) versus time for UHHWWPE $\left(M_{W} \times 4 \times 10^{6}, 0=0.935 \mathrm{~g} / \mathrm{cm}^{3}\right)$ at different levels of applied stress. The duration of the creep step was $10^{3}$ seconds and the temperature $23^{\circ} \mathrm{C}$. The dashed 1 ines represent the recovery predicted using equation (1). (Data frori reference 18) 


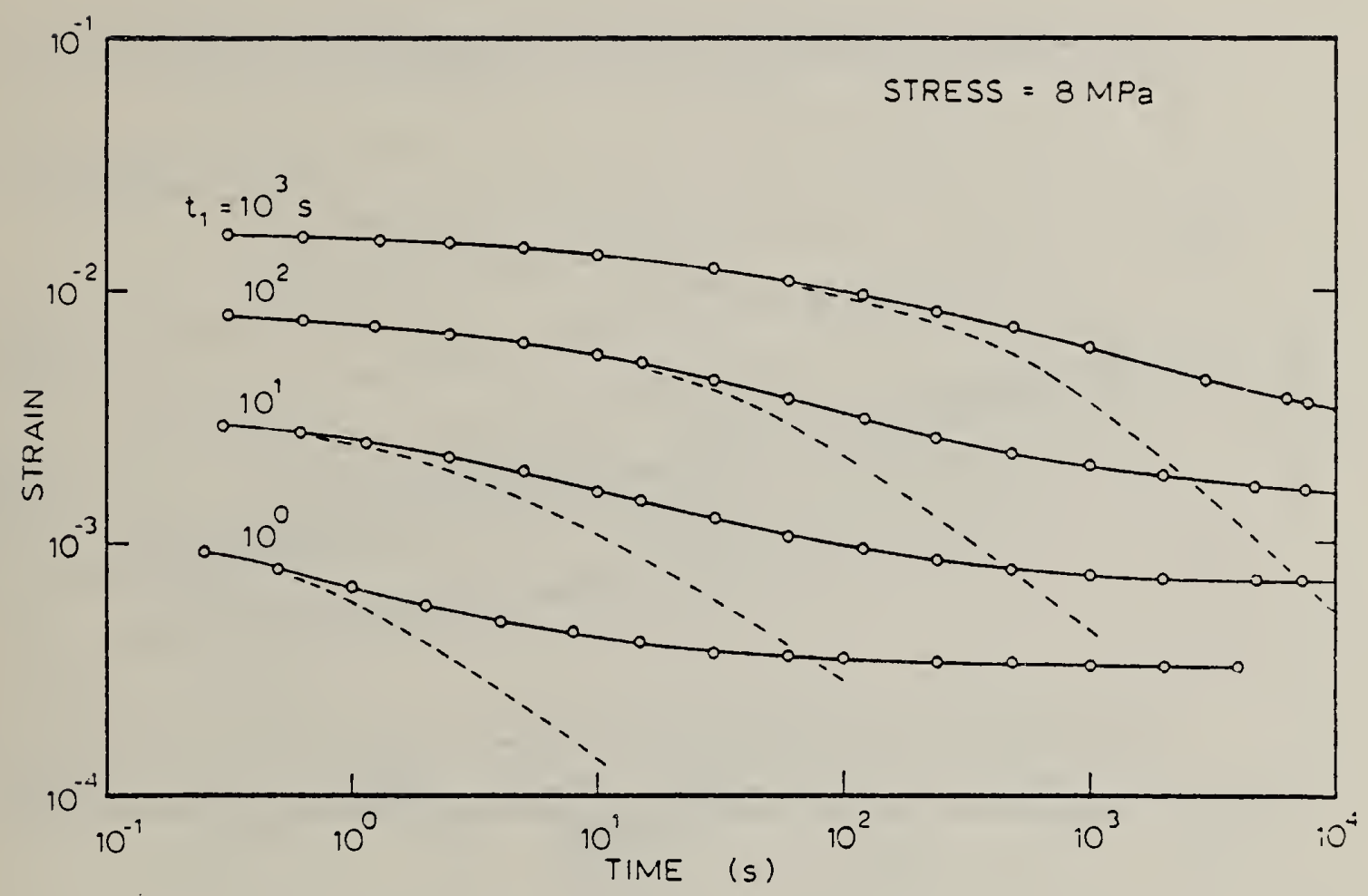

Fig. 2.7.3.1.2 Strain during recovery (after creep in uniaxial extension) from experiments done at constant applied stress (8MPa) but varied creep time, $t_{1}$. The dashed lines represent the recovery predicted using equation ( 1 ). HIHWPE (M $\left.M_{W} \times 4 \times 10^{6}, \rho=0.935 \mathrm{~g} / \mathrm{cm}^{3}\right)$ (Data from reference 18) 


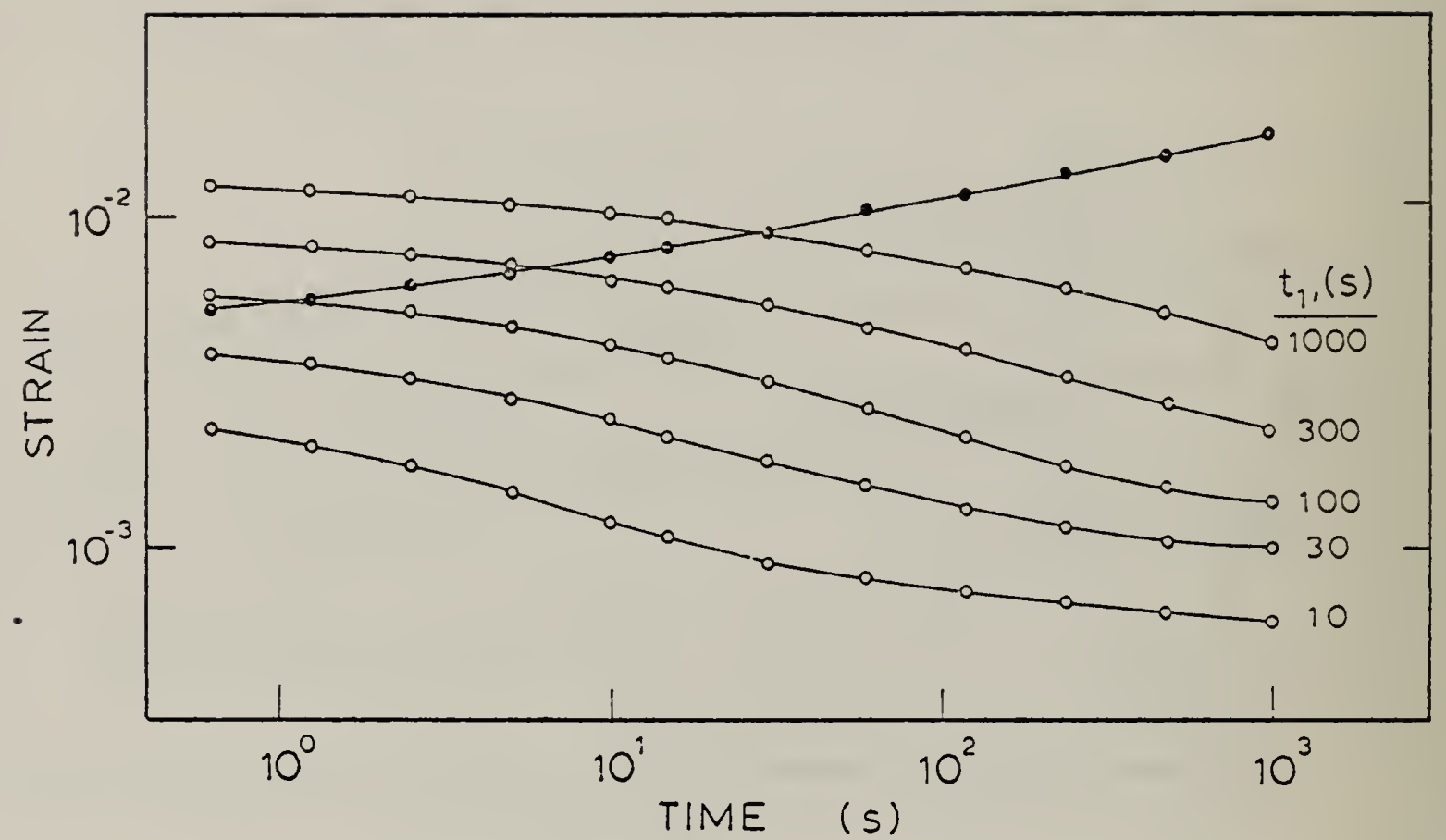

Figure 2.7.3.1.3 Creep strain in uniaxial extension (filled circles) and strain juring recovery (open circles) versus time for UHMWPE $\left(M_{W} \times 4 \times 10^{6}, o=0.935 \mathrm{~g} / \mathrm{cm}^{3}\right)$ at constant appiied stress (4MPa) but varied creep time, $t_{1}$. Temperature $33^{\circ} \mathrm{C}$. (From reference 21) 


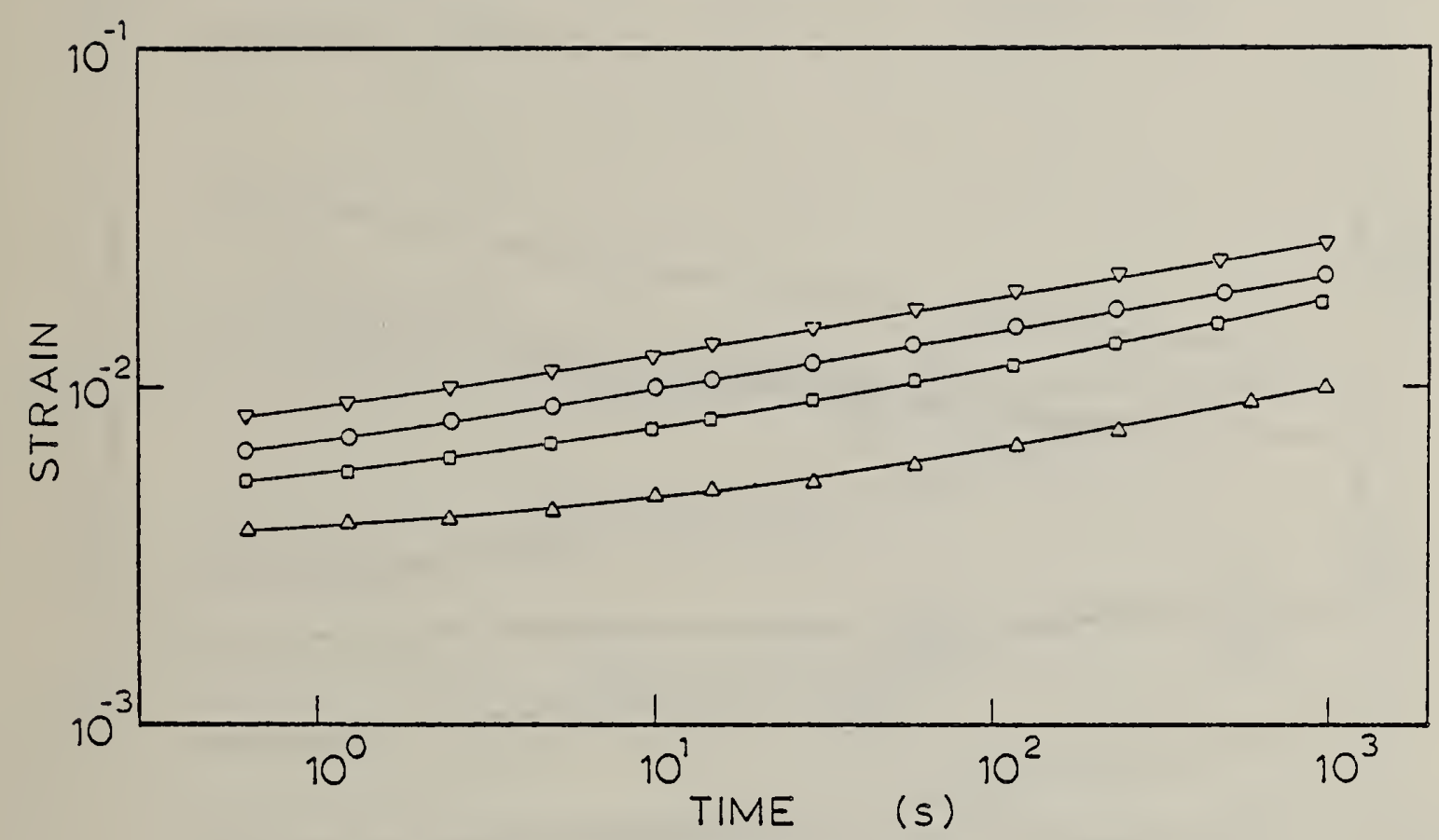

Figure 2.7.3.1.4 Creep curves in uniaxial extension for UHMWPE ( $M_{W} \times 4 \times 10^{6}$, $0=0.935 \mathrm{~g} / \mathrm{cm}^{3}$ ) at four different temperatures. ${ }_{A}=4 \mathrm{MPa} . \quad \triangle 23^{\circ} \mathrm{C}, \square 38^{\circ} \mathrm{C}$, $\bigcirc 47^{\circ} \mathrm{C}$, and $\nabla 62^{\circ} \mathrm{C}$. 
A comparison of the creep behavior of UHMWPE $\left(M_{W} \approx 4 \times 10^{6}\right)$ having different thermal histories is given in Figure 2.7.3.1.5. A significant increase in the amount of creep results if the polymer is quenched from the melt.

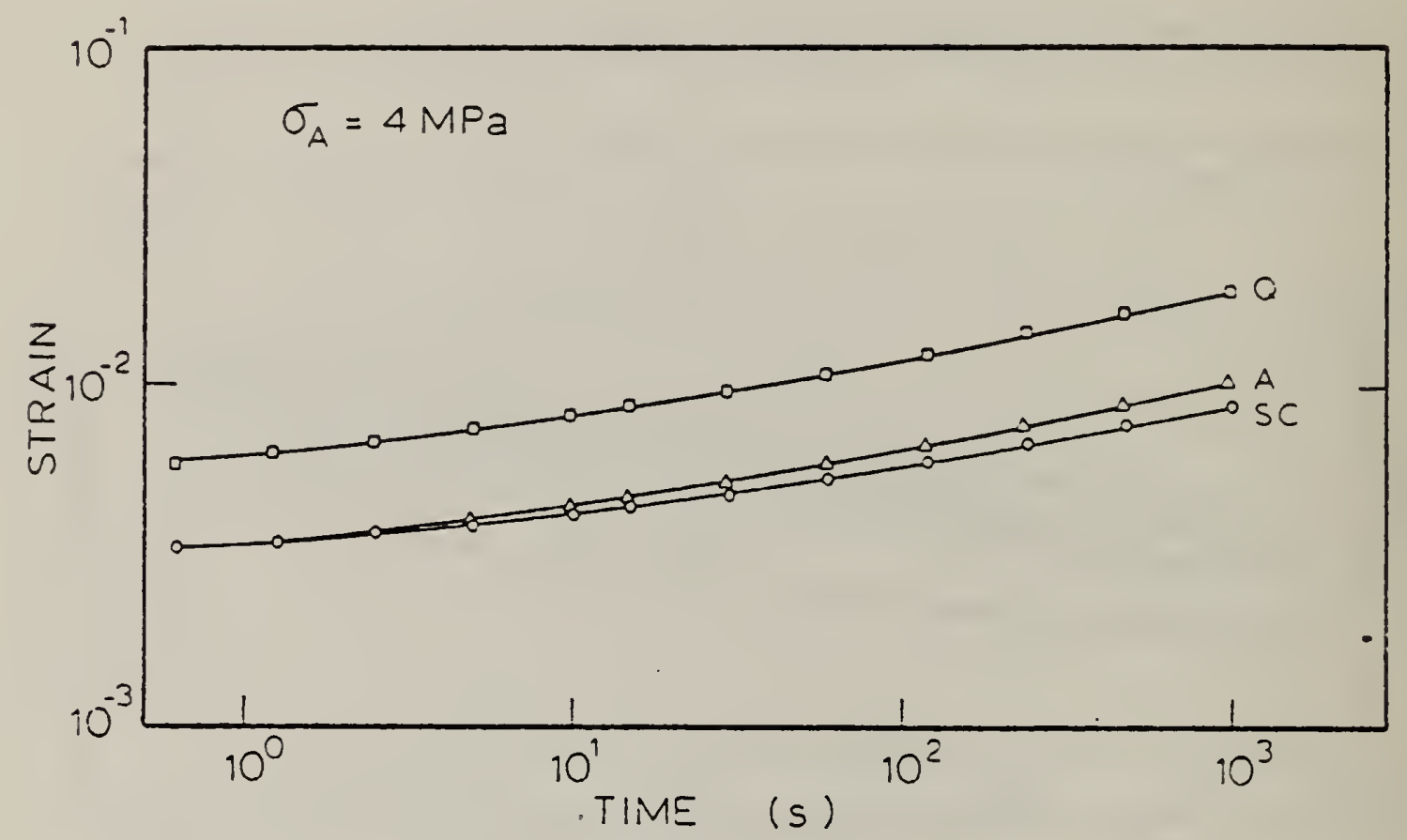

Fig. 2.7.3.1.5 Comparison of creep behavior in uniaxial extension for UHMWPE $\left(M \approx 4 \times 10^{6}\right)$, $q$ - quenched from the melt $\left(0=0.923 \mathrm{~g} / \mathrm{cm}^{3}\right)$, SC slowly cooled from the melt at $\approx 1^{\circ} \mathrm{C}$ per minute $\left(0=0.935 \mathrm{~g} / \mathrm{cm}^{3}\right)$, and $\mathrm{A}$ annealed under nitrogen atmosphere at $130^{\circ} \mathrm{C}$ for 72 hours followed by $135^{\circ} \mathrm{C}$ for 48 hours. Applied stress $4 \mathrm{MPa}$ (Data from reference 19). 
Figure 2.7.3.1.6 provides a comparison of the creep behavior of UHMWPE ( $\left.M_{w} \approx 4 \times 10^{6}, 0=0.935 \mathrm{~g} / \mathrm{cm}^{3}\right)$ in uniaxial extension and uniaxial compression. With the exception of the curves obtained at a stress of 15.6MPa no significant difference in behavior is observed between extension and compression. At $15.6 \mathrm{MPa}$ the strain is as large as ten percent at times approaching $10^{3}$ seconds and the true stress is significantly less in compression than in extension, even tough the engineering stress is the same.

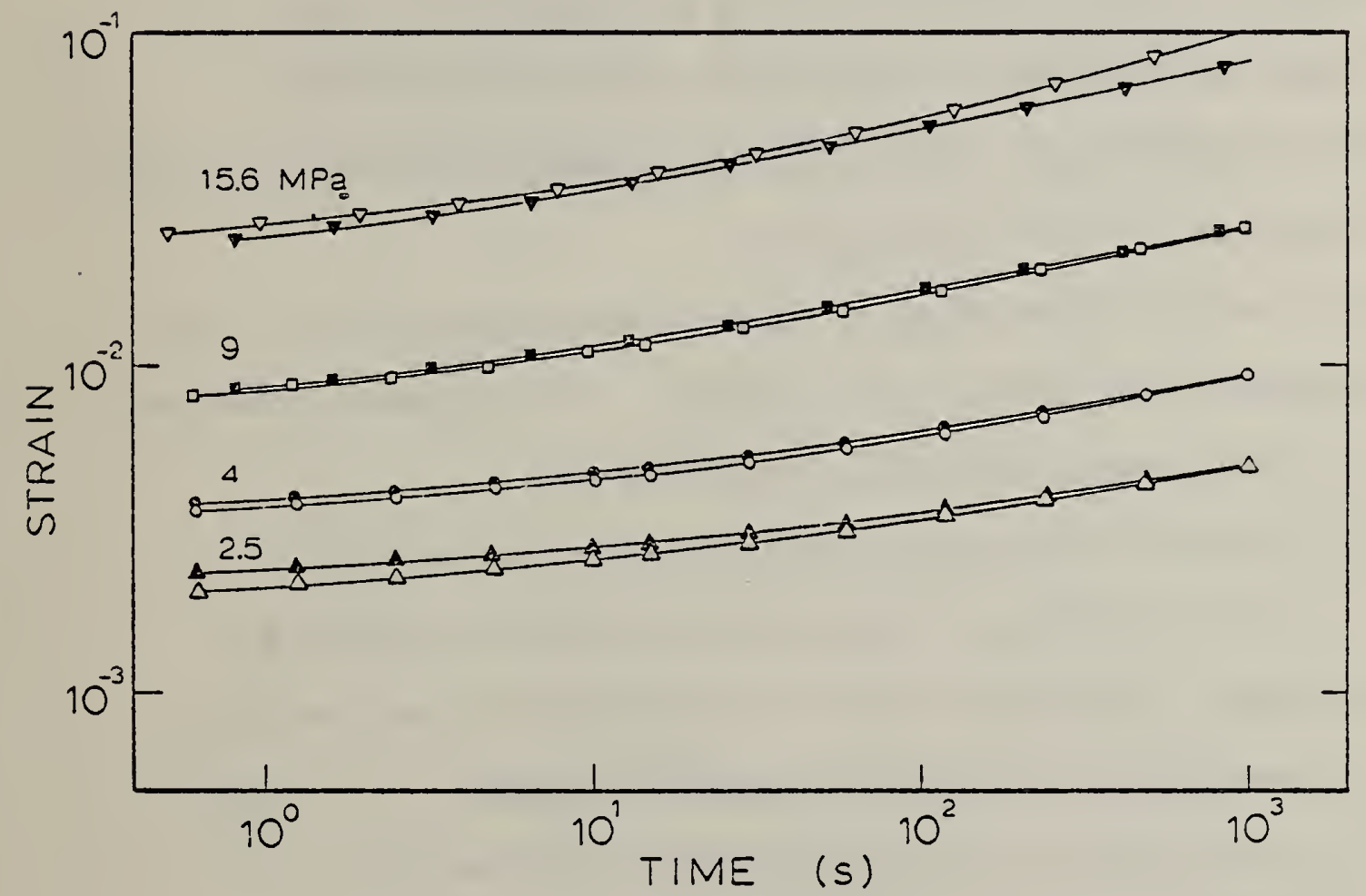

Fig. 2.7.3.1.6 Comparison of creep behavior of UH!WPE in uniaxial extension (open symbols) and uniaxial compression (filled symbols). $M_{W} \approx 4 \times 10^{6}, 0=0.935 \mathrm{~g} / \mathrm{cm}^{3}$. (Data from reference 21 ). 


\subsubsection{Long tinile Creep at Sma11 Deformations}

If the time under load in uniaxial extension is longer than about one day and the maximum creep strain remains small $(<5 \%)$, then the creep behavior deviates from that described in Section 2.7.3.1. Figure 2.7.3.2.1 illustrates this behavior for UHIWPE in uniaxial extension. Similar data can be found in reference [22] for both the extension and compression of UHMWPE. A break occurs in the creep curve between $10^{4}$ and $10^{5}$ seconds beyond which the creep proceeds more slowly, and on $10 \mathrm{~g}-\log$ coordinates the creep curve can be represented by a straight line. The same behavior is observed in certain lower molecular weight polyethylenes and polypropylene $[23,24]$. Turner and Moore have reported [24] that the break point, or "discontinuity", in the creep curve depends upon the processing conditions in the following ways:

(1) The break point moves to longer times as the rate of cooling from above the melting point decreases. This movement corresponds to a horizontal silift only of the break time.

(2) The break point moves from one strain to a smaller one in a vertical fashion as the storage time prior to testing increases. The vertical shift is large for the quenched polymer and undetectable for the fully annealed inaterial.

(3) When plotted on $\log -\log$ coordinates the creep curve maintains the same shape for a range of material states and therefore a range of coordinates of the break point. 
(4) Beyond the break point the slope of the creep curve is independent of the stress level and temperature for strains below about $3 \%$ in uniaxial extension and for temperatures up to at least $60^{\circ} \mathrm{C}$.

(5) The break point decreases in time with increased temperature or applied stress.

From Figure 2.7.3.2.2 it can be seen that the same behavior occurs in uniaxial compression as well. However, in the case of uniaxial compression, the creep curves in the region from the break point up to times of 600 hours or longer have the same slope for stresses at least as 1 arge as $16 \mathrm{MPa}$ and strains of $10 \%$.

Figure 2.7 .32 .3 demonstrates that the break point shifts to shorter times with increased temperature. An increase in temperature from $23^{\circ} \mathrm{C}$ to $64^{\circ} \mathrm{C}$ decreases the break point by approximately two decades in time. 


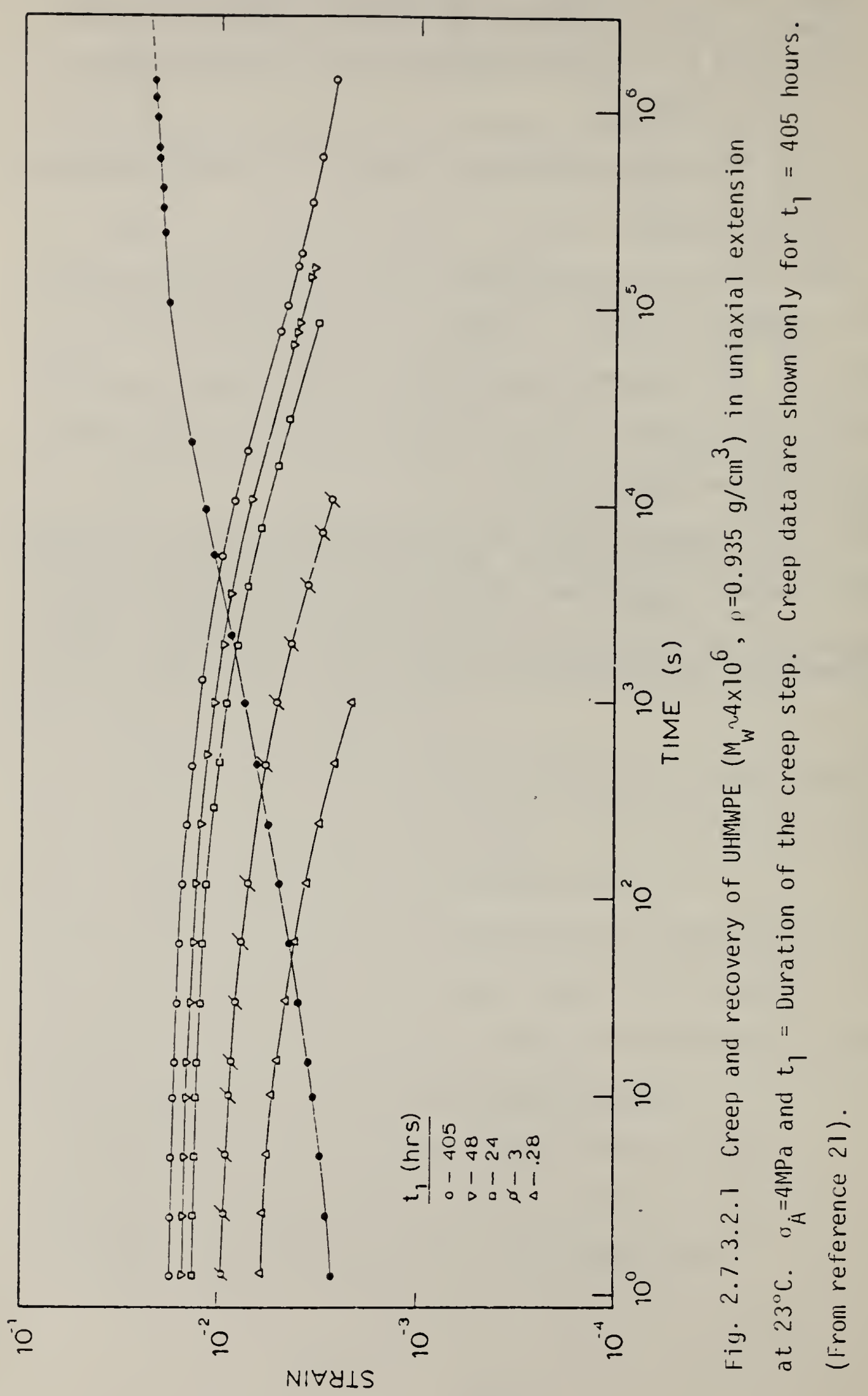




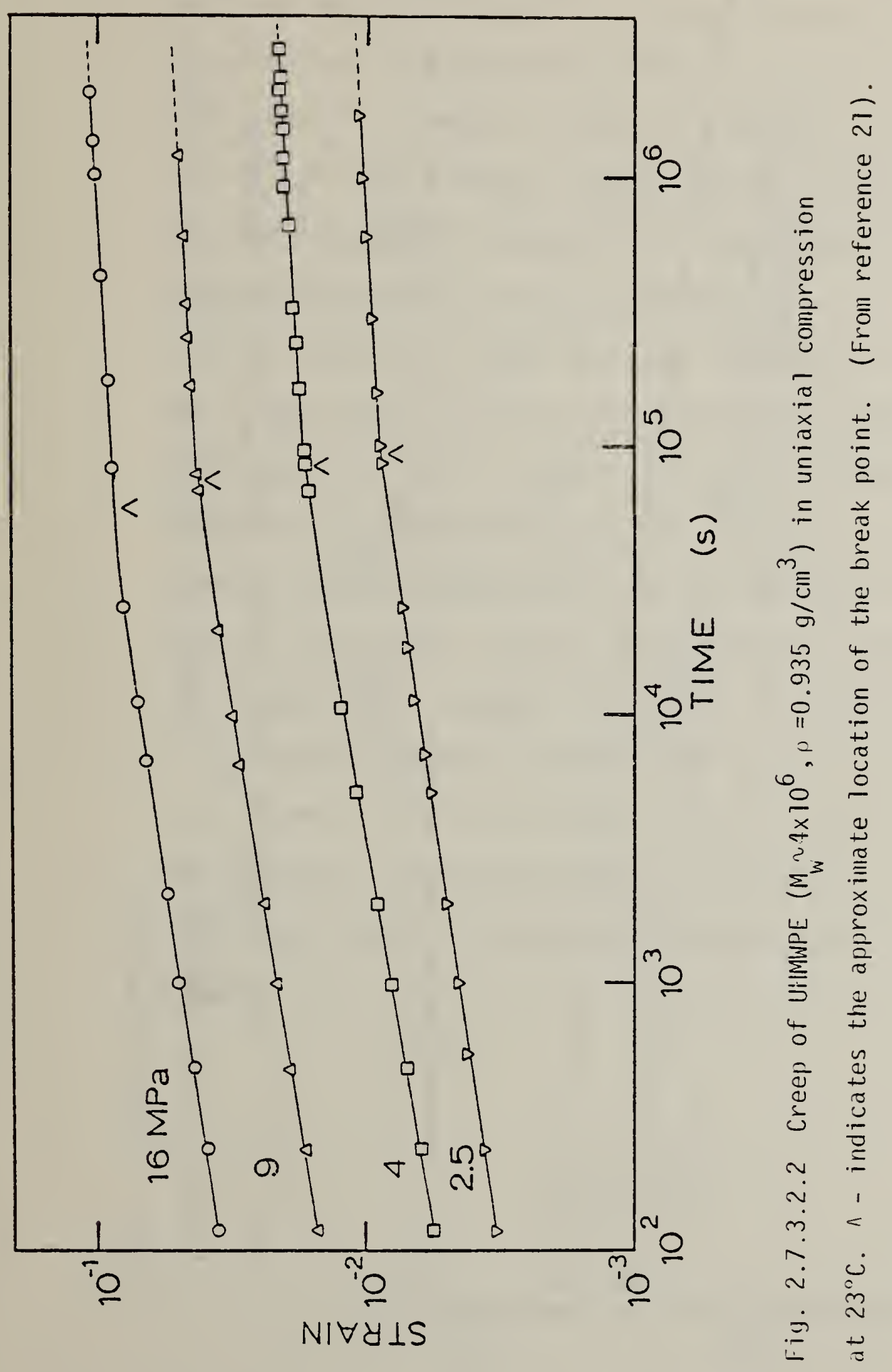




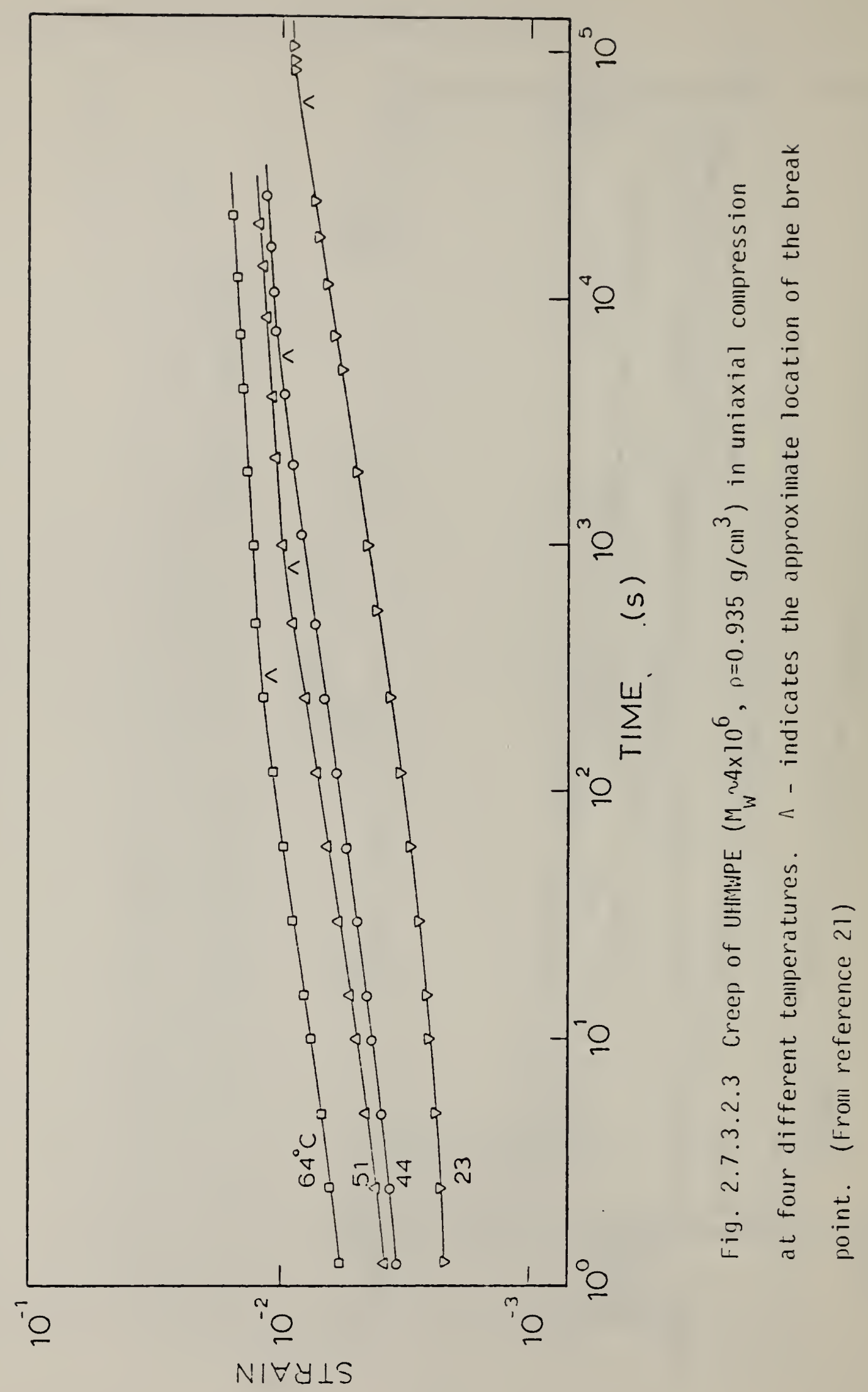




\subsubsection{Creep_at Large Deformations}

When the applied stress is larger than about $9 \mathrm{MPa}$ the creep behavior of UHIWWE in uniaxial extension changes in character from that observed at smaller values of stress. Creep curves typical of UHMWPE are shown in Figures 2.7.3.3.1 and 2.7.3.3.2 for two different lots of polymer obtained from the same resin producer. Characteristic of each curve is a region in which the creep is very rapid followed by a plateau region at large deformations where the creep proceeds very slowly. The time range during which the rapid creep occurs depends upon the magnitude of the applied stress. The maximum stretch ratio ( $\lambda$ ) attainable in these materials at $23^{\circ} \mathrm{C}$ is from $\lambda \sim 4$ to $\lambda \sim 8$ depending upon the magnitude of the applied stress and molecular weight of the polymer. Similar creep curves for UHMUPE quenched from the melt into ice water are shown in Figure 2.7.3.3.3. The principal differences between these creep curves and the creep curves for the slowly cooled polyiner are that, for a given applied stress, the quenched material experiences a much greater deformation initialiy, and its maximum attainable stretch ratio is less. 


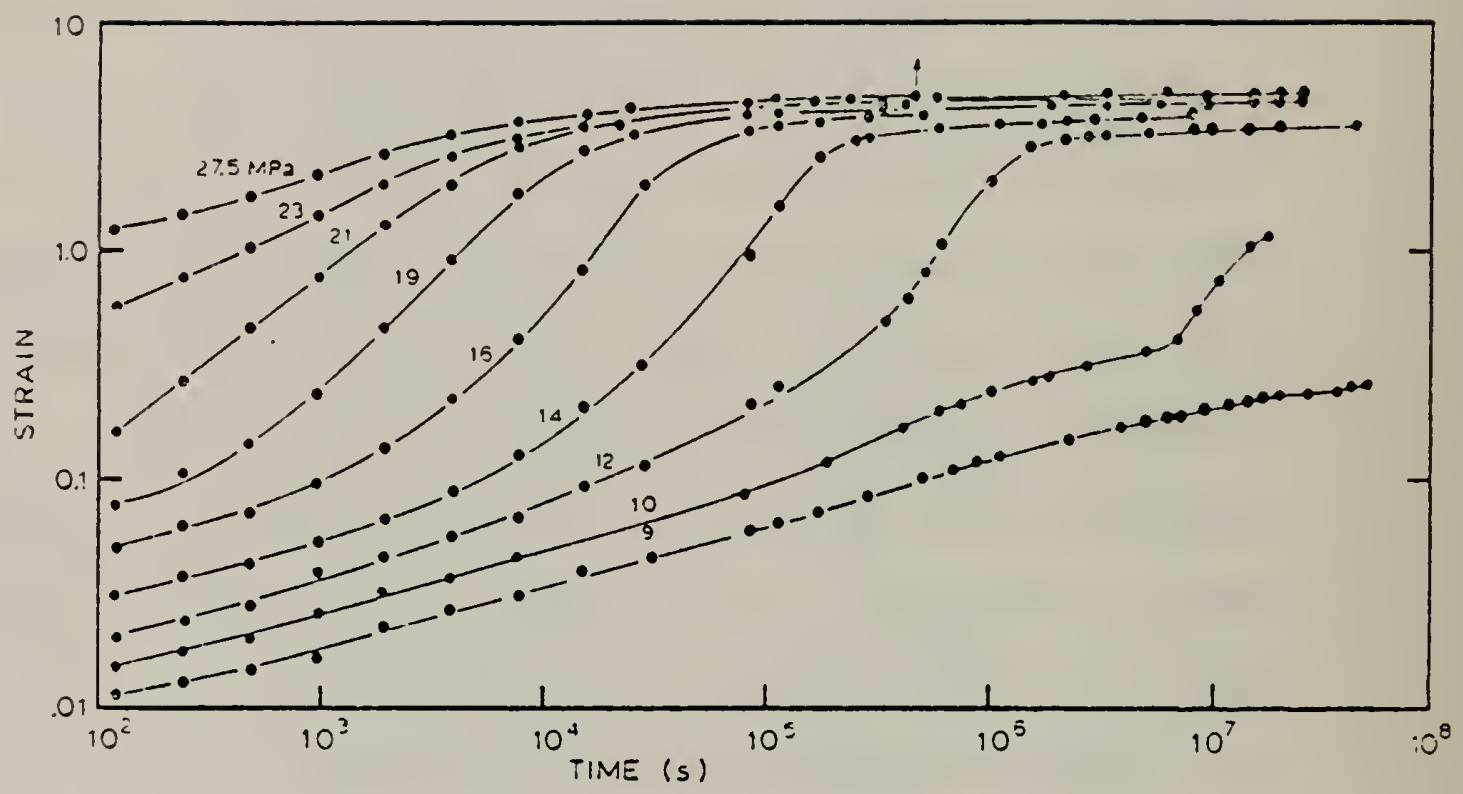

Fig. 2.7.3.3.1 Tensile creep of UHMWPE $\left(0=0.935 \mathrm{~g} / \mathrm{cm}^{3}, w_{w}{ }^{2} 7 \times 10^{6}\right)$ at various levels of applied stress at $23^{\circ} \mathrm{C}$. The arrow indicates the time of fracture for the specinen at a stress of 27.5Mpa. (From reference 12). 


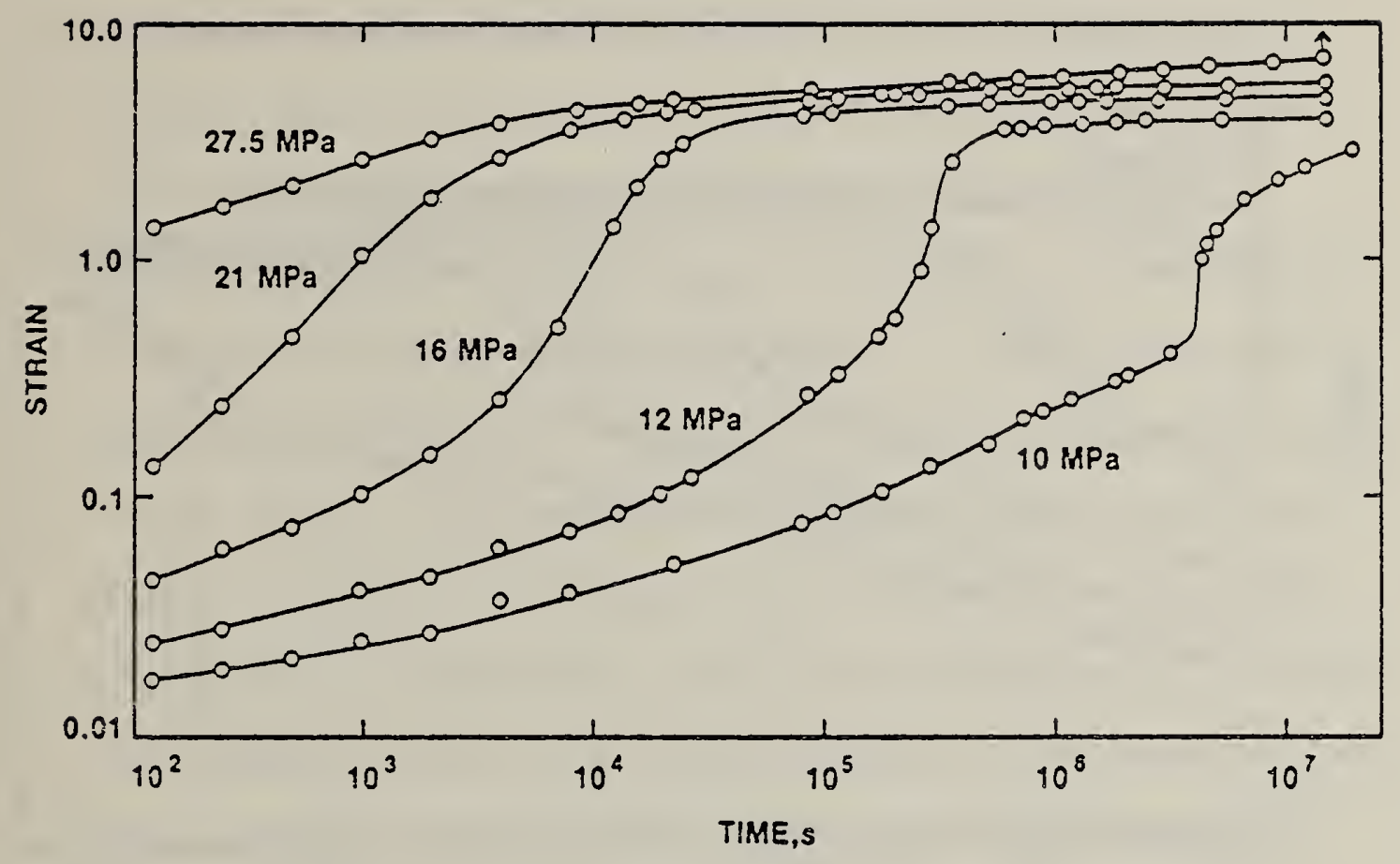

Fig. 2.7.3.3.2 Tensile creep of UHMWPE $\left(c=0.947 \mathrm{~g} \mathrm{~cm}^{3}, \mathrm{~m}_{w} 2 \times 10^{6}\right)$ at various levels of applied stress at $23^{\circ} \mathrm{C}$. The arrow indicate the time of fracture for the specimen at a stress of 27.5MPa. (From reference 11). 


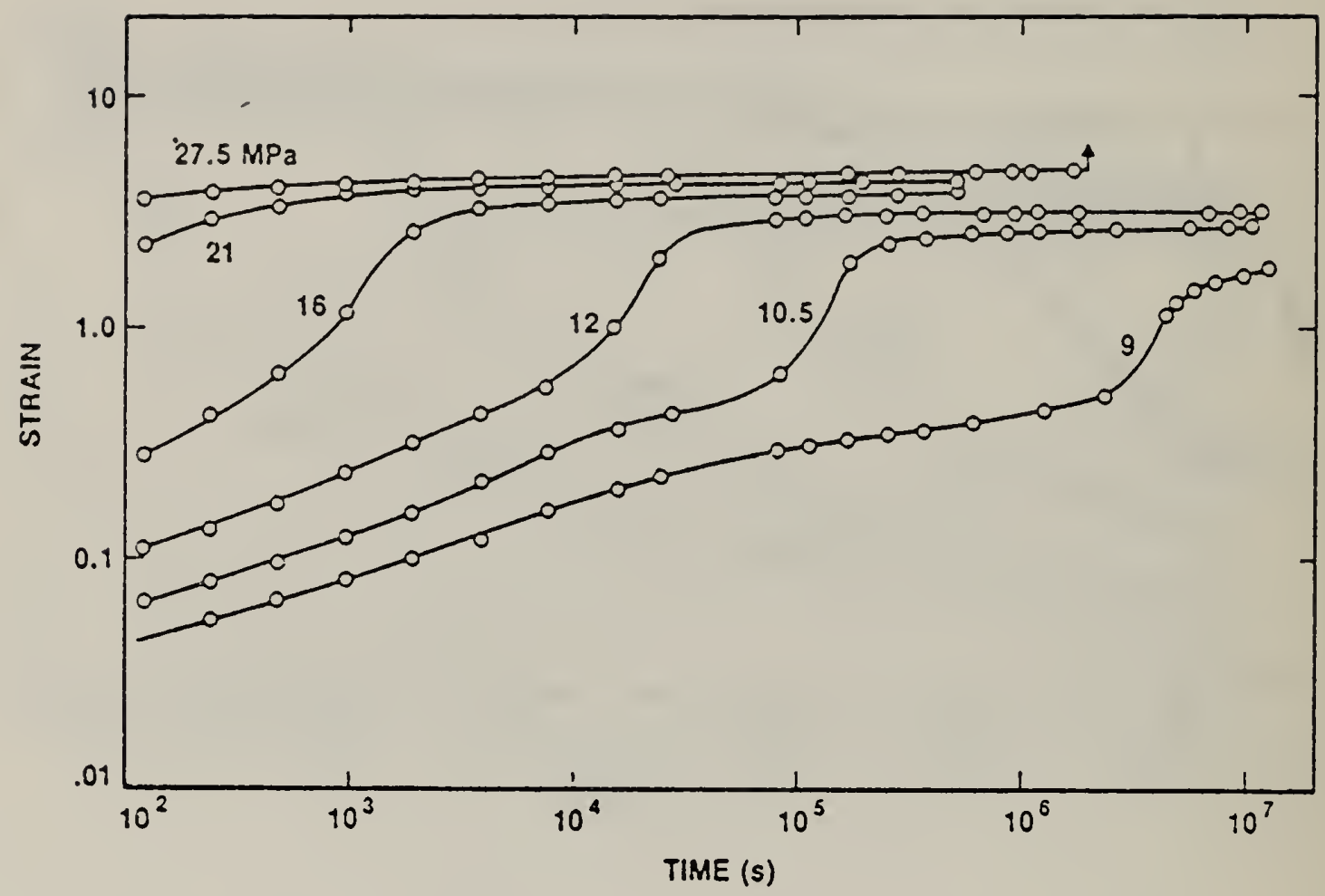

Fig. 2.7.3.3.3 Tensile creep of quenched UHMWPE $\left(0=0.923 \mathrm{~g} / \mathrm{cm}^{3}\right.$, $M_{w}{ }^{2} 4 \times 10^{6}$ ) at various levels of applied stress. Temperature $23^{\circ} \mathrm{C}$. The arrow indicates the time of fracture for the specimen at a stress of $27.5 \mathrm{MPa}$. (From reference 12). 


\subsubsection{Stress Relaxation}

A method commonly used to characterize the time dependent mechanical behavior of polymeric materials is stress relaxation. In this method the sample is subjected to a constant deformation and the stress response is determined as

a function of time. By carrying out a series of tests at different levels of strain, it is then possible to generate a set of isochronal stress-strain curves. Two such sets of curves are shown in Figure 2.7.4.1 for different lots of UHMWPE. In each case the sets of specimens were cut from compression molded sheets which were cooled from the melt at approximatley $1^{\circ} \mathrm{C}$ per minute. Both materials exhibit nonlinear viscoelastic behavior, even at the smallest values of strain for which data are shown. At large strains ( $\varepsilon>0.10$ ) the behavior of the UHMWPE is not characteristic of most lower molecular weight polyethylenes, which upon application of the step in strain undergo necking and cold-drawing.

The effect of annealing on the isochronal stress-strain behavior of UHMWPE is shown in Figure 2.7.4.2. The isochrones for the annealed polymer tend to flatten at the large strains and during application of the largest step the annealed sample necked. Increasing the crystallinity by only about $5:$ can significantly alter the isochronal stress-strain behavior. 


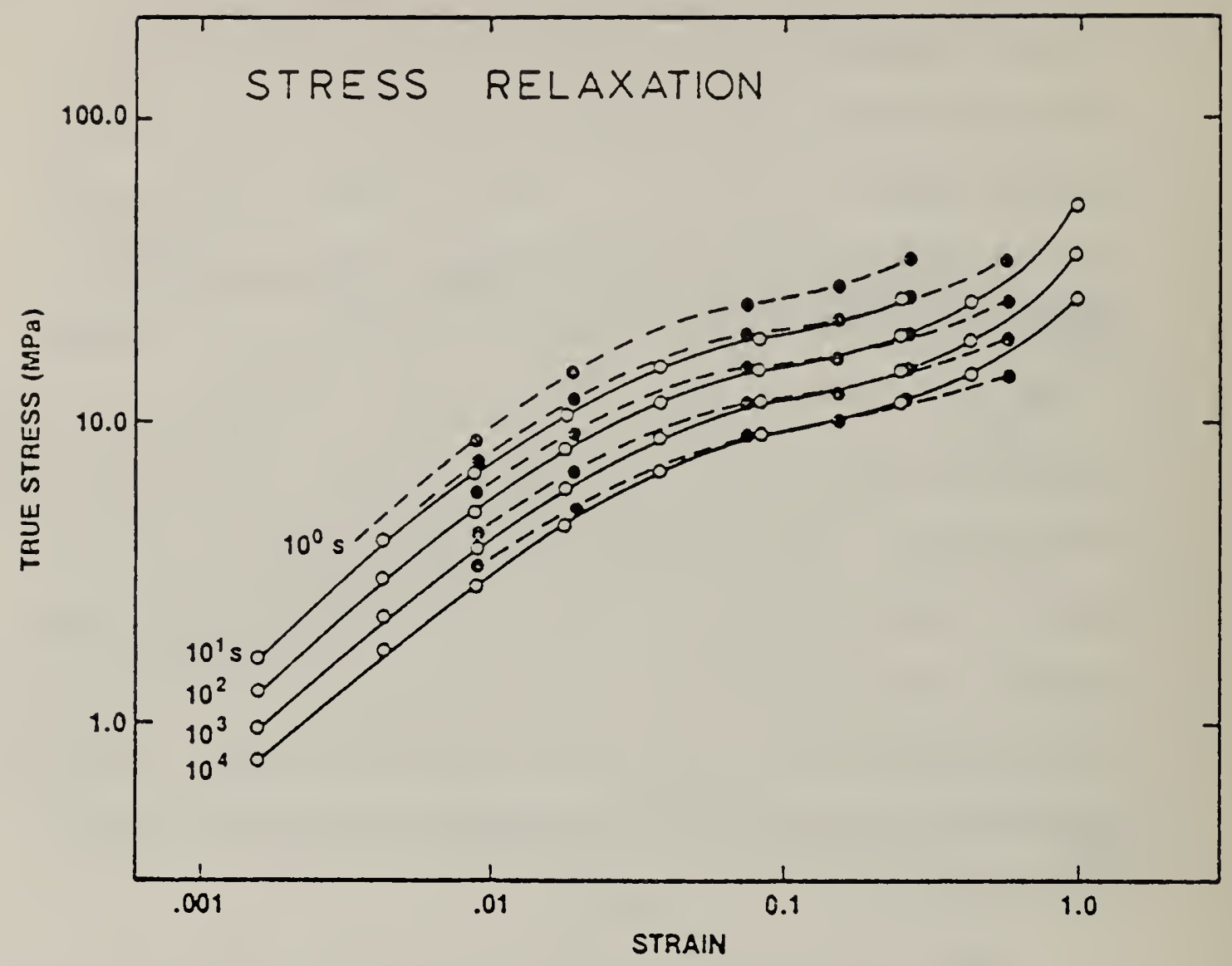

Figure 2.7.4.1 Isochrones of true stress versus strain for UHMWWPE (cooled from the melt at $1{ }^{\circ} \mathrm{C}$ per minute) $0-M_{W} 4 \times 10^{6},-M_{W} 2 \times 10^{6}$. s - seconds (From reference 11). 


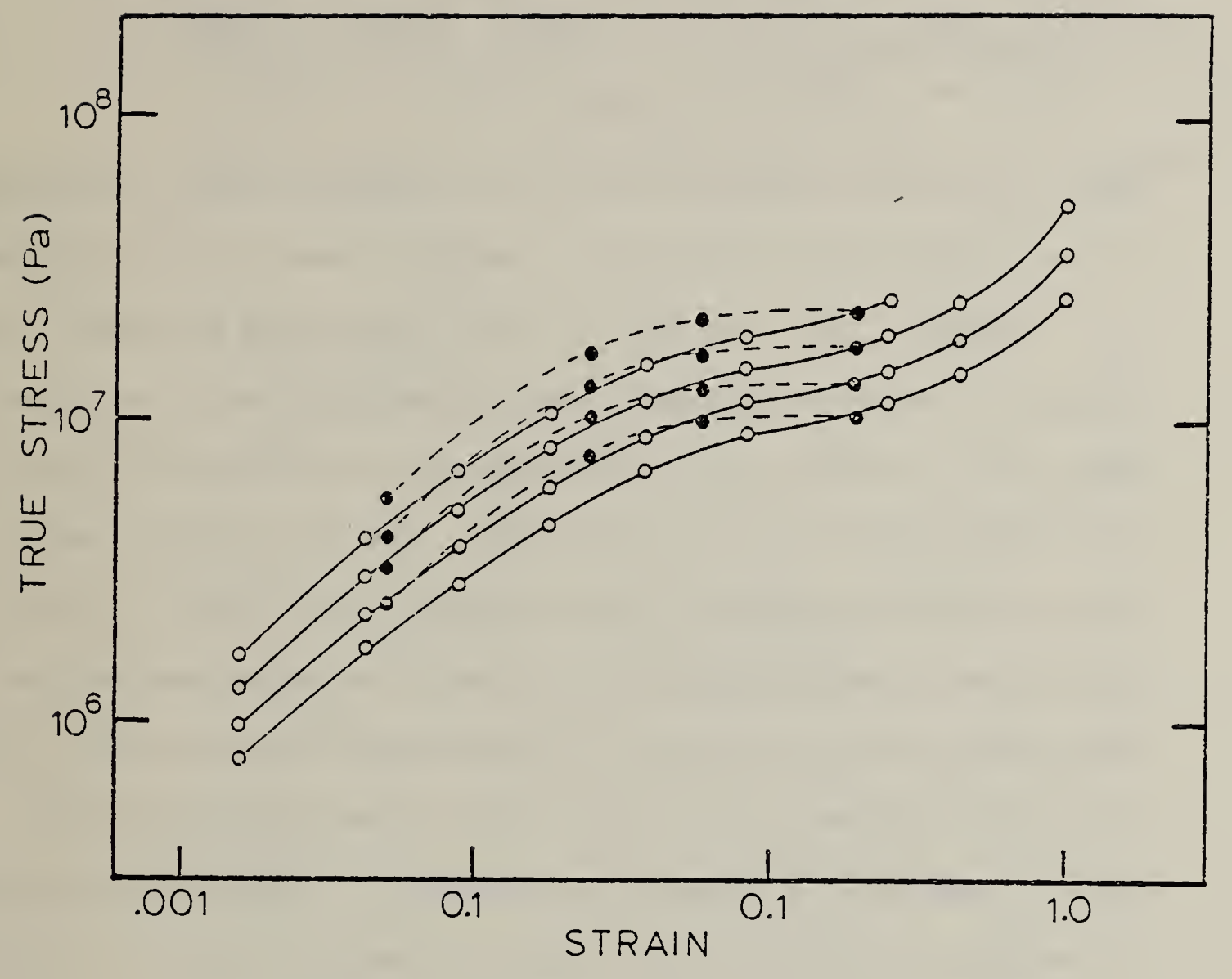

Fig. 2.7.4.2 Isochrones of true stress versus strain for UHMWWE $\left(M_{W} \approx 4 \times 10^{6}\right)$. 0 - cooled from the melt at $\approx 7^{\circ} \mathrm{C}$ per minute $\left(0=0.934 \mathrm{~g} / \mathrm{cm}^{3}\right)$, - - annealed $\left(\rho=0.942 \mathrm{~g} / \mathrm{cm}^{3}\right)$. (From reference 11$)$. 


\subsubsection{Fatique}

Fatique is generally studied under one of two conditions, either at constant load (static fatigue) or with sinusoidal loading. It is common practice to subject the test specimen to a sinusoidal loading history, or strain history, of the form.

$$
\sigma(t)=P+Q \sin \omega t,
$$

where $P$ is the mean level and $Q$ sin wt is the oscillatory component of the applied stress, or strain, w being $2 \pi$ times the test frequency.

Figures 2.7.5.1 and 2.7.5.2 show fatigue data for UHMWPE for the case in which the specimens were subjected to tension only and where $P=Q$. In Figure 2.7.5.1 the logarithm of the time to failure is plotted versus the peak stress $(P+Q)$. For this type of loading history the maximum strain in the specimen is not fixed, but rather the specimen elongates during the course of the experiment and may reach several times its original length before fracture occurs. Each data Doint represents the average value of the logarithms of the failure times for a minimum of six specimens. The solid line represents the results of tests carried out under a constant load $P+0$. For the given values of $P$ and $Q$ and the range of frequency examined the lifetime under constant load defines a lower bound to the lifetime under cyclic loading.

In Figure 2.7.5.2 the logarithm of the time to failure is plotted versus the test frequency for tests carried out at four different levels of peak stress $(P+C)$. The dashed 1 ine represents the behavior which would result if the lifetime were "cycle dependent". By cycle dependent is meant that the failure occurs after a given 
number of cycles independent of the frequency. The particular case shown represents failure after 60 cycles. The 1 ine is not unique, but will shift up or down depending upon the assumed number of cycles. However the slope will remain independent of the number of cycles assumed. For UHMWPE, the fatiuge lifetime under conditions of sinusoidal loading is not cycle dependent. 


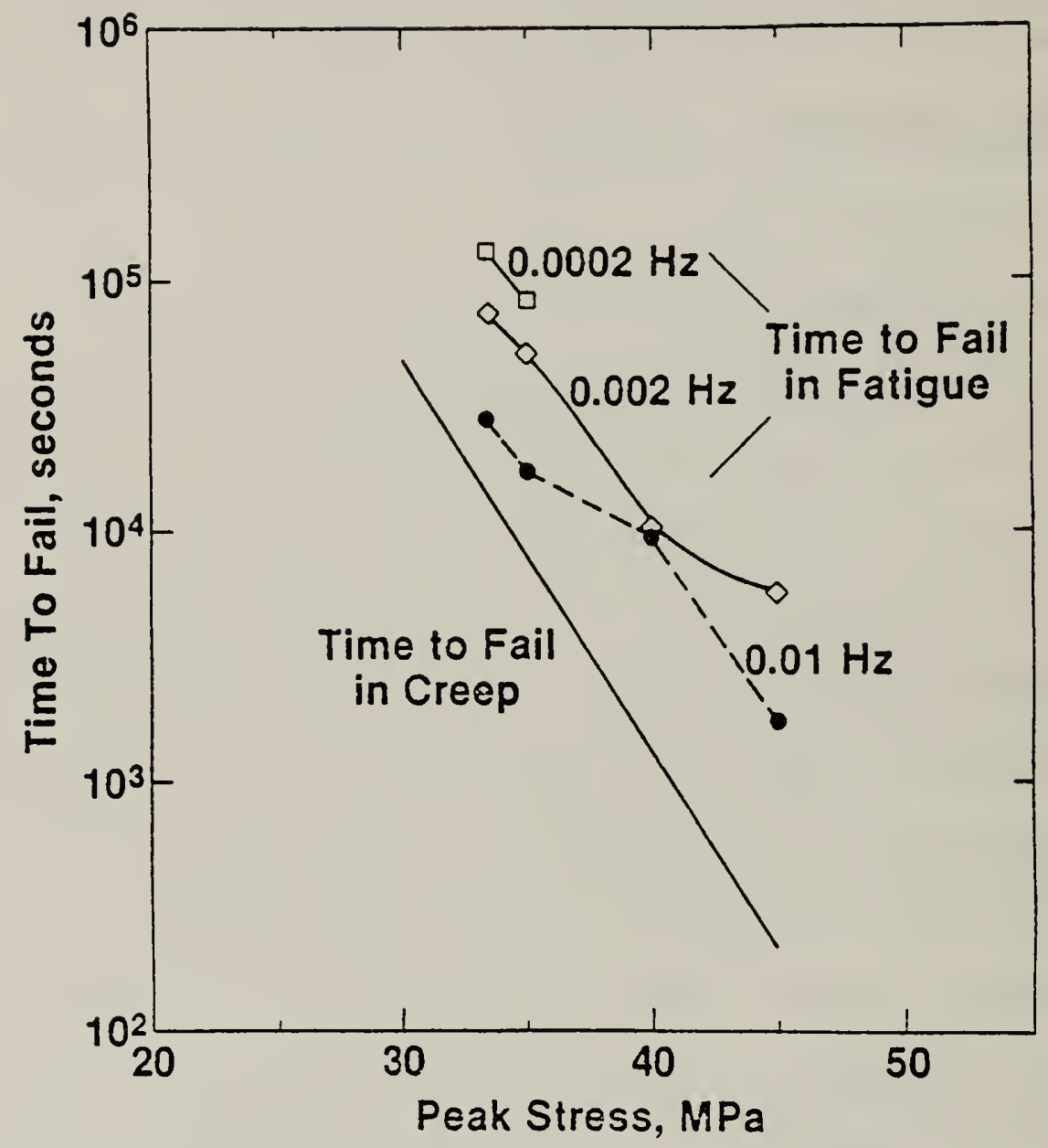

Fig. 2.7.5.1 Log. time to failure versus $10 \mathrm{~g}$. engineering stress for UHMWPE $\left(M_{W}=4 \times 10^{6}\right.$, density $\left.=0.935 \mathrm{~g} / \mathrm{cm}^{3}\right)$. The solid line corresponds to the behavior observed for specimens tested to failure at a constant load equal to the peak engineering stress under sinusoidal loading. (From reference 11 ). 


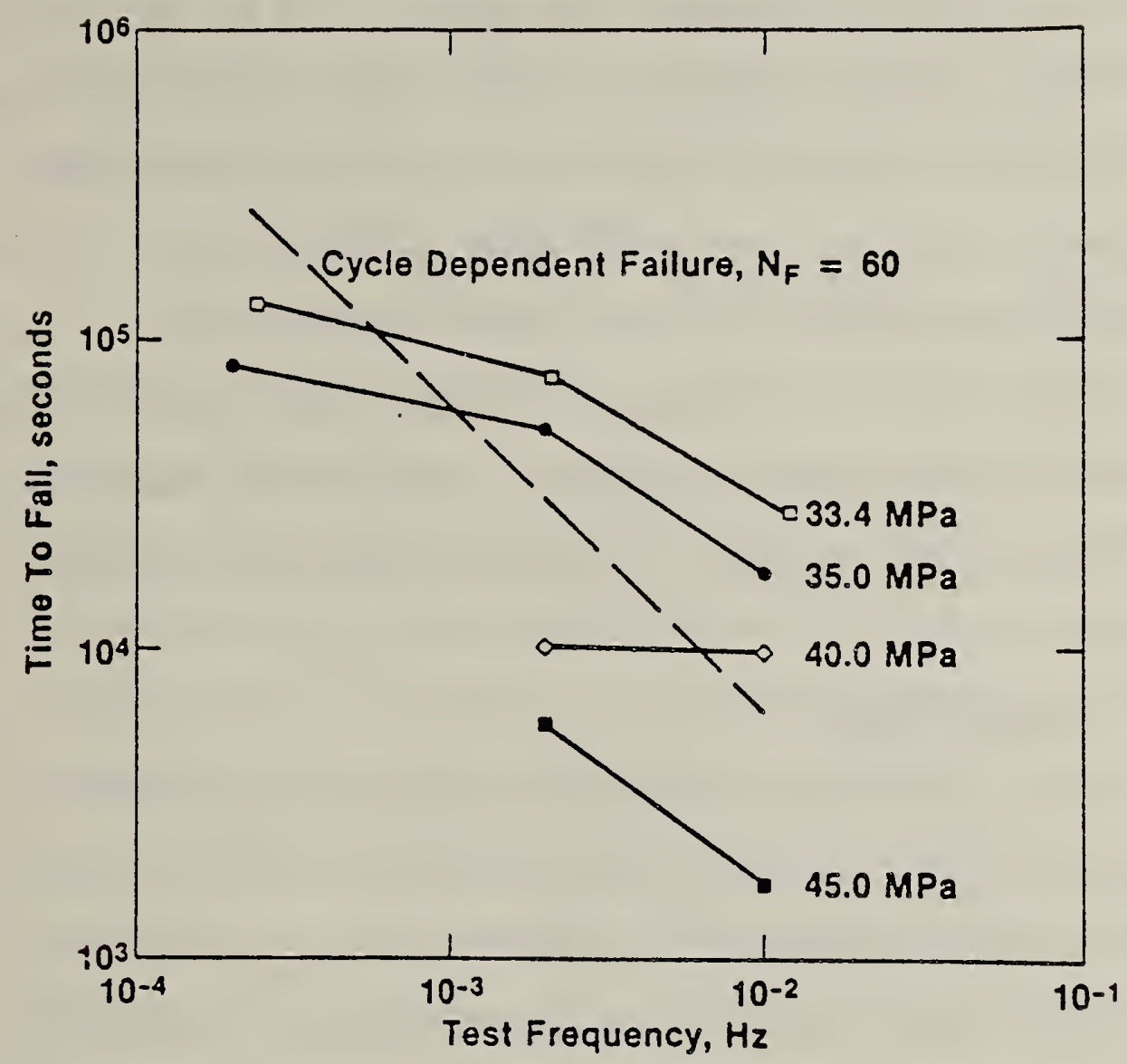

Fig. 2.7.5.2 Log. time to failure versus $\log$ test frequency for UHMWPE $\left(M_{W} \simeq 4 \times 10^{6}\right.$, density $\left.=0.935 \mathrm{~g} / \mathrm{cm}^{3}\right)$ tested at four levels of peak engineering stress. The dashed line corresponds to the behavior which would be observed if the lifetime were cycle dependent where it has been assumed that failure occurred after 60 cycles. (From reference 11). 


\subsection{Wear}

Wear represents an important aspect of materials characterization and performance in applications such as orthopaedic devices, yet it remains a most difficult phenomenon to quantify. In his review article on wear (1982) entitled "WEAR-SCREENING AND JOINT SIMULATION STUDIES VS. MATERIALS SELECTION AND PROSTHESIS DESIGiv" Clarke [24] concludes:

It is disappointing that despite the voluminous literature in the areas of materials wear-screening and joint wear-simulation studies, the data are so fragmented and contradictory. Virtually every aspect conceming the significance and effect of Laboratory wear devices, test paraneters, materials types, and treatments on the resulting wear performance is in dispute.

\subsubsection{Types of Wear}

Wear is generally classified into one of three types [25].

(1) abrasive wear - caused by hard asperities on the counterface or by hard particles between the surfaces.

(2) fatigue wear - the detachment of material as a result of cyclic stress variations on a localized scale.

(3) adhesive wear - transfer of material from one surface to the other as a consequence of the forces of adhesion between them.

However, there can be considerable uncertainty in determining the point at which abrasive wear, involving plastic deformation and cutting of the polymer surface, becomes fatigue wear as the topography of the different surfaces change with time. 


\subsubsection{Methods for Wear Testing}

Laboratory wear testing of surgical implant UHMWPE is done using either a wear-screening machine or a joint simulator. Such devices fall into one of three categories [25]. A category 1 wear-screening device makes no special provisions to simulate physiological conditions, and provides only a first-level comparison of a materials' wear resistance.

Category 2 devices also make no attempt to reproduce a prosthesis geometry nor provide simulation of the dynamic joint-loading profiles. Parameters such as contact stress, frequency, and stroke-amplitude are held to within a range applicable to human joint performance. The three specimen geometries most often used in wear-screening devices are the disk-on-flat, annulus-on-flat, and pin-on-flat.

Category 3 devices are joint simulators which test.actual prostheses with load and motion characteristics similar to the natural joints behavior, and may use physiological fluids as a lubricant.

\subsubsection{Wear Rate Measurements}

Laboratory methods for determining wear in UHMWPE include (1) the change in a particular specimen dimension, (2) specimen weight loss, or (3) weight of collected wear debris [25]. Most wear studies have been done using method (1). However, under load UHMWPE experiences creep and upon unloading exhibits both a recoverable component and a plastic, or nonrecoverable: 
component of the creep. Creep complicates any test which determines wear by a dimensional method since the methodology must be able to separate the deformation due to wear from that due to creep. The results of one study [33] (Table 2.8.3.1) indicate that the non-recoverable creep component in UIHMVIFE can be as large as the actual wear. At $6.4 \mathrm{MPa}, 219 \mathrm{~mm}$ of elastic (recoverable) creep and $17 \mu \mathrm{m}$ of plastic (non-recoverable) creep were detected.

\section{Table 2.8.3.1}

COMPARISON OF CREEP AND WEAR ESTIMATES FOR DISC-OIH-FLAT WEAR STUDIES OF POLYETHYLENE AT VARIOUS STRESS LEVELS ${ }^{\grave{a}}$

Minimum Contact stress

\begin{tabular}{|c|c|}
\hline $\begin{array}{l}\text { Total creep } \\
\text { (C y })\end{array}$ & Total wear \\
\hline
\end{tabular}

\section{1}

5.3

224

366

279

28

7.6

9.2

13.8

14.5

564 .

56

7.7

17.8

660

102

20

18

1219

198

30

279

23

\footnotetext{
a - From reference 33

$b$ - Includes both the recoverable and nonrecoverable creep.
} 
Method (2) for assessing wear involves measuring the loss in weignt of the specimen as wear progresses. This method can also be subject to large errors unless the weight gain due to fluid sorption is corrected for. In some cases the magnitude of the fluid absorption weight gain has been found to be larger than the weight loss from wear [34-37]. Wear data for UHMIWPE are shown in Figure 2.8.3.1 where correction factors for bovine serum absorption have been applied to pin-on-flat specimen geometries. In these tests wear specimens and identical control specimens were presoaked in serum for several weeks to minimize fluid sorption during the wear test.

Method (3) in which the wear debris is collected and weighed is used principally in studies involving cateanry 3 devires (joint simulators). This method is subject to the limitations that (1) it cannot be used with lubricants such as biological fluids because of contamination by proteinaceous material, (2) rigorous washing and filtering of debris to insure total particle entrapment is required, and (3) artifacts may always be present due to fluid sorption by UHIMWPE particles and contamination by extraneous matter.

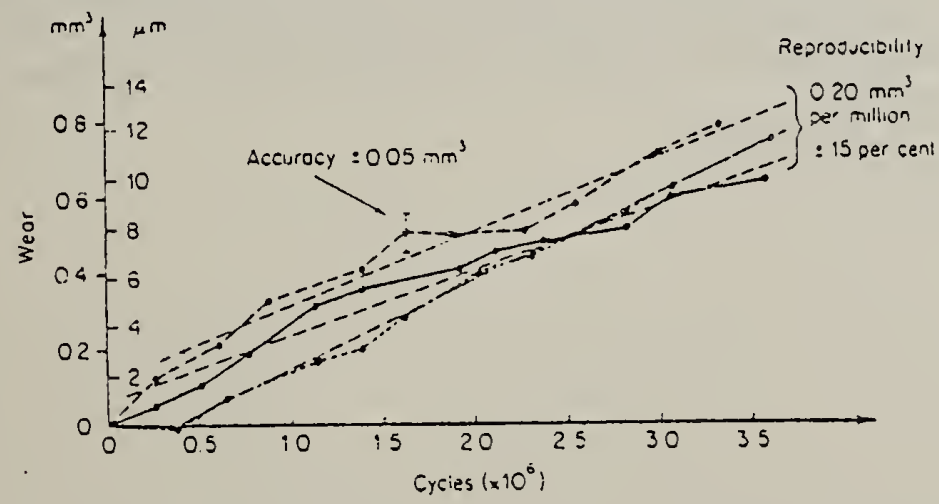

Figure 2.8.3.1 Linear regression data for pin-on-flat wear-screening tests. Data represented three polyethylene specimens run against 316 stainless-steel counterfaces with bovine serum lubrication. (From references 38 and 39 ). 


\section{8 .4 Wear Rate Data}

Quantitative comparison of polyethylene wear rates is difficult because different types of polyethylenes from different manufacturers have been treated and evaluated under widely different test conditions in a variety of wear test machines. A representative sampling of different wear studies reported in the literature is given in Table 2.8.4.1.

Table 2.8.4.1

COMPARISON OF SCME OF THE COMPLEXITIES APPARENT IN TRYING TO COMFARE LABORATORY WEAR PREOICTIONS FOR UHAIIPS

Study, [Ref.]

Seedrom et al. [27]

Galante and Restoker [28]

Scales arid vizight [30] Dumbletion and Sinen [31] ifickellop et al. [32]

$$
\text { Polyethylene Mis } \times 10^{6}
$$

$$
\text { type }
$$

specific

Wear machine

\section{Pin-on-flat}

Phillips 5095

HiFAX 1900

RCH 1000

HDP HIFAX

HIF.AX

0.1

HiFAY 1000

RCit $1000^{b}$

HiFÃX 1900

HiFAX 1900

oisc-on-flat

1.25

3.0

3.0

\section{Pin-on-flat ${ }^{c}$}

Annulus-on-flat

Pin-on-flat 'iear

technique

Lubricalit

Synovia? fivid

Nater

Annulus-on-flat

D

Plasria
Stress rangz (iApa)

3. $E$

2. $8-E .2$

3.45

iis

$0.9-11.3$

$3.45-6.9$

Note: 0 , dimensionäl wear measurement; $1 S$, not specified; ' $\lambda$, weight loss technique of wear measurement.

a Various treatments of UHM'd surgical grade high density polyethylene - all starilized (2.5 Mrad)

b Two different suppliers.

c Pin of metal, flat of polyethylene.

(From reference 25.) 
Tables 2.8.4.2 through 2.8.4.6 present some results from different wear studies concerned with the effects of minimum contact stress, testing time, and riolecular weight on the wear of UHIIIPE.

\begin{tabular}{|c|c|c|}
\hline \multirow{4}{*}{$\begin{array}{l}\text { Minimum } \\
\text { contact stress }\end{array}$} & \multicolumn{2}{|c|}{ POLYETHYLENE WEAR DATA FROM DISC-ON-FLAT } \\
\hline & WEAR TESTS & . \\
\hline & $W u m$ & \\
\hline & (wear/year) & $W\left(3.45 \mathrm{~N} / \mathrm{mm}^{2}\right)$ \\
\hline 3.1 & 1.43 & 1.59 \\
\hline 5.3 & 2.35 & 1.53 \\
\hline 9.2 & 4.71 & 1.77 \\
\hline 13.8 & 8.57 & \\
\hline 14.5 & 16.64 & \\
\hline 17.8 & 23.44 & \\
\hline
\end{tabular}


Table 2.8.4.3

POLYETHYLENE WEAR OATA CALCULATED FROM

ANNULUS-O!I-FLAT WEAR TESTS COMPARING

WEAR RATES AT 1 YEAR EFFECTIVE USE

$\begin{array}{ccc}\text { Test no. } & \text { Contact stress } & \text { Wear } \\ 1 & \left(\mathrm{~N} / \mathrm{mm}^{2}\right) & (\mu \mathrm{m} / \text { year }) \\ 2 & 1.03 & 1.2 \\ 3 & 1.55 & 1.2 \\ 4 & 2.24 & 3.3 \\ 5 & 2.76 & 4.9 \\ 6 & 3.79 & 7.3 \\ 7 & 4.48 & 7.7 \\ 8 & 5.93 & 10.1 \\ 9 & 7.07 & 9.1 \\ 10 & 9.17 & 10.0\end{array}$

Note: Test device $=$ annulus-on-flat; sliding distance $=10.7 \mathrm{~km}$;

years effective use $=1$ year; contact stress $=1-11.2 \mathrm{i} / \mathrm{mm}^{2}$; 1 ubricant = water; temperature $=$ room; velocity $=38.1 \mathrm{~mm} / \mathrm{sec}$. Also, $\|=0.845 p+$ 2.19, $r=0.85$. At $P=3.45, H=5.1 \mathrm{um} /$ year, at $P=6.9, H=8.0 \mathrm{~m} /$ year . (From reference 31 ). 
Table 2.8.4.4

COMPARISON OF SHORT-TO LONG-TERM TESTS OF POLYETHYLENE

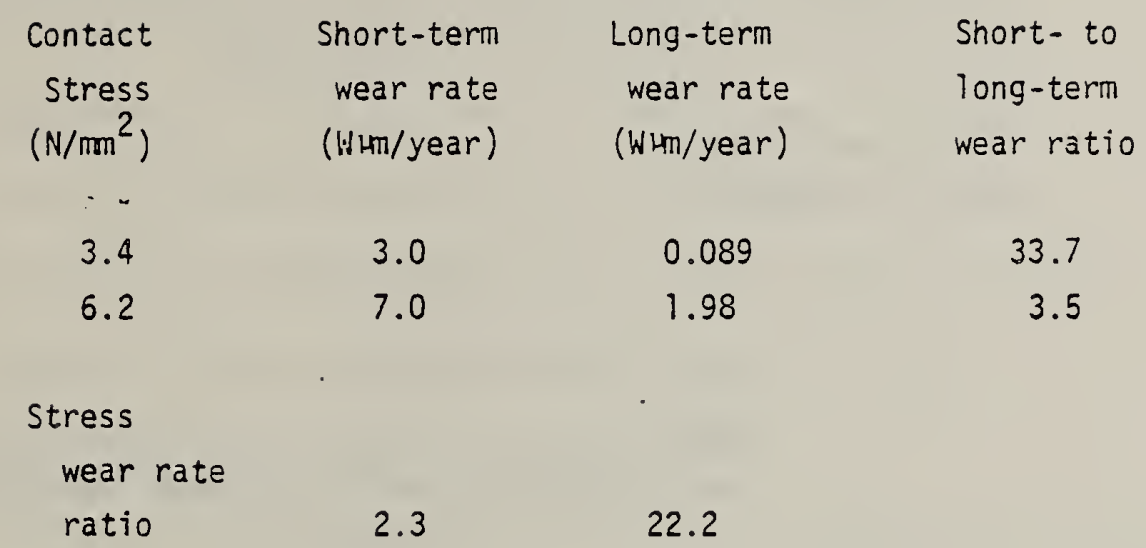

Note: Test device $=$ disc-on-flat; sliding distance $=25.4 \mathrm{~km}$ and greater; years effective use $=2.4$ and greater, contact stress $=3.4-6.2 \mathrm{~N} / \mathrm{mm}^{2}$; lubricant $=$ water; temperature $=37^{\circ} \mathrm{C}$; velocity $=$ not specified. (From reference 40 ). 
Table 2.8.4.5

WEAR RATES OF POLYETHYLENE RELATED TO

MOLECULAR "NEIGHT

$$
\begin{aligned}
& \text { Molecular weight } \\
& \left(\times 10^{6}\right)
\end{aligned}
$$$$
-
$$

3.96

3.23

2.90

2.66
Wear

(W $\mu \mathrm{m} /$ year $\mathrm{EU})$

6.42

1.07

i. 07

3.21

3.21

\section{Variation $=\times 1.5$}

Variation $=\times 6$

Note: Test device $=$ disc-on-flat; sliding distance $=127 \mathrm{~km}$; years effective use $=11.87$; contact stress $=3.4 \mathrm{i} / \mathrm{mm}^{2} ;$ lubricant = water; temperature $=37^{\circ} \mathrm{C}$; velocity $=$ not specified.

- Hould not dissolve.

(From reference 40 ).

Table 2.8.4.6

COMPARISON OF MACHINED POLYETHYLEIE (A, $1.5 \times 10^{6}$ MOLNT) AND MOULDED POLYETHYLENE ( $8,3 \times 10^{6} \mathrm{MOL}$ WT) FOR THREE

\begin{tabular}{|c|c|c|c|c|}
\hline & Polyethyiene & & & \\
\hline Counterface & $\begin{array}{l}\text { (A:machined; } \\
B \text { :moulded) }\end{array}$ & $\begin{array}{c}\text { llo. } \\
\text { specimens }\end{array}$ & $\begin{array}{r}\text { Wear rate } \\
(\text { Wun/year } 5 U)\end{array}$ & $\begin{array}{l}\text { Hear } \\
\text { ratio }(\%)\end{array}$ \\
\hline$T i-6-4$ & A & 3 & $4.6 \pm 0.3$ & 43 \\
\hline$T i-6-4$ & B & 1 & 1.99 & \\
\hline 316 SS & A & 1 & 7.67 & \\
\hline $316 \mathrm{SS}$ & $B$ & 1 & 4.04 & 53 \\
\hline $\mathrm{CO} \mathrm{Cr}$ & A & 1 & 7.67 & \\
\hline $\mathrm{Co} \mathrm{Cr}$ & B & 1 & 3.56 & 46 \\
\hline
\end{tabular}
METAL ALLOYS

Note: Test device $=$ pin-on-flat; sliding distance $=$ not specified; years effective use $=$ not specified; contact stress $=3.4 \mathrm{~N} / \mathrm{mm}^{2}$; lubricant $=$ ringers; temperature $=$ not specified; velocity $=$ not specified. (From reference 41 ). 
The term "years effective use" is derived from the sliding distance under the load phase of a walking cycle for a $22.2 \mathrm{~mm}$ diameter hip. Based upon the results of several studies [27, 32, 42] the sliding distance under load is arbitrarily set [25] at about $10.7 \mathrm{~km} /$ year for a hip-flexion arc of approximately $55^{\circ}$. In wear-screening studies, the wear rate is commonly reported in terms of wear depth of the component "per year of equivalent use" with one year representing $10.7 \mathrm{~km}$ sliding distance under load. Clarke [25] has defined a "wear factor", or "wear index", given by

$$
k=V_{/ L X}
$$

where $V$ is the wear volume, and $L$ and $X$ are the applied load and sliding distance respectively. The measured volume of wear is normalized by dividing by the sliding distance and load parameters. The unit micron/ year of effective use incorporates the $10.7 \mathrm{~km}$ sliding distance as well as a nominal contact stress in the range $3.45 \mathrm{MPa}$.

\subsection{Effects of High Energy Radiation}

Sterilization of UHMWPE components in orthopedic prostheses is done using high energy radiation, most commonly gamma irradiation. The typical dose is in the 2-4 Mrad range. In addition to sterilization, high energy radiation also causes chemical crosslinking and/or degradation of the polymer [43-45]. In the absence of oxygen, radiation is said to produce a net crosslinking effect which occurs preferentially in the amorphous regions [46]. There is additional evidence that some crosslinking occurs within the crystals, possibly limited to the fold surfaces $[47,48]$. Crosslinking and/or degradation can alter the mechanical behavior from that of the unirr diated polymer. Section 2.9 describes various aspects of the changes in physical and mechanical behavior of UHMWPE brought about by high energy radiation. 


\subsubsection{Density and Crystallinity}

One effect of high energy radiation is to increase the density, or percent crystallinity, of the UHINWPE. Figures 2.9.1.1 and 2.9.1.2 indicate how the percent crystallinity and density increase with increased irradiation dose.

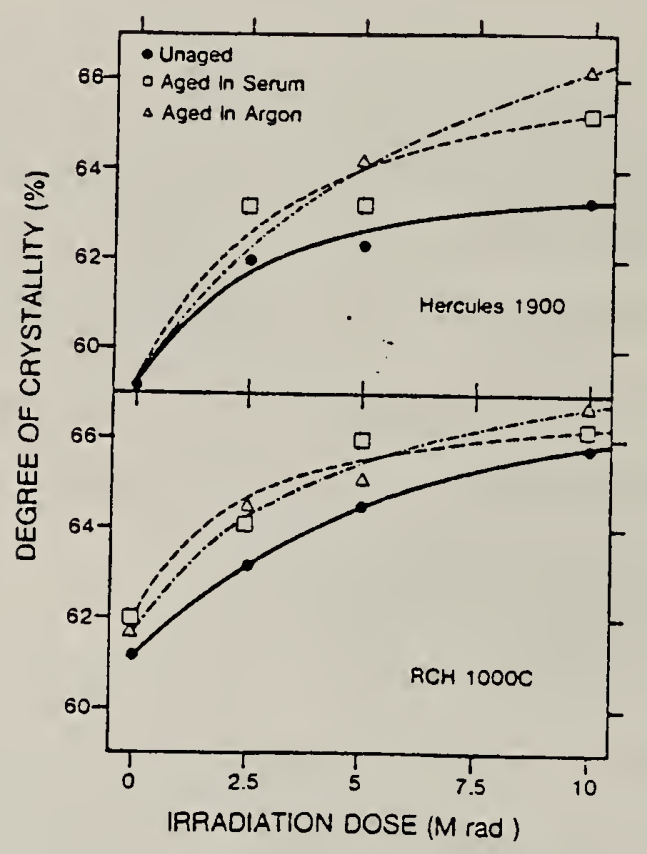

Fig. 2.9.1.1 The degree of crystallinity, calculated from the density, versus irradiation dose (gamma irradiation) for UHMWPE from two different commercial sources. [From Roe, Grood, Shastri, Gosselin, and Noyes, J. Biomed. Mat. Res., 15, 209 (1981). Reprinted by permission of John Wiley \& Sons, Inc. (c) ]. 


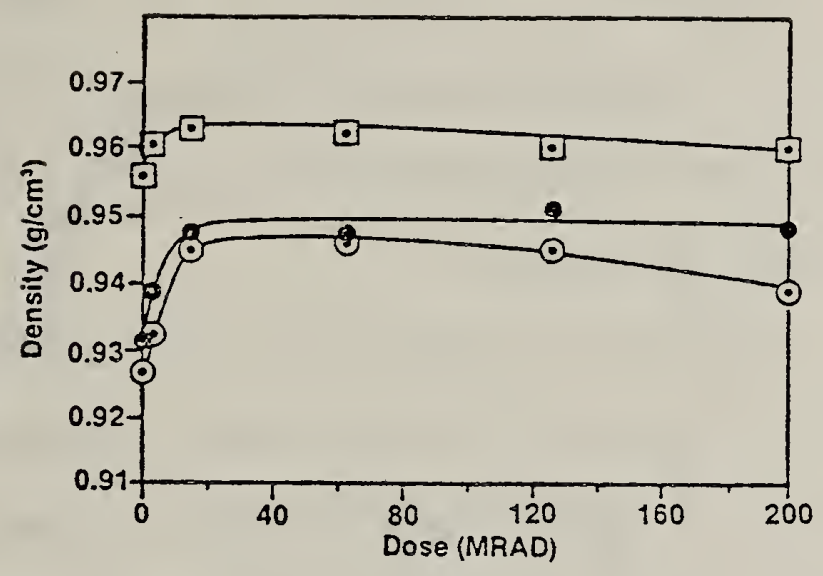

Fig. 2.9.1.2 Density as a function of irradiation Dose ( $\beta$ irradiation) for two different experimental samples of UHMWIPE $(\ominus, \bullet)$ and normal molecular weight polyethylene (অ). [From Bhateja, Andrews, and Young, J. Polymer Sci., 21, Polymer Physics Ed., 523 (1983). Reprinted by permission of John Wiley \& Sons, Inc. (c) ]. 
Both scts of data indicate that the density increases with dose for doses up to at least 10 Mrad. Two explanations for the increase in density have been given; (1) highly constrained tie molecules are preferentially severed by the irradiation, thus removing hinderance to further crystallization [46]; and (2) greater localized chain mobility occurs due to energy absorption during irradiation, and the material tends to reorganize in the direction of higher crystallinity [49]. There also is evidence that subsequent to the irradiation, aging of UHMIIPE occurs, and the density continues to increase over a period of many inonths [50].

\subsubsection{Melting Behavior}

The effect of high energy radiation on the melting behavior of UItHW is is less well defined than in the case of the density. Bhateja et. a). [46] report that for an experimental sample of UHMWPE, which was subjected to $B$ radiation, an increase in the temperature of the DSC mielting peak of about $5-7^{\circ} \mathrm{C}$ occurred over the first 16 Mrad of radiation. These results are shown in Figure 2.9.2.1. 


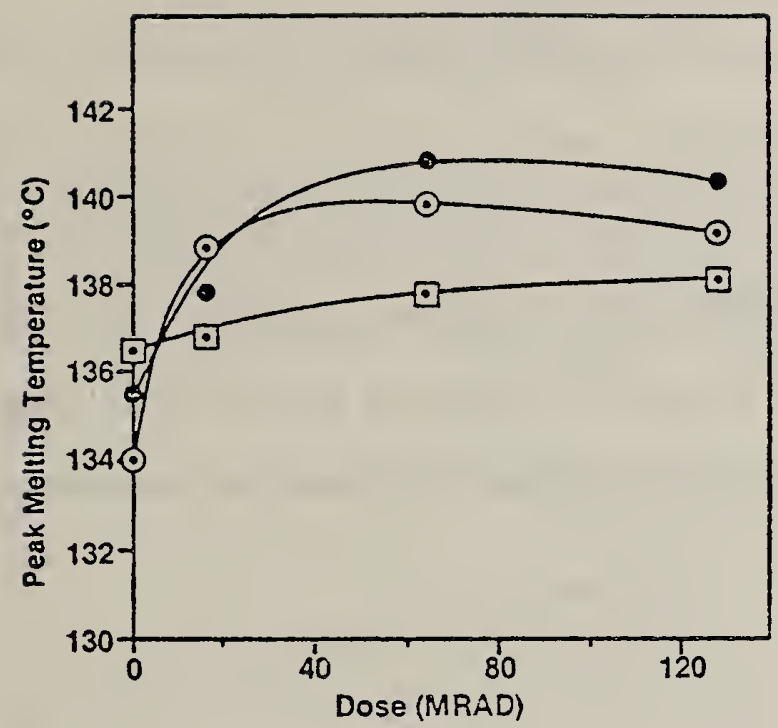

Fig. 2.9.2.1 Effect of $B$ radiation dose on the OSC (differential scanning calorimetry) peak melting temperature. $\theta, \bullet-$ UHMWPE, $\square$ normal molecular weight polyethylene. (From Bhateja. Andrews, and Young, J. Polymer Sci., 21, Polymer Physics Ed., 523 (1983).

Reprented by permission of John Wiley \& Sons, Inc. (].] 
On the other hand, Roe et. al [4S] compared the DSC curves for two specimens of a commercial grade UHMWPE, which were $\alpha$ irradiated to 0.0 and $10.0 \mathrm{Mrad}$ respectively, and found little or no change in position of the primary melting peak centered around $137^{\circ} \mathrm{C}$. A small secondary melting peak was observed at around $120^{\circ} \mathrm{C}$ for the specimen irradiated to $10 \mathrm{Mrad}$.

\subsubsection{Tensile Yield Stress}

The tensile yield stress is defined as the peak engineering stress occurring at tensile yield. Several studies have been made of the effect of high energy radiation on the tensile yield stress of UHMWPE. Data showing tensile yield stress as a function of radiation dose, for doses up to $200 \mathrm{Mrad}$, are shown in Figure 2.9.3.1. The yield stress is found to increase with increased dose. 


\subsubsection{Tensile Yield Point Elongation}

The effect of $\gamma$ irradiation on UHMIVPE is to decrease the elongation at yield [49]. Most of the reduction occurs during the first 5 Mrad of irradiation (Figure 2.9.4.1).

\subsubsection{Tensile Modulus}

The effect of high energy irradiation on UHMWPE is to increase the tensile modulus with increased dose. Data are shown in Figure 2.9.5.1 for polymer subjected to $B$-irradiation [46] and $\gamma$ - irradiation [49].

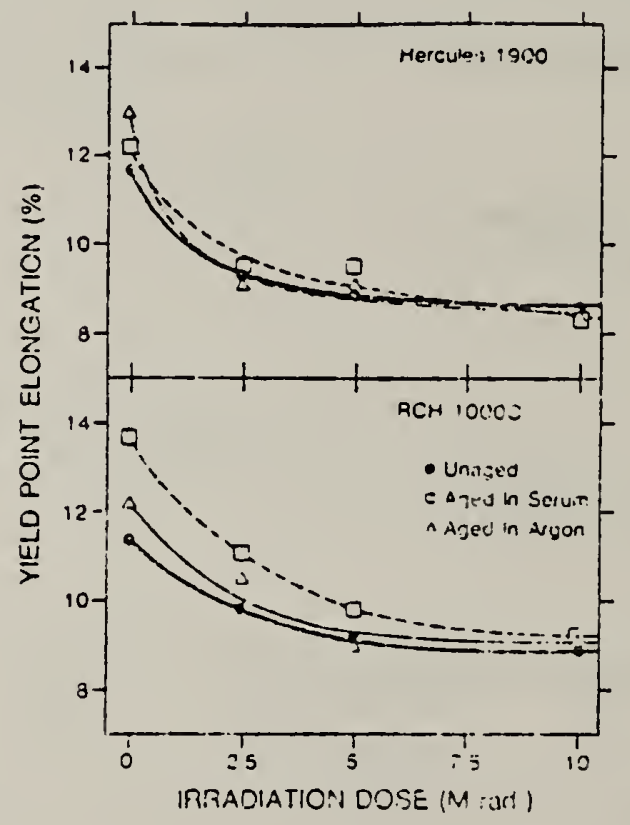

Fig. 2.9.4.1 Elongation at the yield point stress as a function of irradiation dose for two different commercial UHMWPE polymers. $\gamma$ - irradiation. [From Roe, Grood, Shastri, Gosselin, and Noyes, J. Biomed. Mat. Res., 15, 209 (1981). Reprinted by permission of John lit ley \& Sons, Inc. (c)?. 


\subsubsection{Impact Strength}

Du Plessis et al [53] report that the impact strength of irradiated UHMU.JPE decreases significantly with an increase in irradiation dose. Their data are shown in Figure 2.9.6.1 for specimens irradiated in the presence of three different environments.

\subsubsection{Surface Hardness}

Du Plessis et al [53] report that the surface hardness (Type D-Shore) of UHMWPE increases when the polymer is irradiated ( $\gamma$ rays) in the presence of crosslinking agents, but not so irradiated in a nitrogen atmosphere. (Figure 2.9.7.1).

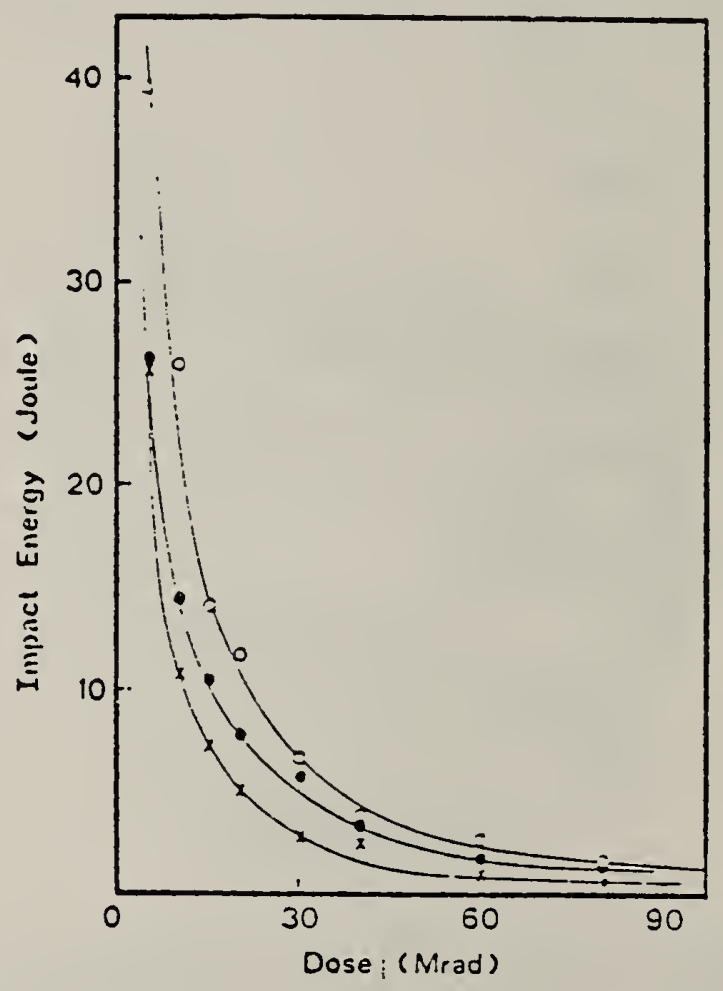

Fig. 2.9.6.1 Izod impact energy as a function of dose for UHAWPE radiation crosslinked ( $\gamma$ rays) in the presence of crosslinking agents or nitrogen. $\mathrm{O}-\mathrm{N}_{2}, X-\mathrm{CH} \equiv \mathrm{CH}$, and $-\mathrm{CH} \equiv \mathrm{CH}+\mathrm{CTFE}$ (chlorotrifluoroethylene). [From du Plessis, Grobbelaar, and Marais, Radiat. Phys. Chem., $\underline{9}, 647$ (1977), reprinted by permission of Pergamon Press Inc., $\mathcal{\subseteq} I$. 


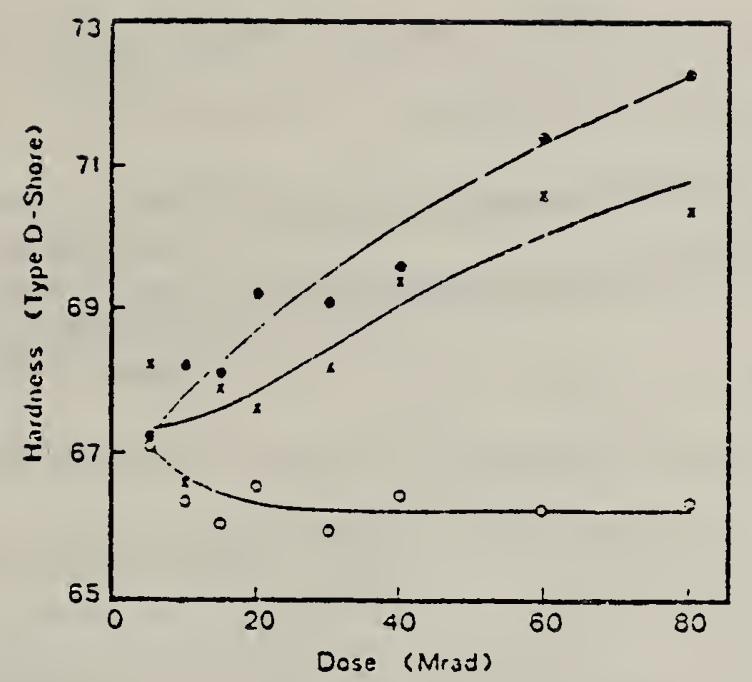

Fig. 2.9.7.1 Surface hardness of UHMWPE as a function of radiation dose for UHMUPE radiation crosslinked ( $\alpha$ rays) in the presence of crosslinking agents or nitrogen. $0-\mathrm{N}_{2}, X-\mathrm{CH} \equiv \mathrm{CH}$, and - $\mathrm{CH} \equiv \mathrm{CH}+\mathrm{CTFE}$. [From du Plessis, Grobbelaar, and Marais, Radiat. Phys. Chem., $\underline{9}$, 647 (1977), reprinted by permission of Pergamon Press Inc., $\mathcal{c} 1$. 


\section{9 .8 Creep}

Exposure to high energy radiation improves the resistance of UHMWPE to creep, even at relatively low irradiation doses. An example of the short time creep and recovery behavior at small deformations in uniaxial extension is shown in Figure 2.9.8.1 for a commercial sample of UHMWPE (MW $4 \times 10^{6}$ and $\mathrm{c}=0.935 \mathrm{~g} / \mathrm{cm}^{3}$ prior to irradiation) subjected to relatively low doses of $\gamma$ - irradiation. The creep strain after $10^{3}$ seconds decreases with increased dose.

A comparison of the room temperature creep behavior in uniaxial extension is shown in Figure 2.9.8.2 for a commercial UHMWPE polymer both unirradiated and irradiated at three different doses. At the longer times the creep strain is significantly less in more highly irradiated samples.

Bhateja and Andrews [54] report a similar behavior for samples of UHMWPE irradiated to doses of 3 -irradiation as high as 64 Mrad. Their results are shown in Figure 2.9.8.3. 


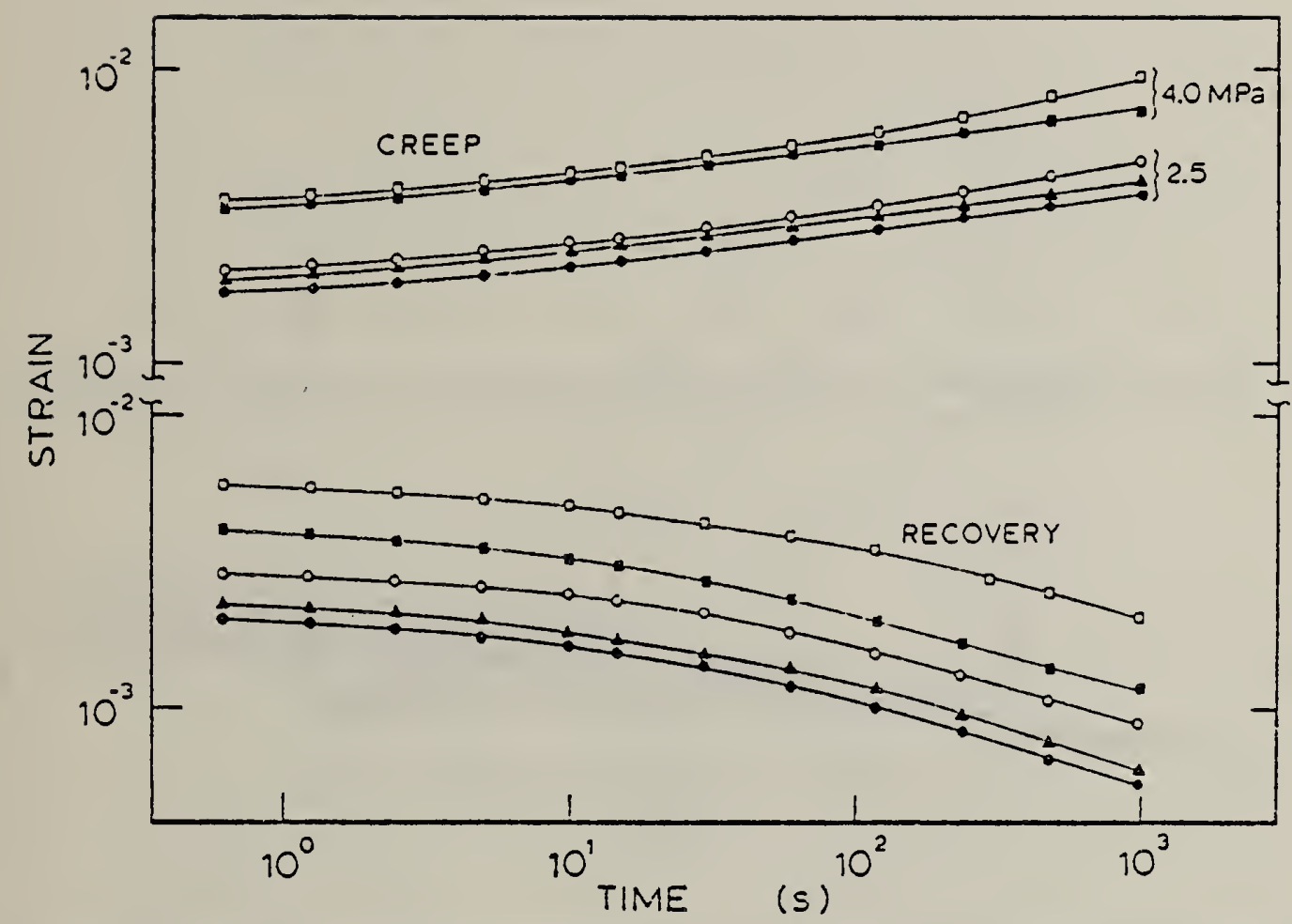

Fig. 2.9.8.1 Effect of $\gamma$ irradiation on the creep and recovery behavior in uniaxial extension of UHMWPE $\left(M_{W} \approx 4 \times 10^{6}, \rho=0.935 \mathrm{~g} / \mathrm{cm}^{3}\right)$. Temperature $23^{\circ} \mathrm{C}$, Engineering stress 2.5 and $4.0 \mathrm{MPa}$, length of creep step $10^{3}$ seconds. ○-0 Mrad, $\triangle-3.74 \mathrm{Mrad}$, and -6.28 Mrad dose. (From reference 21). 


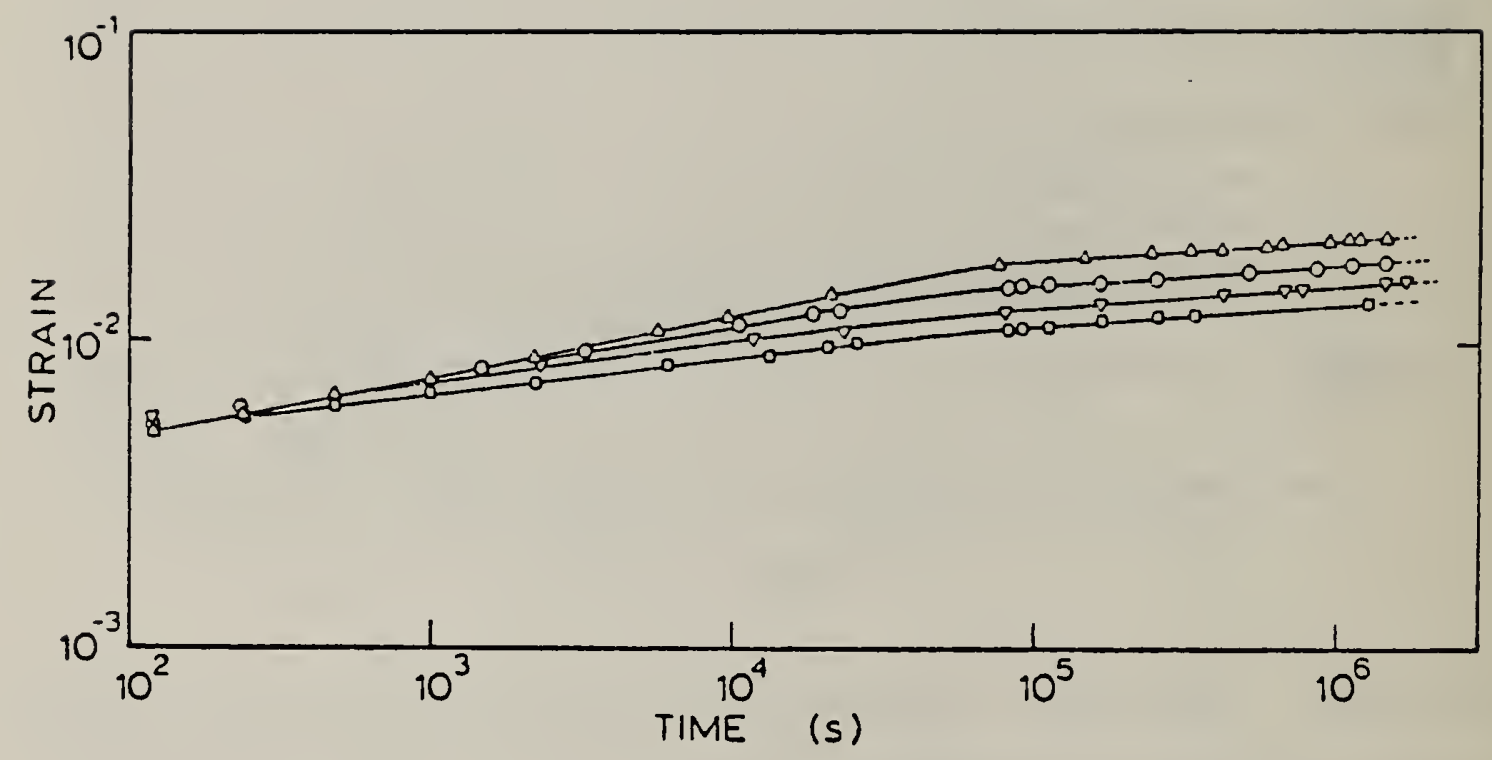

Fig. 2.9.8.2. Room temperature uniaxial creep behavior of UHMWPE $\left(M_{W} 24 \times 10^{6}\right.$, $\rho=0.935 \mathrm{~g} / \mathrm{cm}^{3}$ ) irradiated with various does of $\gamma$-irradiation. Engineering stress 4MPa. 4 - 0 Mrad, $0-1.18 \mathrm{Mrad}, 7-3.74 \mathrm{Mrad}$, and $\square-6.28 \mathrm{Mrad}$. (From reference 21). 


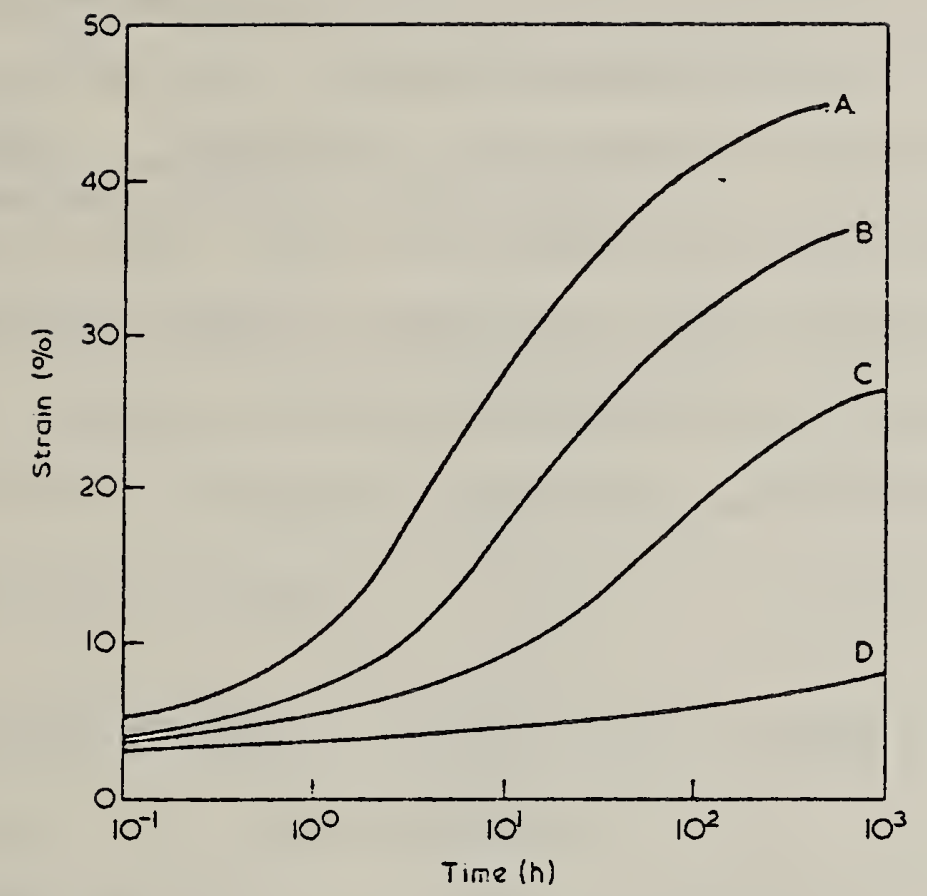

Fig. 2.9.8.3 Creep strain (uniaxial extension) versus time for UHMWPE at an engineering stress of $10.3 \mathrm{MPa}$. A-OMrad, B-4Mrad, C-16Mrad, and D-64Mrad. (B radiation) (From Bhateja and Andrews, Polymer, 24, 150(1983). Reprinted by permission of Butterworth Scientific, Ltd. (C) ]. 


\subsubsection{Stress Relaxation}

No data are available.

\subsubsection{Fatigue}

Only limited data are available on the effect of high energy radiation on the fatigue behavior of UHIIWPE. Table 2.9.10.1 shows some of the fatigue results of Nusbaum and Rose [52]. The samples were cycled for the number of cycles indicated and at the peak stress indicated. After $10^{7}$ cycles at $1.7 \times 10^{4} \mathrm{KPa}$, several of the irradiated specimens showed a pronounced neck, whereas unirradiated samples did not. They concluded that the irradiation rendered the UIHIWPE slightly weaker than the as-received polymer, and where cyclic loading is concerned, irradiation may aggravate creep under some conditions.

Table 2.9.10.1 Fatigue in Uniaxial Tension of UHNWWPE at $23^{\circ} \mathrm{C}$

\begin{tabular}{|c|c|c|c|c|}
\hline \multirow[b]{2}{*}{ Specimen } & \multicolumn{2}{|c|}{$\begin{array}{l}2.5 \times 10^{6} \text { cycles in water at a } \\
\text { peak stress of } 1.03 \times 10^{4} \mathrm{k} \cdot \mathrm{aa}\end{array}$} & \multicolumn{2}{|c|}{$\begin{array}{l}10^{7} \text { cycles in serum at a ceak } \\
\text { stress of } 1.72 \times 10^{4} \mathrm{kPa}\end{array}$} \\
\hline & As received & Irradiated* & As received & Irradiated* \\
\hline $\begin{array}{c}\text { Yield Stress } \\
\left(\times 10^{4} \mathrm{kPa}\right)\end{array}$ & 2.36 & 2.47 & & \\
\hline Strain & 0.15 & 0.15 & & \\
\hline $\begin{array}{l}\text { Lower Yield } \\
\text { Stress }\left(\times 10^{4}\right. \\
\text { kPa })\end{array}$ & 2.22 & 2.1 & 2.19 & 2.05 \\
\hline Strain & 0.53 & 0.67 & 2.8 & 3.3 \\
\hline
\end{tabular}

* 2.5 Mrad dose (s-radiation)

(From reference 52 ) 


\subsubsection{Effect of Radiation on Wear}

A number of studies have examined the effect of radiation on the wear properties of UHMWPE. Several of these are listed in Table 2.9.11.1.

Table 2.9.11.1

WEAR-SCREENING STUDIES INVESTIGATING THE EFFECT OF RADIATION STERILIZATION ON UHMW POLYETHYLENE ${ }^{\mathrm{a}}$

\begin{tabular}{|c|c|c|c|c|}
\hline Study & Polyethylene & Sterilization & Test device & Lubricant \\
\hline Dumbleton [29] & HIFAX 1900 & $\begin{array}{c}\text { 20-1000 lirad } \\
\text { (argon) }\end{array}$ & Annulus-on-f & t Plasma \\
\hline Scales $[30]$ & RCH 1000 & $\begin{array}{l}2.5 \text { Mrad } \\
\text { (ethylene oxide } \\
\text { autoclaved) }\end{array}$ & Pin-on-flat & Serum \\
\hline Unge thum [55] & HDPE & $\begin{array}{c}0-15 \text { Mrad } \\
\text { (air) }\end{array}$ & Pin-on-flat & Serum \\
\hline McKellop [56] & HiFAX 1900 & $\begin{array}{c}\text { 0-7.5 Mrad } \\
\text { (air) }\end{array}$ & Pin-on-flat & Serum \\
\hline Grobbelaar [57] & RCH 1000 & $\begin{array}{l}\text { 0-80 Mrad } \\
\text { (acetylene) }\end{array}$ & Sand-slurry & test \\
\hline Jones [58] & & $\begin{array}{l}0-5 \text { Mrad } \\
\text { (air) }\end{array}$ & & Dry \\
\hline
\end{tabular}

In Table 2.9.11.2 it can be seen, that tne results of these studies are quite varied. This may be a consequence of differences in sterilization technique and wear test methodology. Tables 2.9.11.3-5 summarize the results of three different studies concerned with the wear behavior of a - irradiated URMTPE. Clarke [25] concludes "It would appear that irradiation sterilization generally increases polyethylene wear. At the levels generally used (2.5Mrad), the likely increase is about 200 to $300 \%$." 
Table 2.9.11.2

SLMMARY OF IRRADIATION STERILIZATION EFFECTS ON POLYETHYLENE WEAR RATES ${ }^{b}$

\begin{tabular}{lccc} 
& Sterilization & Effect on wear \\
\cline { 2 - 3 } Study & range (Mrad) & Decrease & Increase \\
Dumbleton [29] & $0-1000$ & - & 3.6 \\
Scales [30] & $0-2.5$ & 2.1 \\
Ungethum [55] & $0-15$ & None & None \\
Jones [58] & $0-5$ & 0.3 & 8 \\
Grobbelaar [57] & $0-80$ & \\
McKellop [56] & $0-7.5$ & \\
a Wear increased 360\% from 0-20 Mrad, returned to unsterilized wear rates \\
at 200 Mrad, and then increased 40\% by 1000 Mrad. \\
brom reference 25.
\end{tabular}

Table 2.9.11.3

SUMMARY OF WEAR DATA COMPARING WEAR RATES OF STERILE HIFAX 1900 POLYETHYLENE ${ }^{a}$

Treatment

Unsterile

20 Mrad

$200 \mathrm{Mrad}$

1000 Mrad

$\begin{array}{ccc}\text { Wear/year EU } & \text { Wear } & \text { Cverall } \\ \left(\begin{array}{l}W \\ \mathrm{~m}\end{array}\right) & \text { ratio variation }\end{array}$

13.9

1.0

1.4

5.4

0.4

7.5

0.5

Note: Test device $=$ annulus-on-flat; sliding distance $=10.7 \mathrm{~km}$; years effective use $=1.0$ year; contact stress $=3.4 \mathrm{~V} / \mathrm{mm}^{2} ;$ luoricant $=$ serum; temperature $=$ room; velocity $=81.3 \mathrm{~mm} / \mathrm{sec}$.

${ }^{a}$ From reference 29 . 
Table 2.9.11.4

WEAR DATA FOR POLYETHYLENE DISCS (RCH 1000) SLIDING ON COBALT CHROME (METAL PIN $=12.56 \mathrm{~mm}^{2}$ CONTACT AREA ${ }^{\mathrm{C}}$ )

No. Wear rate Wear

Test Sterilization Treatment specimens ( $W \mu \mathrm{m} /$ year) $W(3.45 \mathrm{~N} / \mathrm{mm}$ ) ratio

$\begin{array}{lllllll}\text { A } & \text { Nonsterile } & -- & 7 & 130 \pm 20 \% & 56 & 1.0 \\ \text { Bonsterile } & -- & 4 & 142 \pm 3 \% & 62 & 1.1 \\ 2.5 \text { Mrad } & -- & & 274 \pm 9 \% & 119 & 2.1 \\ 2.5 \text { Mrad } & \text { Boiled } 14 \text { days }^{b} & 2 & 189 & 82 & 1.4 \\ 2.5 \text { Mrad } & \text { Boiled 50 days } & 2 & 109 & 47 & 0.8\end{array}$

Note: Test device $=$ pin-on-flat; sliding distance $=$ not specified; years effective use = not specified; contact stress $=7.96 \mathrm{~N} / \mathrm{mm}^{b} ;$ lubricant = serum; temperature $=20^{\circ} \mathrm{C}$; velocity $=$ not specified.

arom different manufacturer.

boiled in saline solution.

From reference 30

Table 2.9.11.5

HiFAX 1900 WEAR DATA WHEN SLIDING ON STAINLESS STEEL ${ }^{a}$

$\begin{array}{cccc}\begin{array}{c}\text { Stress } \mathrm{N} / \mathrm{mm}^{2} \\ (\mathrm{c} / \mathrm{min})\end{array} & \begin{array}{c}\text { No. of } \\ \text { specimens }\end{array} & \begin{array}{c}\text { Wear } \\ \text { (W m/year })\end{array} & \begin{array}{c}\text { Volumetric wear } \\ \left(\mathrm{mm}^{3} / \text { year }\right)\end{array} \\ 3.45(60) & 3 & 0.36 \pm 15 \% & 0.025 \\ 6.9(100) & 3 & 0.65 \pm 15 \% & 0.048\end{array}$

Note: Test device $=$ pin-on-flat; sliding distance $=188 \mathrm{~km}$; years effective use $=17.6$ years; contact stress $=3.45-6.9 \mathrm{~N} / \mathrm{mm}^{2}$; lubricant $=$ serum; temperature $=$ room; velocity $=60-100 \mathrm{c} / \mathrm{min}$.

$a_{\text {From }}$ reference 38 


\section{References}

[1] Annual Book of ASTM Standards published by the American Society For Testing and Materials, 1916 Race St. Philadelphia, PA 19103, 1982 Edition, Part 46.

[2] G. B. McKenna, F. Khoury, and J. M. Crissman, "Relationship Between Morphology and Mechanical Properties of Ultra High Molecular Weight Polyethylene," First Annual Report to the FDA, Bureau of Medical Devices, Task 80-01, NBS-BMD Interagency Agreement, October, 1980 (NBSIR $81-2209 F D A$ ).

[3] G. W. Halldin and I. L. Kamel, Poly. Eng. \& Sci., 17, No. 1, 21 (1977).

[4] R. H. Marchessault, B. Fisa, and H. D. Chanzy, Crit. Rev. Macromol. Sci., 1,315 (1972).

[5] Annual Book of ASTM Standards, Part 35.

[6] Annual Book of ASTM Standards, Part 9.

[7] K. C. Chen, E. J. Ellis, and A. Crugnola, SPE, 39 th ANTEC, 270-272 (1981).

[8] For a discussion of the equilibrium melting point of polyethylene see for example, J. D. Hoffma.I. G. T. Davis, and J. I. Lauritzen Jr., "The Rate of Crystallization $n$ : Linear Polymers with Chain Folding," Chapter 7 (see pars $50 \%$ ), in Treatise on Solid State Chemistry Vol. 3, N. B. lir.nr:g Zdi. Plenuri Press N.Y. (1976).

[9] -uiletin, "Hostalen GUR UHMW Polymers", American Hoechst Corp., Somerville, New Jersey.

[10] Report No. DFG-18A, "Compression Molding Techniques," Hercules Inc., Wilmington, Delaware.

[11] J. M. Crissman, F. Khoury, and G. B. McKenna, "Relationship Between Morphology and Mechanical Properties of Ultra High Molecular Weight Polyethylene", Second Annual Report to the FDA Bureau of Medical Devices, task 80-01, NBS-BMD Interagency Agreement, December, 1981 (NBSIR 82-2493 FDA)

[12] J. M. Crissman, G. B. MCKenna, and F. Khoury, SPE, 40th ANTEC, 55-58 (1982).

[13] H. L. Wagner and J. G. Dillon, J. Biomed. Mater. Res., 13, 821 (1979).

[14] Report No. F-243, "Machining of 1900 UHMW Polymer Shapes," Hercules Inc., Wilmington, Delaware.

[15] S. K. Bhateja, Polymer, 22, 23 (1981).

[16] Brochure, 1900 UHMW Polymer, Hercules Inc., Wilmington, Delaware. 
[17] J. Berzen, H. W. Birnkraut, and G. Braun, British Poly. Journa 1, 10, $281(1978)$.

[18] L. J. Zapas and J. M. Crissman, Polymer, in Press.

[19] J. M. Crissman, L. J. Zapas, and F. Khoury, "Relationship Between Morphology and Mechanical Properties of U1tra High Molecular Weight Polyethylene", Third Annual Report to the FDA, Bureau of Medical Devices, Task 80-01, NBS-BMD Interagency Agreement, March 1983 (NBSIR 83-2696 FDA).

[20] J. D. Ferry, Viscoelastic Properties of Polymers, John Wiley \& Sons, Inc., New York, 1967.

[21] J. M. Crissman, "Mechanical Properties of U1tra High Molecular Weight Polyethylene", Fourth Annual Report to the FDA, Bureau of Medical Devices, task 80-01, NBS-BMD Interagency Agreement, 1984 (NBSIR 84-? FDA).

[22] J. Berzen and J. Theyssen, Kunststoffe, 68, 42 (1978).

[23] S. Turner, Poly. Eng. \& Science, 6, 306 (1966).

[24] D. R. Moore and S. Turner, Plastics \& Polymers, 42, 41 (1974).

[25] I. C. Clarke, Chemical Rubber Company (CRC) Critical Reviews in Biomedical Engineering, 8 , Issue 1, 29-91 (1982).

[26] J. K. Lancaster, Plast. Polym., 41, No. 156, 297-306 (1973).

[27] B. Seedhom, D. Dowson, and V. Wright, Wear, 24, 35 (1973).

[28] J. 0. Galante and W. Rostoker, Acta Orthopaed. Scand., Supp1. 145 (1973).

[29] J. H. Dumbleton and C. Shen, Wear, 29, 163 (1974).

[30] J. T. Scales and K. W. J. Wright, Acta Orthop. Belg., 41 (Supp1. 1), $160(1975)$.

[31] J. H. Dumbleton and G. Shen, Wear, 37, 279 (1976).

[32] H. Mekellop, I. C. Clarke, K. Markoff, and H. Amstutz, J. Biomed. Mater. Res., 12, 895 (1978).

[33] W. Rostoker and J. O. Galante, J. Biomed. Mat. Res., 13, 957 (1979).

[34] I. Duff-Barclay and D. T. Spi17man, Proc. Inst. Mech. Eng., 181 (3J), 90, London, $(1966 / 1967)$. 
[35] H. C. Amstucz, J. Biomed. Mat. Res., 3, 547 (1968).

[B6] P. S. Walker, D. Dow'son, M. Longfield, and V. Wright, Proc. Inst. Mech. Eng., 181 (3J), 133-135, London, (1967).

[37] R. J. Pawluk and iv. S. Eftekhar, Trans. Orthop. Res. Soc., I, $56(1976)$.

[38] H. Hckellop, I. C. Clarke, K. Markolf, and H. Amstutz, J. Bioned. Mat. Res., 15, 619 (1981).

[39] I. C. Clarke, P. J. HicGuire, D. Hu11, R. Okuda, and A. Sarmiento, Trans. Orthop. Res. Soc., $\underline{-6}, 185$ (1981).

[40] W. Rostoker and J. 0. Galante, J. Biomed. Mat. Res., 10, 303 (1976).

[4 1] D. Miller, R. Ainsworth, J. Dumbleton, E. H. Miller, and G. Shen, Wear, 28, 207 (1974).

[42] J. Charnley, Plastics in Medicine and Surgery, Plastics and Rubber Institute, London, 3.1 (1975).

[43] A. Charlesby, Atomic Radiation and Polymers, Pergamon Press, ilew York, 1960.

[44] F. A. Makhlis, Radiation Physics and Chemistry of Macromolecules, Wiley, New York, 1975.

[45] M. Dole, Polyn. Plast. Technol. Eng., 13, 41 (1979).

[46] S. K. Bhateja, E. H. Andrews, and R. J. Young, J. Polym. Sci., 21. Polymer Physics Edition, 523-536 (1983).

[4 7] E. H. Andrews and I. G. Voigt-Martin, Proc. R. Soc. London Ser. A, 327, 251 (1972).

[48] R. Nagaeawa and K. Kobayashi, J. App 1. Phys., 41, 4276 (1970).

[49] R. J. Roe, E. S. Grood, R. S. Shastri, C. A. Gosselin, and F. R. Noyes, J. Biomed. Mat. Res., 15, 209-230 (1981).

[50 ] S. K. Bhateja, Polymer, Commun., 23, 654-655, (198:2).

[51] C. T. Lue, E. J. ElTis, and A. Crugnola, 29th SPE ANTEC, Boston, MA, $246(1981)$. 
[52] iv. J. Nusbaum, and R. M. Rose, J. Biomed. Mater. Res., 13, 557-576 (1979).

[53] T. A. du Plessis, C. J. Grobbelaar, and F. Marais, Radiat. Phys. Chem., 9, 647-652 (1977).

[54] S. K. Bhateja and E. H. Andrews, Polymer, 24, 160-166 (1983).

[55] M. Ungethum, Artificial Hip and Knee Joint Technology, M. Schaldach and D. Hohmann, Eds., Springer-Verlog, Base1, 491 (1976).

[56 ] H. McKellop, G. Griffin, I. Clarke, and K. Markoff, Proc. 26th Orthopaedic Research Society Meeting, Atlanta, GA, Feb. 5-7, 99 (1980).

[57] C. Grobbelaar, T. du Plessis, and F. Marais, J. Bone Jt. Surg., $60-B, 370$ (1978).

[58] W. Jones, W. Hady, and A Crugnola, NASA Technical Paper 1462 , May (1979). 



\section{TABLE OF CONTENTS FOR SECTION 3}

Subject

3. Poly(methyl methacrylate) Acrylic Bone Cement .......... 3-1

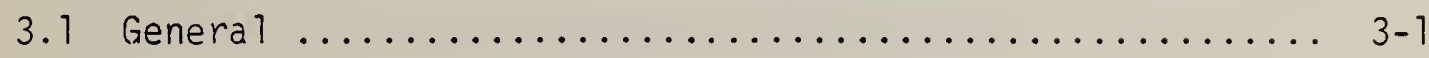

3.2 Trade Names and Specifications $\ldots \ldots \ldots \ldots \ldots \ldots \ldots . . \ldots \ldots$

3.2.1 Trade Names $\ldots \ldots \ldots \ldots \ldots \ldots \ldots \ldots \ldots \ldots . . .6 \ldots \ldots$

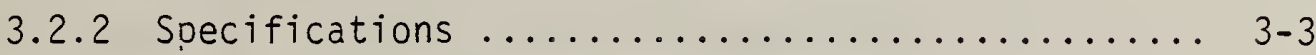

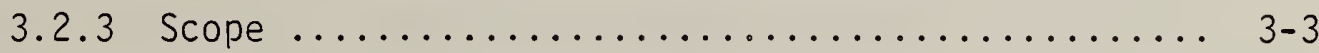

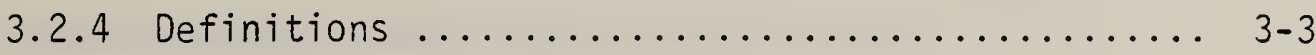

3.2 .5 Physical Requirements $\ldots \ldots \ldots \ldots \ldots \ldots \ldots \ldots .3-3$

3.2 .5 .1 Liquid $\ldots \ldots \ldots \ldots \ldots \ldots \ldots \ldots \ldots \ldots \ldots \ldots \ldots \ldots \ldots$

3.2 .5 .2 Powder $\ldots \ldots \ldots \ldots \ldots \ldots \ldots \ldots \ldots \ldots .3-4$

3.2.5.3 Powder-Liquid Mixture $\ldots \ldots \ldots \ldots \ldots$ 3-4

3.2.5.4 Cured Polymer ................. 3-4

3.2.6 Test Methods for Bone Cement Characterization

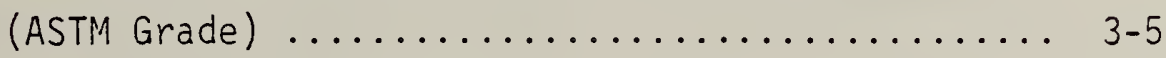

3.2.6.1 Test Conditions ................ 3-5

3.2.6.2 Viscosity Change $\ldots \ldots \ldots \ldots \ldots \ldots \ldots .3-5$

3.2.6.3 Doughing Time ................ $3-5$

3.2.6.4 Maximum Temperature $\ldots \ldots \ldots \ldots \ldots \ldots$ 3-6

3.2.6.5 Setting Time $\ldots \ldots \ldots \ldots \ldots \ldots \ldots \ldots .3 .6$

3.2 .6 .6 Intrusion $\ldots \ldots \ldots \ldots \ldots \ldots \ldots \ldots \ldots \ldots \ldots \ldots \ldots$

3.2.5.7 Compressive Strength ............. 3-10

3.2.6.8 Indentation and Recovery ......... 3-11

3.2.6.9 Water Sorption ............... 3-17

3.2.6.10 Solubility $\ldots \ldots \ldots \ldots \ldots \ldots \ldots \ldots .3-12$ 


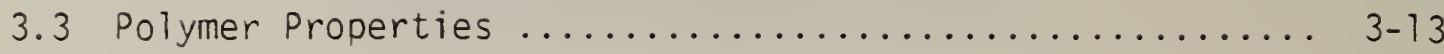

3.3.1 Raw Polymer ............................ 3-13

3.3.1.1 General ....................... 3-13

3.3.1.2 Liquid Monomer ................. $3-13$

3.3.1.3 Polymer Powder .................. 3-14

3.3.1.4 Other Constituents ............... 3-15

3.3.2 The Curing Cement ..................... 3-17

3.3.3 Cured Cement ........................... 3-19

3.3.3.1 General ........................ 3-19

3.3.3.2 Physical and Chemical Properties ....... 3-19

3.3.3.3 Mechanical Properties of Cured Bone

Cement ........................ 3-27

3.3.3.3.1 Static Properties ......... 3-27

3.3.3.3.2 Fracture and Crack Growth Characteristics ............ 3-33

3.3.3.3.3 Viscoelastic Behavior of Acrylic Bone Cement ........ 3-41

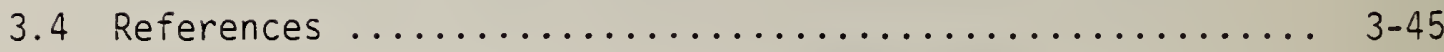


3. Poly(methyl methacrylate) Acrylic Bone Cement

3.1 Genera 1

The poly(methyl methacrylate) (PMMA) used in orthopedics as a bone cement consists essentially of a powder of methacrylate polymer which is mixed with a liquid monomer. This mixture forms a dough which reacts over a period of several minutes, depending on conditions, to form a hardened cement. The cement thus formed is a sort of composite of a PMMA matrix material (the polymerized liquid) filled with particles (the powder). The resulting product, thus, does not necessarily exhibit the same properties exhibited by commercially available poly(methyl methacrylates) which are generally homogeneous, high molecular weight polymers.

Certain of the materials labeled as PMMA bone cements are in reality not pure methyl methacrylate homonolymers, but are copolymers.

A separate section will deal with this subject.

3.2 Trade Names and Specifications

3.2.1 Trade Names 1

Table 3.1 lists the trade names and major sources for Acrylic bone Cements.

${ }^{1}$ Certain commercial materials are identified in this report in order to specify them adequately. In no case does such identification imoly recommendation or endorsement by the National Bureau of Standards. 


\section{Trade Names and Manufacturers of PMMA}

\section{Bone Cements}

Trade Name

CMW

Palacos R

Sulfix

Surgical Simplex $P$

Zimmer Bone Cement

Omniplastic
Manufacturer

CMW Laboratories Limited

Bone Cement Division

Blackpool, FY4 4CF

England

Kulzer and Co.

GMBH

Bad Homburg

West Germany

Sulzer Brothers Limited

Medical Engineering Department

$\mathrm{CH}-8401$

Winterthur

Switzerland

North Hill Plastics Limited London $\mathrm{N} 16$

England

Distributed in U.S. by:

Howmedica, Inc.

Orthopedics Div.

359 Veterans Bivd.

Rutherford, N.J. 07070

Zimmer USA

Warsaw, Indiana 46580

U.S.A.

Cintor Orthopedic

Division of Johnson \& Johnson Products, Inc Braintree, MA. 02184 


\subsubsection{Specifications}

The principle specifications for acrylic bone cements intended for use in surgical implant applications are those contained in ASTM F-451-76 Standard Specification for ACRYLIC BONE CEMENTS [1]. The following are sections excerpted from the ASTM specifications.

\section{$3.2 .3 \underline{\text { Scope }}$}

3.2.3.1 The specification covers self curing resins used primarily for the fixation of internal orthopedic endoprostheses.

3.2.3.2 Units of premeasured powder and liquid are supplied in a form suitable for mixing to set "in vivo".

3.2.3.3 While a variety of copolymers may be incorporated, the composition of the set cement shall contain poly(methacrylic acid esters) as the main ingredients.

\subsubsection{The specification covers compositional and} physical performance and packaging requirements but does not cover toxicity or biocompatibility of the cement.

\subsubsection{Definitions}

3.2.4.1 Unit - one package or vial of preweighted powder component or 1 iquid component.

3.2.5 Physical Requirements (ASTM Grade)

3.2.5.1 Liquid:

Appearance - The liquid shall be clear and free of deposits or sediment on visual examination in its container.

1 Reprinted, with permission from the Annual Book of ASTM Standards. Copyright, ASTM, 1916 Race Street, Philadelphia, PA 19103. 
Stability - The liquid shall not increase in viscosity to such an extent that its flow time is increased more than $10 \%$ when heated in the dark and in its original container to $60 \pm 2^{\circ} \mathrm{C}$ for 48 hours. Sterility - The liquid, as poured from its container, shall pass the tests described in "Sterility Tests - Liquids and Ointments" [2].

\subsubsection{Powder:}

Appearance - The powder shall be pourable and free of extraneous materials such as dirt or lint.

Sterility - The powder, as poured from its package, shall pass the tests described in "Sterility Tests - Solids" [2].

\subsubsection{Powder - Liquid Mixture: The material shall} exhibit the properties presented in Table 3.2 .

Table 3.2

ASTM Soecifications for Acrylic Bone Cement Powder-Liquid Mixture [1]

Maximum Dough

Time, minutes

5.0

Setting Time

Range, minutes

5 to 15

Maximum $\circ$

Exotherm, $\mathrm{C}$

90

Minimum

Intrusion, $\mathrm{mm}$

2.0

3.2.5.4 Cured Polymer: The material, after setting, shall have the properties presented in Table 3.3 .

Table 3.3

Requirements for Cured Polymer After Settina [1]

Minimum Comoressive Strenath, MPa

70
Maximum: Identation, am

0.14

60

Minimum

Maxii:um

Maxirum 1/ater

Recovery,

Wacer Sorotion,
Solubility $\mathrm{ma} / \mathrm{cm}^{2}$

0.7

0.05 


\subsubsection{Test Methods for Bone Cement Characterization (ASTM Grade)}

3.2.6.1 Maintain all equipment, mixing surfaces and materials at $23 \pm 2^{\circ} \mathrm{C}$ at least 2 hours prior to testing and conduct a 11 tests at $23 \pm 1^{\circ} \mathrm{C}$ unless otherwise specified. 3.2.6.2 Viscosity Change - Record the viscosity change before and after the heating exposure by timing the flow of the liquid level between the 0 and $5 \mathrm{ml}$ marks of a $10 \mathrm{ml}$ measuring pipet. Calculate the change as follows:

$$
\% \text { change }=\left[\frac{t_{A}-t_{B}}{t_{B}}\right] \times 100
$$

where $t_{B}=$ flow time before heating, and $t_{A}=$ flow time after heating exposure for 48 hours in the dark in a closed container at $60 \pm 2^{\circ} \mathrm{C}$. An alternative method for viscosity may be used.

\subsubsection{Doughing Time - Mix all the powder and liquid} of a single unit together as directed by the manufacturer's instructions. Start a chronometer at the onset of combining powder with the liquid and read a11 subsequent times from this stop watch. Approximately 1.5 minutes after the onset of mixing, gently probe the mixture with a surgically gloved finger. Take visual notice as to the formation of fibers between the surface of the mix and the finger as it leaves the surface. Repeat this process of probing from that time at 15 second 
intervals until the gloved finger separates cleanly. Denote the time at which this is first observed as the doughing time. Mix the mixture between determinations to expose fresh material for each probing process.

Make two separate determinations of the doughing time. The two values shall agree within 30 seconds of each other, otherwise repeat the test on two additional units and report the average of all runs.

\subsubsection{Maximum Temperature - Within 1 minute after} doughing time, gently pack approximately $25 \mathrm{~g}$ of the dough into the mold described in Figure 3.1. The mold shall be made of polytetrafluorethylene (PTFE) and be equipped with a No. 24-gage wire thermocouple or similar device positioned with its junction in the center of the mold at a height of $3.0 \mathrm{~mm}$ in the internal cavity. Immediately seat the plunger with a $\mathrm{C}-\mathrm{cl}$ amp or suitable press to obtain the $6.0 \mathrm{~mm}$ specimen height. Upon producing plunger seating remove the excess material and the $C$-clamp or press for the remainder of the procedure. Continuously record the temperature. Continue measuring the time from the onset of mixing the powder with the liquid. Record temperatures until cooling is observed. Report the maximum temperature recorded to the nearest $1^{\circ} \mathrm{C}$. 


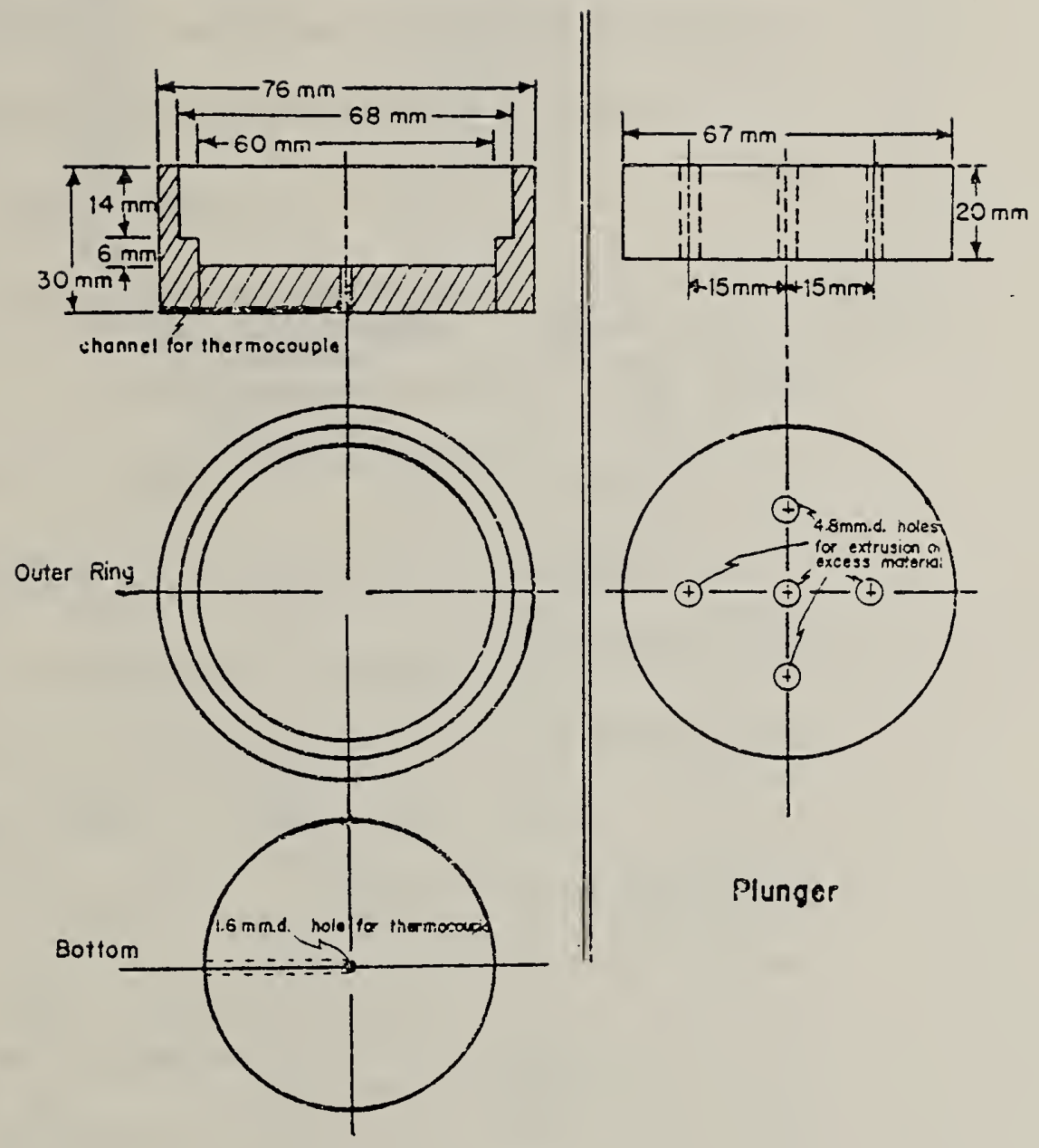

Die

Fig. 3.1 Exothermic Heat Mold. (ASTM F451) [1] 
The maximum temperature shall be the average of two separate determinations reported to the nearest $1^{\circ} \mathrm{C}$. If the difference between the two determinations is greater than $5.0^{\circ} \mathrm{C}$ repeat the test on two additional units and report the average of all four runs to the nearest $7^{\circ} \mathrm{C}$.

3.2.6.5 Setting Time - From the continuous time vs. temperature recording from above, the setting time is that time when the temperature of the polymerizing mass is:

$$
\left(T_{\max }+T_{\text {ambient }}\right) / 2
$$

where $T_{\max }=$ maximum temperature

$\mathrm{T}_{\text {ambient }}=$ Ambient temperature of $23^{\circ}+2^{\circ} \mathrm{C}$

The setting time is reported to the nearest

15 seconds. Two separate determinations of setting time are made and if the two values do not agree to within 1 minute of each other, two additional runs are to be made and the average of four determinations reported as the setting time.

3.2.6.6 Intrusion - The mold necessary for this test is depicted in Figure 3.2. It will be made from PTFE. Mix one unit of powder and liquid according to the manufacturer's recommended procedure. When doughing is achieved, gently pack the entire mixture flat into the mold and insert the plunger. One minute after the doughing time place a load of $49 \mathrm{~N}$ (11 1b) on top of the plunger for 1 minute. Then remove the weight and allow the mixture to set. 


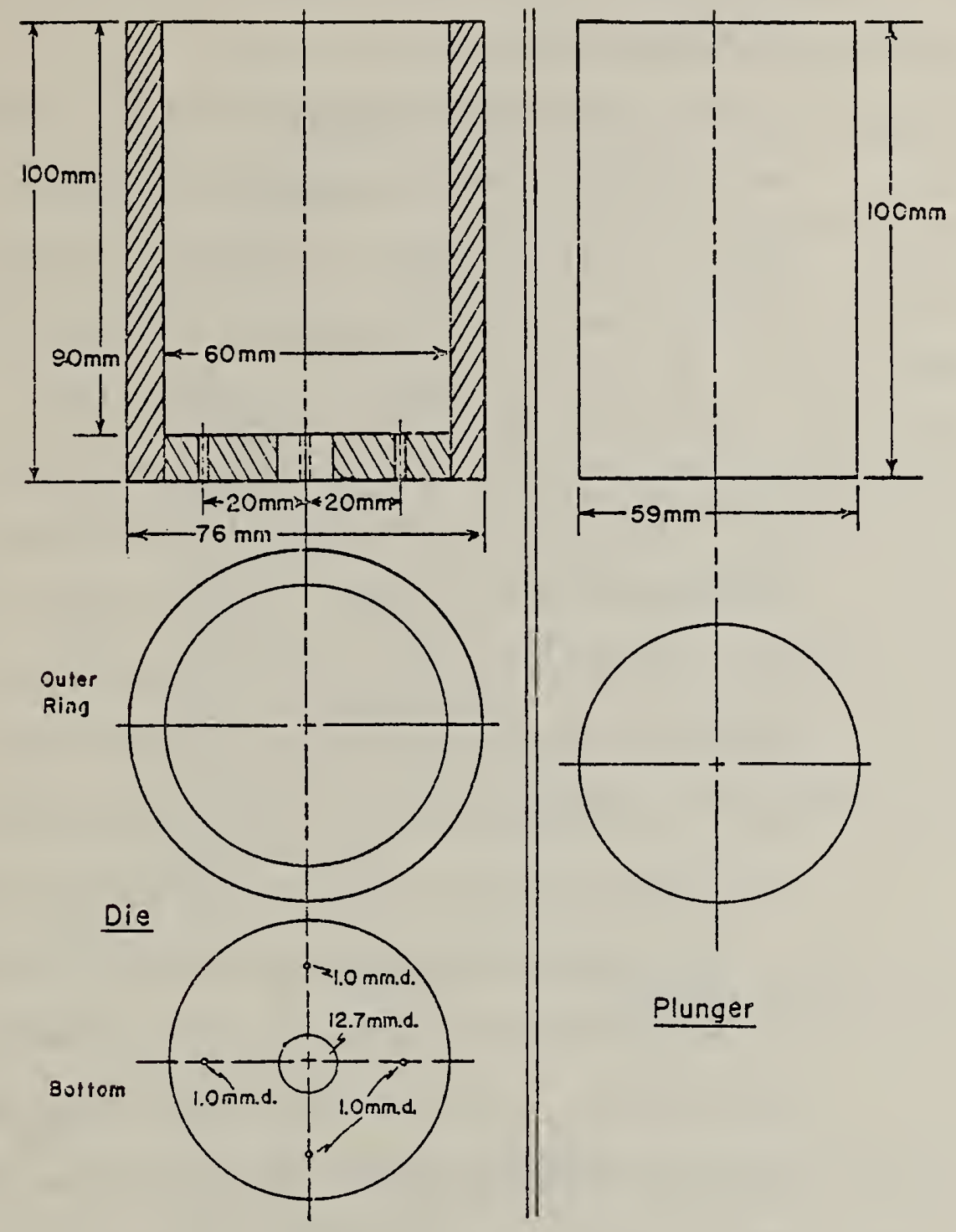

Fig. 3.2 Intrusion Mold. (ASTM 451) [1] 
Following the set, remove the specimen and measure the average height of the intrusion into all four of the $1.0 \mathrm{~mm}$ diameter holes to the nearest $0.5 \mathrm{~mm}$. Run this test once. If the requirement is not met it must do so in a repeat test.

\subsubsection{Compressive Strength - The test specimens shall} be cylinders $12 \mathrm{~mm}$ high and $6 \mathrm{~mm}$ in diameter. The ends shall be flat and smooth and parallel to each other and at right angles to the long axis of the cylinder.

The test cylinders are prepared five at a time by placing five molds on a flat glass plate and slightly overfilling by using one unit of mixed cement at the commencement of dough time. Place a second flat glass plate on top of the molds and hold the glass plates and molds firmly together with a small C-clamp. The ends of the specimens can be faced by polishing with 240 grit paper with water prior to removal from the mold.

The time lapse between the start of mixing and the measurement of compressive strength testing shall be $24 \pm 2$ hours. The tests can be run on any universal testing machine equipped to record load and deformation time. Employ a crosshead speed of 20 or $25.4 \mathrm{~mm} / \mathrm{min}$. Test the specimens without use of any type of pad between the specimen and machine plattens. The failure load shall be the load at the $2: \%$ offset ( $2:$ proof stress), upper yield point, or at fracture, whichever occurs first. The compressive strength is the failure load divided by the original cross sectional area of the sample. It is reported as the average for the five specimens to the nearest $1 \mathrm{MPa}$. 
3.2.6.8 Indentation and Recovery - Determine indentation using a Rockwell superficial hardness tester. Use the disk from 3.2.6.4. Remove any flash or other irregularity which would prevent the disk from seating firmly on the hardness tester. At $24 \pm 2$ hours after the start of mixing, subject the specimen in three separate areas to a minor load of $29.4 \mathrm{~N}$ (6.7 1b.) employing a steel ball of $12.7 \mathrm{~mm}$ in diameter and adjust the dial gage on the hardness tester to zero. Then bring the total load to $294 \mathrm{~N}(66.8 \mathrm{lb}$.$) ,$ for 10 minutes, at which time read the depth of the indentation from the dial gage to the nearest $0.001 \mathrm{~mm}$ This is Reading A. Bring the load back to $29.4 \mathrm{~N}$. After 10 minutes, read the dial gage and record the value as Reading $B$. Round the averages of Reading $A$ and Reading $B$ from the three areas to the nearest $0.01 \mathrm{~mm}$ Record indentation as $A$ (average). Calculate the percent recovery as:

$$
\% \text { Recovery }=\left[\frac{A(a v g)-B(a v g)}{A(a v g)}\right] \times 100
$$

\subsubsection{Water Sorption - Perform the water sorption} test in duplicate on disks 50=1 mim diameter and $0.5=0.1 \mathrm{~mm}$ thick. The specimens may be made in a mold composed of a stainless steel ring $50 \mathrm{~mm}$ in diameter by $0.5 \mathrm{~mm}$ thick. mounted between flat glass plates. Use sheets of cellophane or polyethylene between the mold and the glass plates. Place the powder and liquid mixture into the mold 3 minutes after the start of the mixing. Place a load of $98 \mathrm{~N}$ (22 1b.) on top of the glass plate for the duration of setting. 
After setting remove the specimens from the mold and

lightly sand to dimensions using 240 and 400 grit

abrasive paper successively, backed by a hard, flat surface.

Al1 surfaces of the disk will be smooth and top and bottom will be flat.

Dry the disks in a dessicator containing thoroughty dry anhydrous calcium sulfate $\left(\mathrm{CaSO}_{4}\right)$ or silica gel (freshly dried at $130^{\circ} \mathrm{C}$ ) at $37^{\circ} \pm 2^{\circ} \mathrm{C}$ for 24 hours.

Remove to a similar dessicator at room temperature for

1 hour then weigh with a precision of $0.2 \mathrm{mg}$. Repeat this cycle until the weight loss of each disk is not more than $0.5 \mathrm{mg}$ in any 24 hour period. This weight shall be known as the conditioned mass, ${ }{ }_{C}$.

Immerse the conditioned disk in distilled water at $37 \pm 2^{\circ} \mathrm{C}$ for 7 days after which time remove the disks from the water with tweezers, wipe with a clean, dry hand towel until free from visible moisture, wave in the air for $15 \mathrm{sec}$ and weigh 1 minute after removal from the water.

The resulting weight shall be known as the mass after immersion, $m_{I}$. Calculate the water sorption as follows for each disk:

$$
\text { Water Sorption }=\left(m_{I}-m_{C}\right) / 40 \mathrm{~cm}^{2}
$$

Record the average of the determined values for two disks to the nearest $0.01 \mathrm{mg} / \mathrm{cm}^{2}$. Round the final value (average of two determinations) to the nearest $0.1 \mathrm{mg} / \mathrm{cm}^{2}$.

3.2.6.10 Solubility - After the final weighing in (3.2.6.9), recondition the disks to constant weight in the dessicator 
at $37 \pm 2^{\circ} \mathrm{C}$ as done in 3.2.6.9 above. This shall be known as the reconditioned mass, $m_{R}$. Calculate the value for solubility as follows:

$$
\text { Solubility }=\frac{m_{C}-m_{R}}{40 \mathrm{~cm}^{2}}
$$

Round the final value (average of two determinations) to the nearest $0.01 \mathrm{mg} / \mathrm{cm}^{2}$.

\subsection{Polymer Properties}

\subsubsection{Raw Polymer}

3.3.1.1 General - The characterization of the raw polymer must be considered in light of the means of employment, i.e., as a medical material which will be implanted into the body while it is undergoing a chemical (polymerization) reaction. The properties of each of the two phases of this material prior to handling by the surgeon will affect both its ultimate properties as a bone cement and its handling characteristics in the operating theater. In the following paragraphs are discussed the major constituents of bone cements. In the next section the mechanical properties of the cement will be discussed.

\subsubsection{Liquid Monomer - Bone cements are obtained} from various suppliers and as such the details of composition can vary. However, the major constituents of self-curing and non-crosslinkable bone cements consist of a liquid monomer and a polymeric powder [3-7]. The monomer is a clear, volatile liquid which can polymarize spontaneously even at room temperature, 
for which reason an inhibitor, usually hydroquinone, is added for purposes of storage $[3,4]$. This tendency to polymerize explains the need for the ASTM requirement to measure viscosity changes upon heating the liquid (see section 3.2). Also added to the monomer is an initiator, often a tertiary amine such as dimethylparatoluidine, which has no effect until it reacts with the activator in the powder.

\subsubsection{Polymer Powder - The powder phase of the} cement is a prepolymerized polymethylmethacrylate to which is added an activator, usually benzoyl peroxide. Upon mixing monomer (1iquid) with the powder the cement cures to a solid mass which has many of the properties of commercial PMMA, i.e. the cement at body temperature is an amorphous, glassy polymer.

The properties of the powder phase itself may affect the way in which the cement handles, as well as the ultimate properties of the cement. Particle size, shape and distribution seems to vary with manufacturer's empirical determination of what combination of handling characteristics, cure characteristics, Dorosity of the final cement, etc. represent the best compromises for the final product. In Table 3.4 are shown some typical properties of the bone cement powders. Figure 3 shows a typical micrograph of a bone cement 
powder. In some bone cements the powder is a copolymer of styrene and methylmethacrylate (See Table 3.5).

\subsubsection{Other Constituents - There are two other} ingredients often used in the bone cement. Barium sulfate is used as a radio-opaque additive to enable the cement to be observed on medical x-ray radiographs.

Table 3.4

Some Properties of Powders Used in Commercial Bone Cements

\begin{tabular}{|c|c|c|c|}
\hline Bone Cement & Description of Powder & $\begin{array}{c}\text { Powder Molecular } \\
\text { Weiaht }\end{array}$ & Reference \\
\hline CMW & $\begin{array}{l}\text { Spherical and comminuted powders } \\
\text { ranging in size from } 5-75 \mathrm{um}\end{array}$ & $1.01 \times 10^{5}$ & {$[7]$} \\
\hline Palacos R & $\begin{array}{l}\text { Spherical beads ranging in size } \\
\text { from } 5 \text { to } 100 \text { m with clusters } \\
\text { of } 10-15 \mu \mathrm{m} \text { size particles }\end{array}$ & $4.59 \times 10^{5}(\mathrm{a})$ & {$[7]$} \\
\hline Sulfix-6 & $\begin{array}{l}\text { Similar to Palacos } R \text { but with } \\
\text { fewer clusters. }\end{array}$ & $1.19 \times 10^{5} \quad$ (a) & {$[7]$} \\
\hline $\begin{array}{l}\text { Surgical Simplex } \\
\text { p }\end{array}$ & $\begin{array}{l}\text { Large fraction of polymer } \\
\text { "flour" mixed with soheres of } \\
\text { similar size to the others }\end{array}$ & $8.90 \times 10^{4}(a)$ & {$[7]$} \\
\hline $\begin{array}{l}\text { Surgical } \\
\text { Simplex }\end{array}$ & - & $3.2 \times 10^{4} \quad$ (b) & [8] \\
\hline Surgical Simplex $P$ & $\begin{array}{l}\text { Spheres of varying sizes and } \\
\text { irregular clusters of size } \\
1000 \text { to } 100,000 \mathrm{um} \text {. The most } \\
\text { frequent sphere size was } 25 \mathrm{~mm} \\
\text { and the largest } 40 \mathrm{um} \text {. }\end{array}$ & $\begin{array}{l}4.4 \times 10^{4}(\mathrm{~b}) \\
1.95 \times 10^{5}(\mathrm{a}) \\
1.98 \times 10^{5}(\mathrm{~b})\end{array}$ & $<_{4}^{4}$ \\
\hline
\end{tabular}

(a). Viscosity Average Molecular Weights

(b). Number Average Molecular Weight, From GPC, polystyrene Calibration 



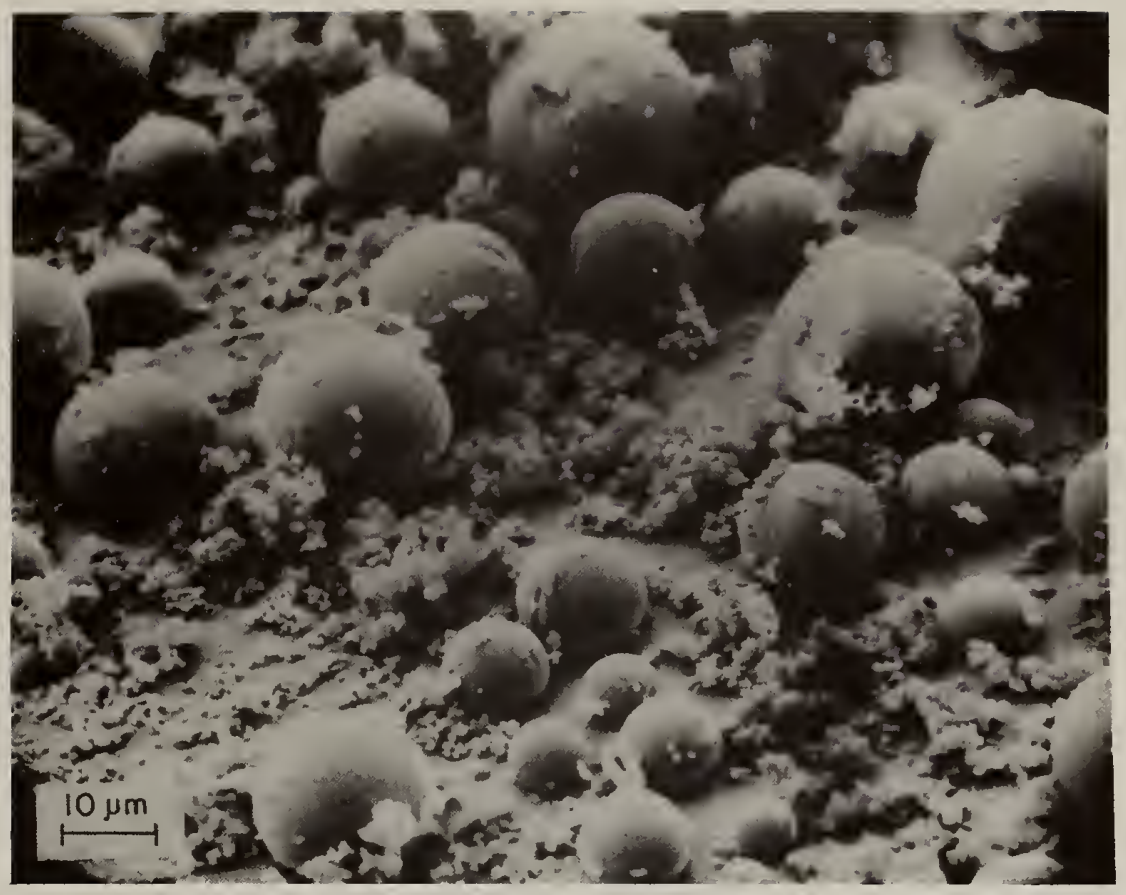

Fig. 3.3 Scanning electron micrograph of powder component of the cement. No difference was observed between radiopaque (barium sulfate-containing) and radiolucent (barium-free) powder. [4] 

The barium sulfate containina powder is indistinguishable from the pure one in the microscope [4]. In addition, various antibiotics can be added to the cement to help fight deep infection $[9,10]$. Table 3.5 shows the inaredients of typical bone cement powder and iquid components.

\section{Table 3.5}

\section{Compositions of Powder and Liquid Phases of Some Commercial PMMA Bone Cements [T]}

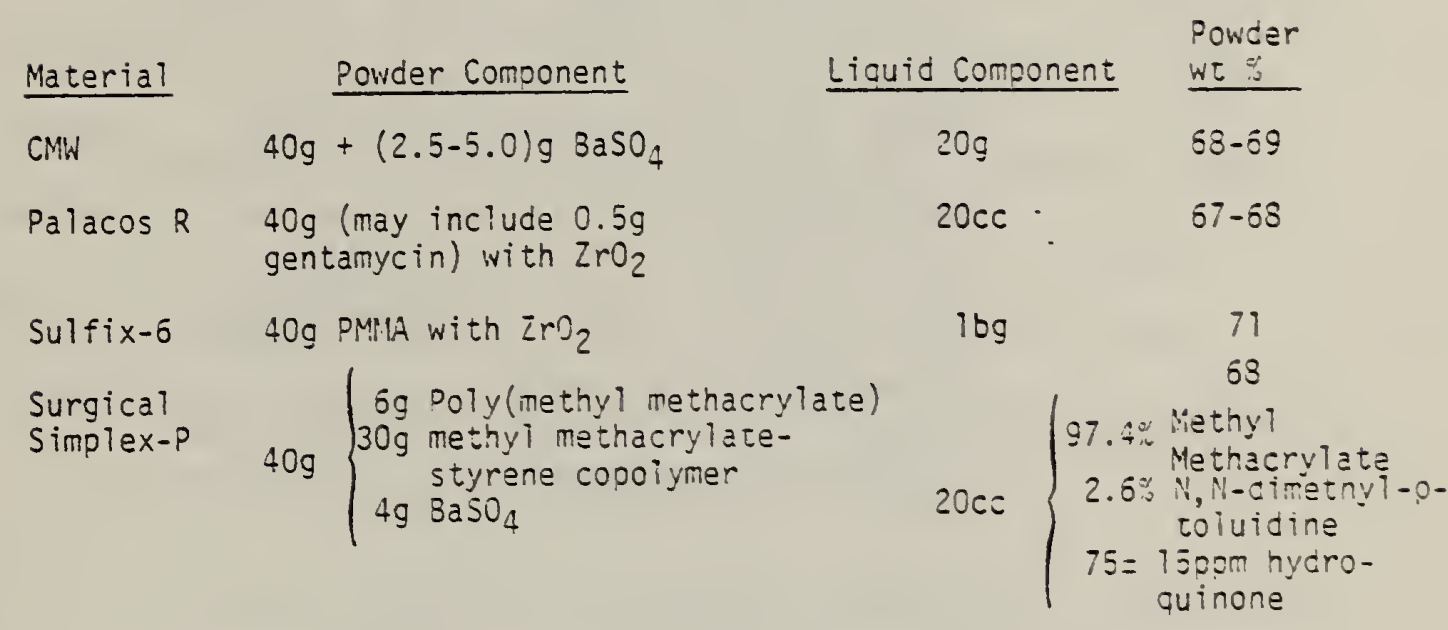

\subsubsection{The Curing Cement}

The mixing of the powder and liquid commences a chemical reaction of polymerization of the liauid monomer. As the cement cures it passes through a "dough" stage during which time it can be handled by the surgeon and implanted. The handling of the dough in the surcery environivent can introduce body fluids and air into the final cured cerent. 
Thus, while most of the laboratory data for bone cement is obtained on samples which have been carefully handled to insure reproducible and controllable results, in order to allow comparisons of behavior, the actual state of the cement "in vivo" may be modified significantly from that obtained in the laboratory.

During polymerization of the bone cement, a considerable amount of heat is generated $[5,13,14]$. The exact geometry of the cement (surface to volume ratio), the speed of reaction, the surface boundary conditions (ambient temperature, heat transfer coefficient at the surface), etc. will obviously affect the peak temperature obtained. As seen in Table 3.6 these temperatures can be quite high and efforts have been made to reduce the curing exotherm $[13,14]$. However, the extent of the problem is controversial and the cement is used quite successfully in spite of it.

Table 3.6 $\frac{\text { Values of Peak Temoeratures Obtaired on }}{\text { Curing PPMiA Bone Cement Masses }}$

Materia?

Surgical "Simplex $P$

II

11

"1
Powder/Liguid Ratio

$1 / 1$

$2 / 1$

$3 / 1$

$2 / 1$

$2 / 1$

$3 / 1$

\section{Peak Temperature ${ }^{\mathrm{a}}$; $\mathrm{C}$ Reference}

$48^{\circ}$
$39^{\circ}$
33
$83-110^{\circ}$
$75-87^{\circ} \mathrm{b}$
73

73

aThe experimental procedures used in [13], [14] and [5 ] were auite different. This is one of the problems in determining the clinical importance of cure exotherm of Pill:A bone cenents.

b Depended upon variables such as relative humidity, storage conditions, presence of radio-opaque material, etc. 


\subsubsection{Cured Cement}

3.3.3.1 General - The cured cement is a two phase system. It consists of the now polymerized monomer filled with the particles of powder. Although the cement is a glassy poly(methyl methacrylate) polymer, its properties can differ appreciably from those of commercially available acrylics. One reason is its two phase nature, simply the existence of a particle/ matrix interface can affect the properties of the material. In addition, the processing of the material at ambient temperature and pressure and as a "dough" results in considerable porosity and resultant change in properties relative to those of the commerical polymer. Finally, the bone cements tend to have lower molecular weights than do the commercial materials. This also affects the material properties. 3.3.3.2 Physical and Chemical Properties - After cure, the bone cement is primarily poly(methyl methacrylate) with small residues from the initiatior, inhibitor and activator materials. In addition, the agents added for radio-opacity and antibiotic activity remain. In a major study of one bone cement, for example, Brauer [4 ], et a1. looked at residual peroxide, residual monomer, and residual hydroquinone after cure. They found that the amount of residual substance changed with time after cure, and "storage" environment. 
In Table 3.7 are shown the results of storage time on the residual peroxide in a cement (Simplex $P$ ) which originally contained $2 \%$ benzoyl peroxide in the powder phase. As can be seen, length of time and storage temperature affect the amount of peroxide remaining. The peroxide appears to continue to react after "cure" is complete. As the author's note [4], however, the amount of peroxide remaining in the cement is small and since the peroxides (either benzoyl peroxide or polymeric peroxide) are insoluble in water, it is unlikely that any appreciable amount of peroxide will leach out of the cured cement under clinical conditions. of, perhaps, greater interest is the observation that residual monomer remains in the cured cement. The amount undoubtedly depends on the exact conditions of cure, but Brauer, et al. [4] cite various literature sources as finding monomer concentrations up to $27 \%$ and that tissue concentrations adjacent to the cement showed up to $1.2 \%$ cement. Brauer, et al [4] found residual monomer contents of up to $33 \%$ during mixing of the dough. This had decreased to only $3.3^{\circ}=$ after one hour. Their results are summarized in Figure 3.4 and Table 3.8 . 
Table 3.7

\section{Residual Peroxide in Cured Bone Cement [4 ]}

\section{Length of Storage}

$1 \mathrm{hr}$ in air, room tenip.

14 months in air, room temp.

21 days in water at $37^{\circ} \mathrm{C}$

21 days in water at $37^{\circ} \mathrm{C}$

15 months in water at $37^{\circ} \mathrm{C}$
Peroxide/Res in $(\mathrm{g} / 100 \mathrm{~g})$

0.81

0.76

0.33

0.21

0.14

${ }^{a}$ Radiopaque material containing barium sulfate.

Table 3.8

Gas-Chromatographic Analyses for Residual

Monomer Content of Cured PMMA Bone Cement [4]

Storage Time

Monomer

\section{$30 \mathrm{~min}$}

$60 \mathrm{~min}$

$60 \min ^{\mathrm{a}}$

$4 \mathrm{hr}$

$20 \mathrm{hr}$

13 days

45 days

49 days

57 days a

174 days $b$

207 days $^{b}$

215 days

275 days $b$

136 days $c$

3 months
Concentration (\%)

3.25

3.36

$2.83(3.04)^{e}$

2.87

2.70

2.30

2.48

2.21

$2.12(2.27)^{e}$

2.60

2.48

2.42

2.26

1.44

1.08

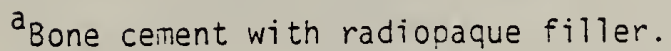

bamples mixed in 3:1 powder-liquid ratio.

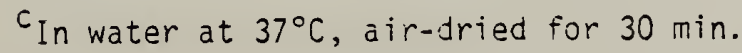

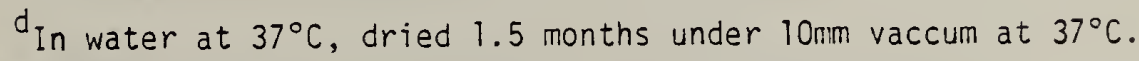

e Monomer concentration based only on resin content of bone cement. 


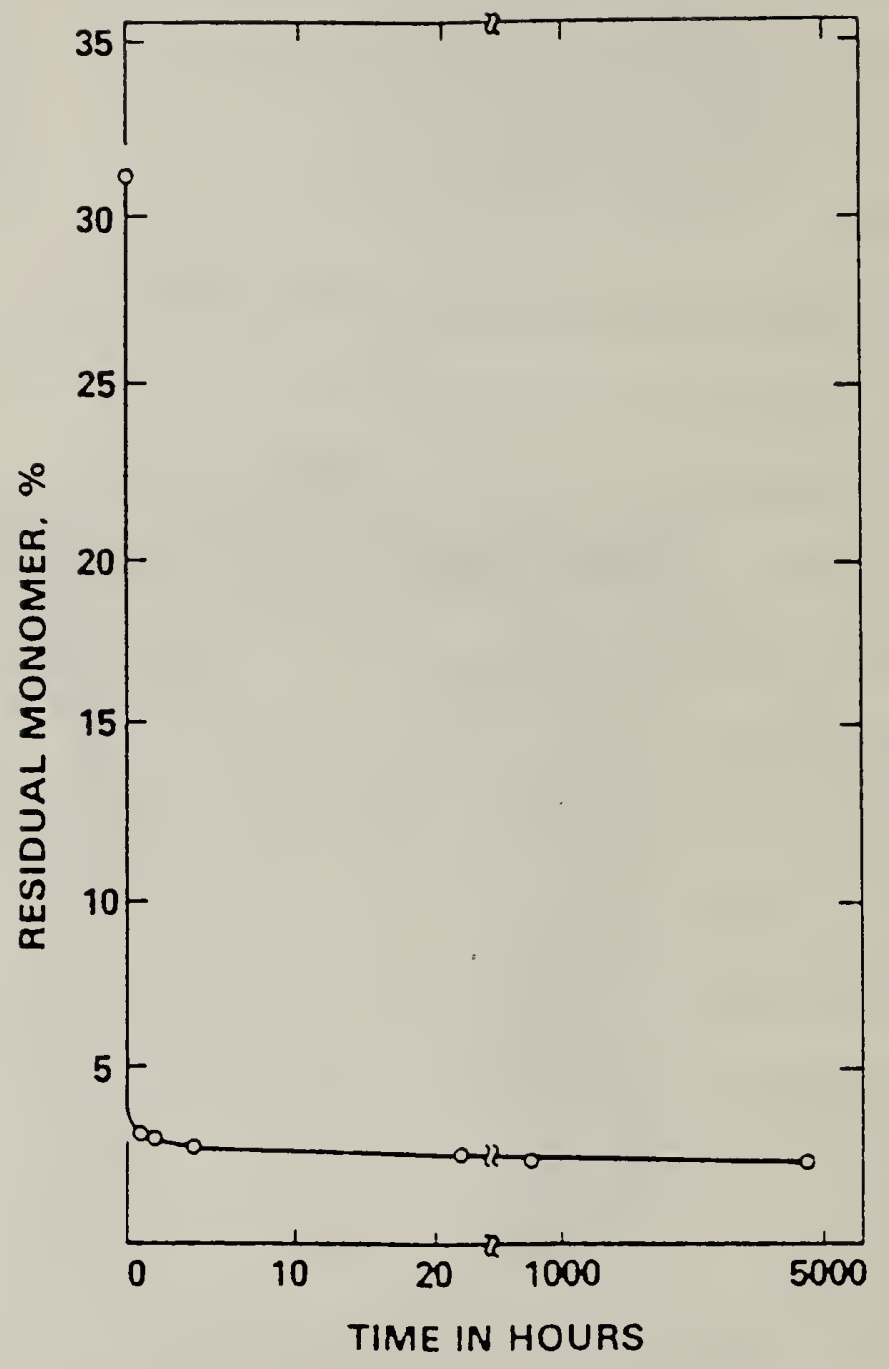

Fig. 3.4 Change of residual nionomer in cured cement with storage time in air at room temperature. [4] 
Of additional interest is the fact, which can be seen from Figure 3.4 and Table 3.8 that the monomer content of the cured cement decreases more if the material is stored in water. The monomer is apparently leached out in the water.

The amount of residual N, N-Dimethyl-p-toluidine (DMPT) in the cured cement is of the order of $0.4 \%$

[4] and there is no evidence that it leaches out into the environment after storage in water. Table 3.9 shows the amounts of hydroquinone in the monomer, powder and cured bone cement. The amount of residual hydroquinine can be seen to be quite small.

The cured cement has a molecular weight similar to, but slightly higher than that of the powder. In Table 3.10 are sunmarized some molecular weight data for the powder and cured cements. Also presented are data for a commercial polymer. Figure 3.5 shows the molecular weight distribution for the powder and for the cured cement. It is not surprising, given their higher molecular weights, that the industrial PMMA's have better mechanical properties than do the bone cements. However, for the rapid diffusion of monomer and swelling of powder consistent with appropriate doughing times, a comparatively low molecular weight poly(methy? methacrylate) powder is, perhaps, a desirable ingredient for bone cements [4]. 


\section{Sample Analyzed}

$20 \mathrm{ml}$ methyl methacryiate $+1.50 \mathrm{mg}$

HO

$19.5 \mathrm{ml}$ methyl methacrylate $+0.08 \mathrm{~m} 1$ OMPT $+1.00 \mathrm{mg} \mathrm{HO}$

$19.5 \mathrm{ml}$ methyl methacrylate $+0.5 \mathrm{ml}$ DMPT $+1.50 \mathrm{mg} \mathrm{HQ}$

$20 \mathrm{ml}$ methyl methacrylate $+1.50 \mathrm{mg} H Q$ $+1.50 \mathrm{mg} \mathrm{QC}$

Cured bone cement ( $41.20 \mathrm{~g})$

Cured bone cement $(35.61 \mathrm{~g}$ )

Bone cement powder $(40 \mathrm{~g})$, average of 3 runs

$a_{H Q}=$ hydroquinone.

${ }^{b_{D M P T}}=$ dimethyl-o-toluidine.

${ }^{C} Q=$ benzoquinone.

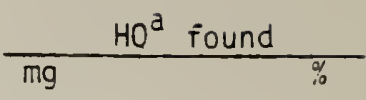

1.50

1.06

1.59

3.10

0.53

$13 \times 10^{-4}$

0.17

$5 \times 10^{-4}$

$₹ 0.05$

$21 \times 10^{-4}$

Table 3.10

Molecular Weights of Powder and Cured Materials

\begin{tabular}{|c|c|c|c|c|c|}
\hline Material & State & $H_{n}$ & $M_{v}$ & $M_{w}$ & Reference \\
\hline Simplex $P$ & $\begin{array}{l}\text { Powder } \\
\text { Cured }\end{array}$ & $\begin{array}{l}44,000 \\
51,000\end{array}$ & $\begin{array}{l}195,000 \\
203,000\end{array}$ & $\begin{array}{l}198,000 \\
242,000\end{array}$ & [4] \\
\hline CMW & $\begin{array}{l}\text { Powder } \\
\text { Cured }\end{array}$ & - & $\begin{array}{l}101,000 \\
150,000\end{array}$ & - & {$[7]$} \\
\hline Palacos R & $\begin{array}{l}\text { Powder } \\
\text { Cured }\end{array}$ & - & $\begin{array}{l}459,000 \\
435,000\end{array}$ & - & {$[7]$} \\
\hline Sulfix-6 & $\begin{array}{l}\text { Powder } \\
\text { Cured }\end{array}$ & & $\begin{array}{l}119,000 \\
127,000\end{array}$ & - & {$[7]$} \\
\hline Simplex $P$ & $\begin{array}{l}\text { Powder } \\
\text { Cured }\end{array}$ & - & $\begin{array}{l}39,000 \\
97,000\end{array}$ & - & [7] \\
\hline Simplex $P$ & $\begin{array}{l}\text { Powder } \\
\text { Cured }\end{array}$ & $\begin{array}{l}32,100 \\
45,300\end{array}$ & - & - & [8] \\
\hline $\begin{array}{l}\text { Cast PMHA } \\
\text { (Industri }\end{array}$ & de) & 546,000 & - & 639,000 & [12] \\
\hline
\end{tabular}




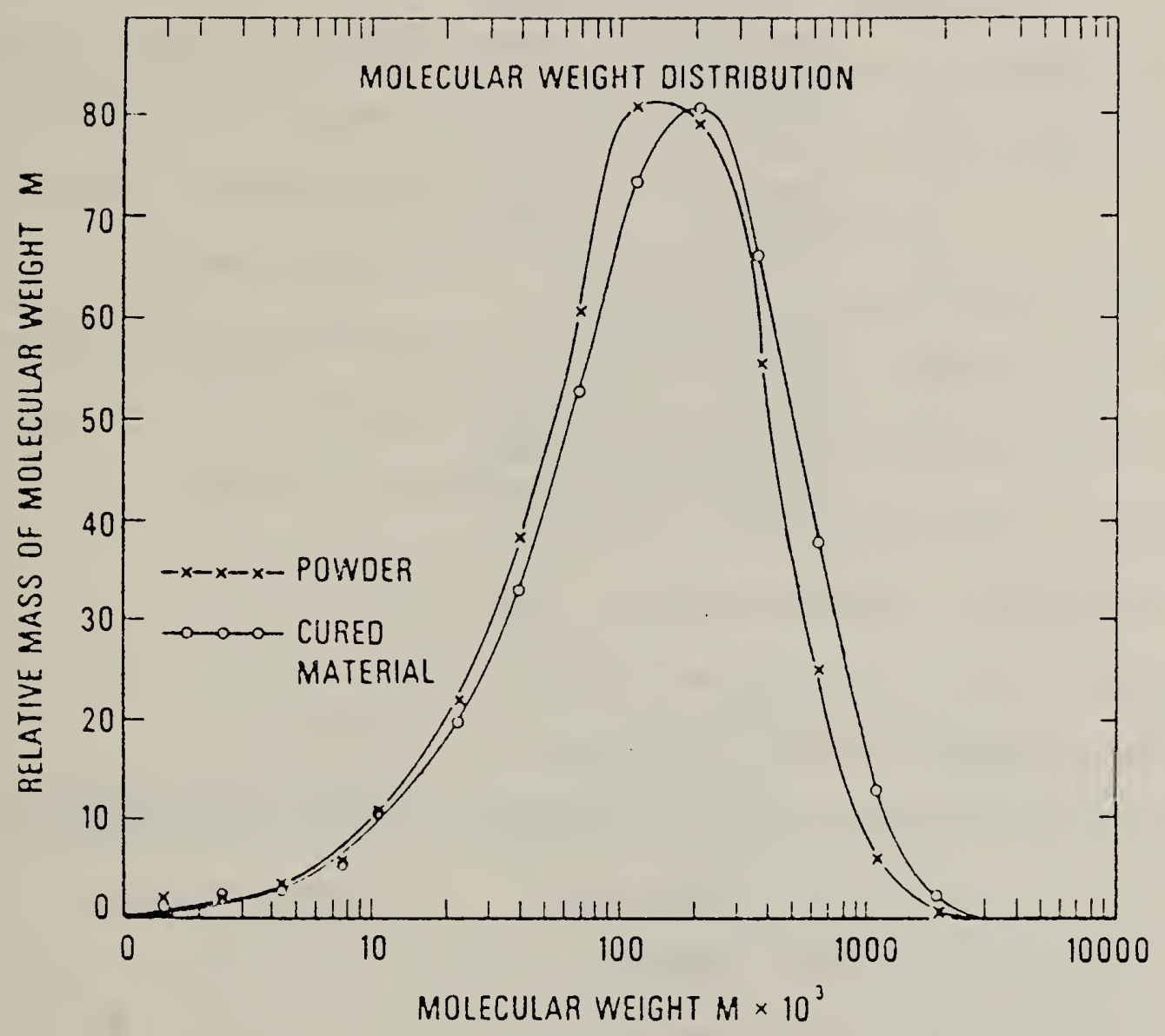

Fig. 3.5 Molecular weight distribution of $\left(-X_{-}\right)$the cement powder and $(-0-)$ cured product. From gel-permeation chromatographic measurements of a $0.25 \%$ solution of the polymer. l:obile phase: tetrahydrofuran; stationary phase: Styrage 1. [4] 
One of the major differences between bone cement and commercial PMMA is the porosity of the bone cement. The mixing of a very viscous "dough" introduces air into the cement and the final product can have considerabl porosity. The amount of porosity will depend upon the exact mixing procedures as well as the powder/ liquid ratio, powder particle size, etc. In Table 3.11 are shown some typical cement porosities obtained by Kusy [ 7] for several bone cements. Obviously there is considerable variability in the data. The precise significance of a relatively high pore volume is difficult to judge since other factors also play a role in the performance of a cement.

\section{Table 3.11}

Porosity of Two Phase Bone Cements [7]

$\begin{array}{lc}\text { Material } & \text { Percent Porosity } \\ & 1.7 \pm 1.2 \\ \text { Palacos } R & 8.0 \pm 3.0 \\ \text { Sulfix } 6 & 1.6 \pm 1.5 \\ \text { Surgical Simplex } P & 5.0 \pm 4.1\end{array}$




\subsubsection{Mechanical Properties of Cured Bone Cement}

3.3.3.3.1 Static Properties - The most

commonly measured properties of bone cement are the quasi-static tensile and compressive strengths

and modulus of elasticity. The tests used to produce values for these parameters are generally run following accepted standardized tests for rigid plastics such as ASTM D638 [15] ASTM D695[16] and ASTM D45[ 1$]$.

As noted in the previous sections, the physical and chemical properties of the cured cement can depend upon the conditions of cure. In addition, the cement changes spontaneously after cure due to either continued curing [3 ] or loss of monomer [5]. Also, in-vivo or in simulated in-vivo environments the PMMA bone cement takes up water which can also change the properties $[4,5]$.

The data in Table 3.12 show some typical properties of bone cement after cure and at ambient conditions. Because the chemical and physical properties of the bone cement are evolving with

* Since PMMA bone cement is a viscoelastic material, this is an apparent modulus value at some arbitrary strain rate. 
time after cure, it can be expected that the mechanical properties will also evolve. Haas, et al. [5] performed indentation and recovery tests (see section 3.2) on cured bone cement and observed changes which varied with temperatures of molding and of ageing (storage after cure) Their results are shown in Figure 3.6. These results correlated well with monomer loss in the cement after curing $[4]$.

Table 3.12

Typical Mechanical Properties for PMMA Bone Cements at Room Temoerature

\section{Material}

Modulus of Elasticity (GPa)

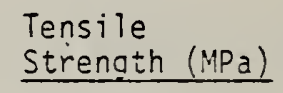

Compressive

CMW

PALACOS R

PALACOS RG

Sulfix-6

Surgical Simplex $P$

2.76

2.62

2.55

2.41

2.55

42.7

46.2

46.2

48.3

33.8

Surgical Simplex $P$ Surgical Simplex $P$ Palacos R

Surgical Simplex $P$ Sulfix-6

Palacos R

Commercial PilMA

2.30

$-$

2.4

2.6

2.4

2.83

$56.9^{\mathrm{a}}$

93.1

80.7

82.0

90

91

87

73.8

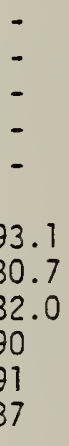

a Transverse Tensile Strength. American Dental Association Specification No.12 [17] 


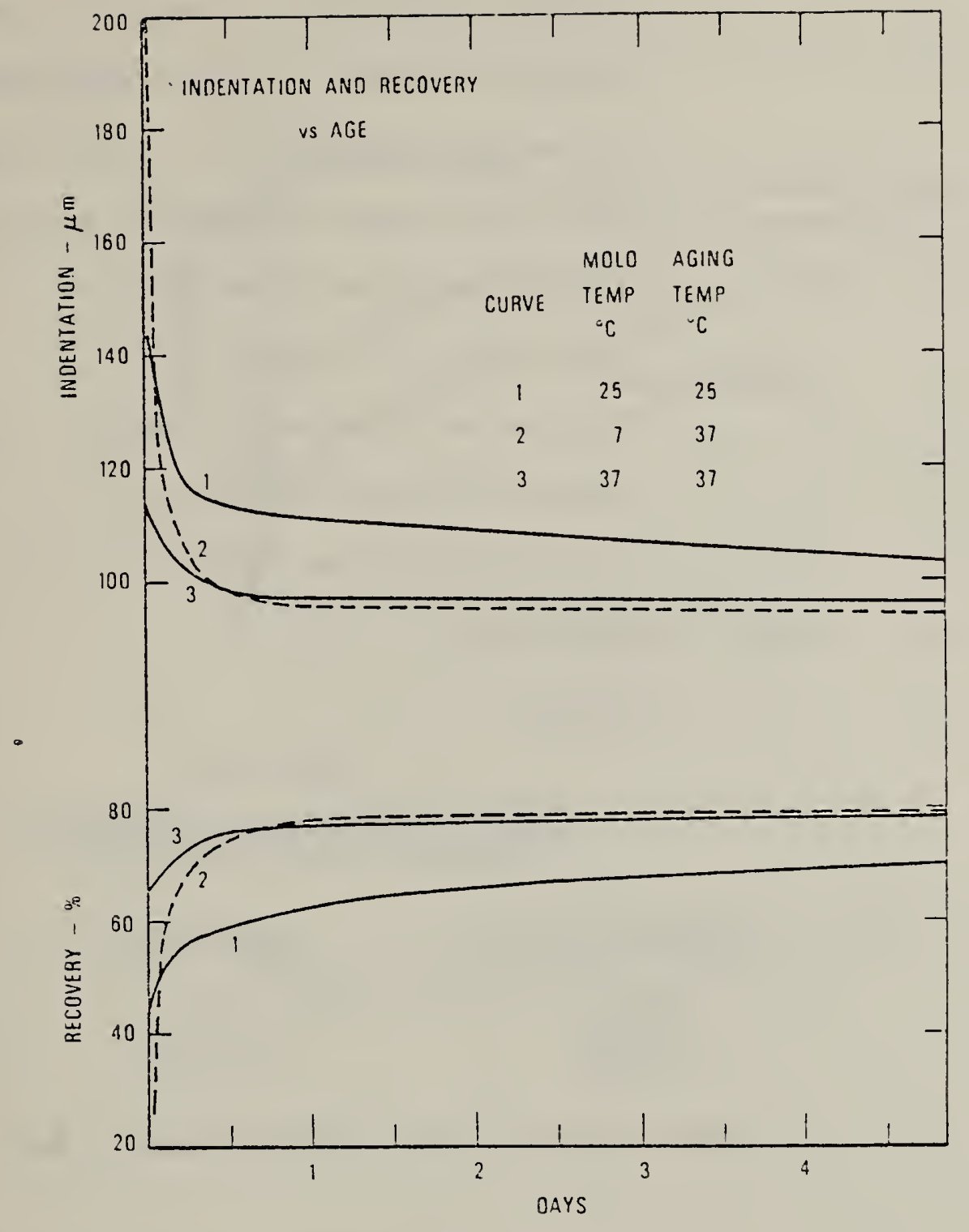

Fig.3.6 Average curves for indentation and recovery of bone cement. Curve 1 is an average of individual curves for three specimens, curve 2 for two specimens, and curve 3 for four specimens, using the indicated mold and aging temperature. [5] 
After curing, the bone cement absorbs water if it is placed in an aqueous environment [ 7 ]. This water abosption can adversely affect the mechanical properties of the bone cement. For example, Rostoker, et al, [20] have tested the flexural strength of bone cements after up to 26 months implantation in rabbits. Their results are shown in Table 3.13. Although there was much scatter in the data (1arge standard deviations) Rostoker, et al. concluded that the degradation after 26 months was significant.

$\underline{\text { Table } 3.13}$

Effect of Implantation Time on Bending Strength of P:ilia Bone Cerent [20]

Time After Molding

1 day

2 months

12 months

26 months
Environmient

air
"in vivo"
"in vivo"
"in vivo"

Failure Stress*

$48.3 \div 3.8$

$48.8 \div 4.9$

$50.9 \div 5.7$

$46.6=6.0$

* Based on Maximum "Elastic" Stress in Beam in 3 point bending.

Comparison of test results for PMMA bone cements made at varying strain rates and temperatures must be made with caution since PMMA is a viscoelastic material. Figure 3.7 shows the effect of strain rate on some properties and Figure 3.8 shows the effect of temperature. 


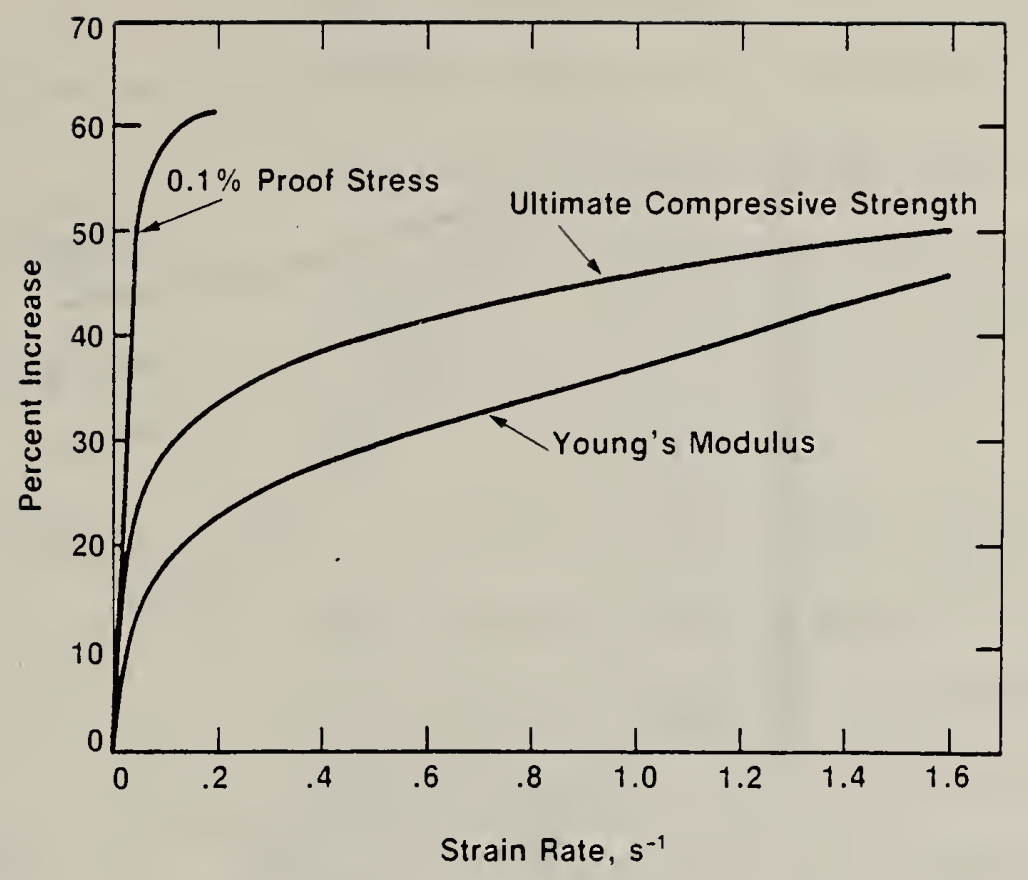

Fig. 3.7 Effect of Strain Rate on the Mechanical Proderties of PMMA Bone Cement. [19] 


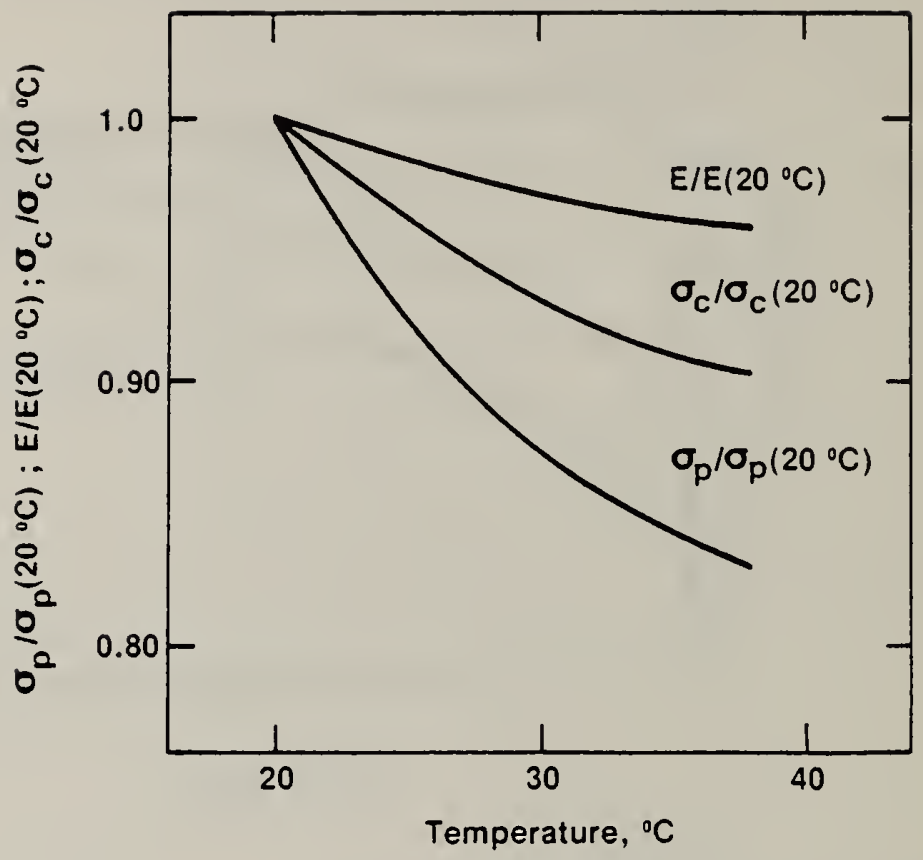

Fig. 3.8 Effect of Temperature on the Mechanical Properties of PMMA Bone Cement. $\sigma_{0}=0.1 \%$ Proof Stress. $\sigma_{c}=$ Compressive Strength. $E=$ Young's Modulus. [19] 


\subsection{Fracture and Crack Growth Characteristics}

Failure of bone cements has been treated using the concept of Fracture Mechanics*. In this, now widely accepted model, it is assumed that failure in the material initiates at an "inherent" flaw when the stress reaches some critical value, $\sigma_{C}$. The inherent flaw is thought of as a crack of length $\mathrm{C}_{0}$, and can be treated statistically.

In static tests, there are two parameters which are often used to describe the resistance of the material to crack propagation: (a) The fracture energy, $\gamma$, required to create new surface or (b) the fracture toughness, KIC. Under plane strain conditions the relationship between failure stress, $\sigma_{f}$, and $\gamma$ is [21]:

$$
\sigma_{f}=\left[\frac{2 E \gamma}{\pi\left(1-v^{2}\right) C_{0}}\right]^{\frac{1}{2}}
$$

where $E$ is the Young's modulus, $C_{0}$ is the inherent flaw size and $v$ is Poisson's ratio ( $\approx 0.35$ for PMMA). Thus, the higher $y$ the greater the resistance to crack propagation.

* The reader is referred to reference [21] for a detailed discussion of fracture mechanics and its application to polymers. 
Similarly the failure stress, $\sigma_{f}$, in terms of the fracture toughness, KIC, (in plane strain Mode I conditions) is [21]:

$$
\sigma_{f}=\left(\frac{K^{2} C}{Q^{2} C_{0}}\right)^{\frac{1}{2}}
$$

where $Q$ is a parameter depending on test geometry. In an elastic material,

$$
r=\frac{K_{I C}{ }^{2}}{E}\left(1-v^{2}\right) \text {. }
$$

As shown in Table 3.14 , bone cement when tested in air at ambient temperatures has a lower fracture toughness, $\mathrm{K}_{I C}$, than does commercial PMMA. However, as Freitag and Cannon [22] have shown in their report on fracture toughness of bone cements, there is considerable variability in the reported values for $K_{\text {IC }}$ in the literature. Thus, the literature values cited by them range from 0.6 to 1.73 times the value they measured on a commercial PMMA. Kusy [ 7] measured fracture energies for bone cements and commercial PMMA and found that the values for the base cement fell within the range of values he measured on two different samples of industrial material. His results are shown in Table 3.15. The reasons, then, that the bone cements have lower tensile strengths than do commercial PMMA lie in the values of the "inherent" 
flaw size, also shown in Table 3.15. Because of either its two phase nature or the porosity of the material the bone cements have inherent flaws which are 5 to 10 times the size of those of commercial PMMA*.

Table 3.14

Fracture Toughness, $K_{I C}$, of Bone Cement Tested in Air at Ambient Temperacure

\begin{tabular}{lcc}
\multicolumn{1}{c}{ Material } & $\mathrm{K}_{\mathrm{IC}}, \mathrm{MN}_{\mathrm{m}}{ }^{-3 / 2}$ & Reference \\
Surgical Simplex $P$ & 1.04 & {$[22]$} \\
Zimmer Cement & 1.24 & {$[22]$} \\
Commercial PMMA & 1.26 & {$[22]$} \\
Surgical Simplex $P$ & 1.0 & {$[23]$} \\
Commercial PMMA & 1.7 & {$[23]$} \\
Surgical Simplex $P$ & 1.6 & {$[24]$}
\end{tabular}

Table 3.15 Fracture Parameters for PMMA Cements at $21^{\circ} \mathrm{C}$ in air $[7]$.

\begin{tabular}{|c|c|c|}
\hline Material & Fracture Energy, $\times \times 10^{-5}\left(\mathrm{erg} / \mathrm{cm}^{2}\right)$ & $\begin{array}{l}\text { Mean Inhereot } \mathrm{Fl} \text { aw } \\
\text { Sixe, } \mathrm{C}_{0} \times 10^{2}(\mathrm{~mm})\end{array}$ \\
\hline $\begin{array}{l}\text { CMW } \\
\text { Palacos } R \\
\text { Sulfix } 6 \\
\text { Surgical Simplex } P \\
\text { Commercial PMMA }\end{array}$ & $\begin{array}{l}2.4 \pm 0.6 \\
2.9 \pm 0.8 \\
3.4 \pm 1.0 \\
2.6 \pm 0.6 \\
1.3 \pm 0.3 \\
3.9 \pm 1.8\end{array}$ & $\begin{array}{r}25 \\
25 \\
25 \\
37 \\
4.8 \\
-\end{array}$ \\
\hline
\end{tabular}

* We note here that based on the values in Table 3.15 , the fracture mechanics analysis does not agree exactly with the inherent flaw concept and fracture mechanics. However the idea is useful for analysis. 
Other variables can affect changes in the bone cement fracture behavior. One widely studied one being the pressure of fabrication. Thus, Freitag and Cannon [22], Beaumont and Young [23] and Sih and Berman [24] have found improvements in $K_{I C}$ with increasing fabrication pressure. However, given the limitations of the operating theater, it is unlikely that increasing fabrication pressures to decrease porosity is likely to be a practical method of improving bone cements.

An important consideration in the fracture of bone cements is the effect of environment on the fracture toughness. Simply testing bone cement in water results in an increase in $K_{I C}$ [23]. Similar results are found for testing in Bovine Serum [22]. Both these increases in toughness may be due to plasticization at the crack tip by the fluid. However, the major interest is the effects of environment on the material after long times of exposure to the environment.

Kusy [ 7] has measured the fracture energy and inherent flaw size of bone cements after 10 months in distilled water. Results are presented 
in Table 3.16. In comparing these results with those of Table 3.15 it must be noted that the trio sets of tests were carried out at different temperatures. Literature values reported by Kusy [ 7], however, show little effect of temperature changes from ambient to $37^{\circ} \mathrm{C}$ on either $\gamma$ or $C_{0}$ and it does, therefore, appear that the ageing of the cement in aqueous environment leads to little change in fracture toughness, but large increases in $C_{0}$ and, therefore, decreases in tensile strength.

Table 3.16

\section{Fracture Parameters for pma Cements
after Immersion in Distilied : Water $[7] 1$}

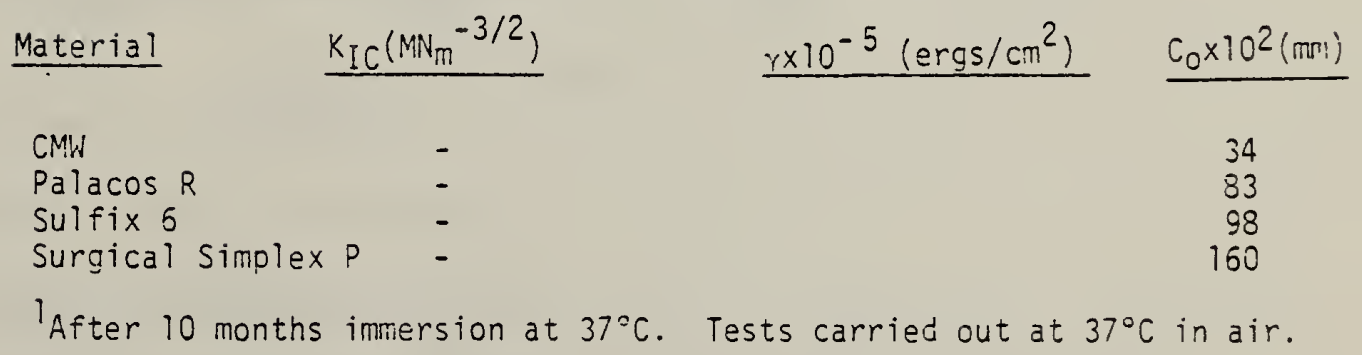


The fatigue behavior of bone cement has been little characterized. Figure 3.9 shows some typical $\mathrm{S}-\mathrm{N}$ behavior for a bone cement after work by Freitag and Cannon [25]. Similar results were obtained by pilliar, et al. [26]. Table 3.17 indicates that the lifetime in fatigue is greater in Bovine serum than in air. The conclusions drawn on differing bone cements in reference [25] are disputed in reference [27].

\section{Table 3.17}

Comparison of Fatigue Lifetime of PMinA Bone Cement in Bovine Serum and in air. at $3 T^{\circ} \mathrm{C}[25]$.

\section{Test Environment}

Air Bovine Serum
Fatique Lifetime, Cycles

$$
2.7 \times 10^{5}
$$$$
3.8 \times 10^{6}
$$

*Rotating Beam Fatique. Stress level not reported.

A problem in characterizing fatigue behavior of polymers is their viscoelastic nature. Thus, at high frequencies thermal buildup may cause premature failure. In addition, total fatique Tifetime is frequency sensitive in such a fashion that prediction of failure time or cycles to failure at $1 \mathrm{hz}$ from data obtained at $35 \mathrm{hz}$, for example, can lead to an incorrect estimate of 
lifetime. Figure 3.10 shows how test frequency

affects the fatigue 1 ifetime for a commercial

PMMA [28]. Discussions of this problem can be

found in references [29] and [30].

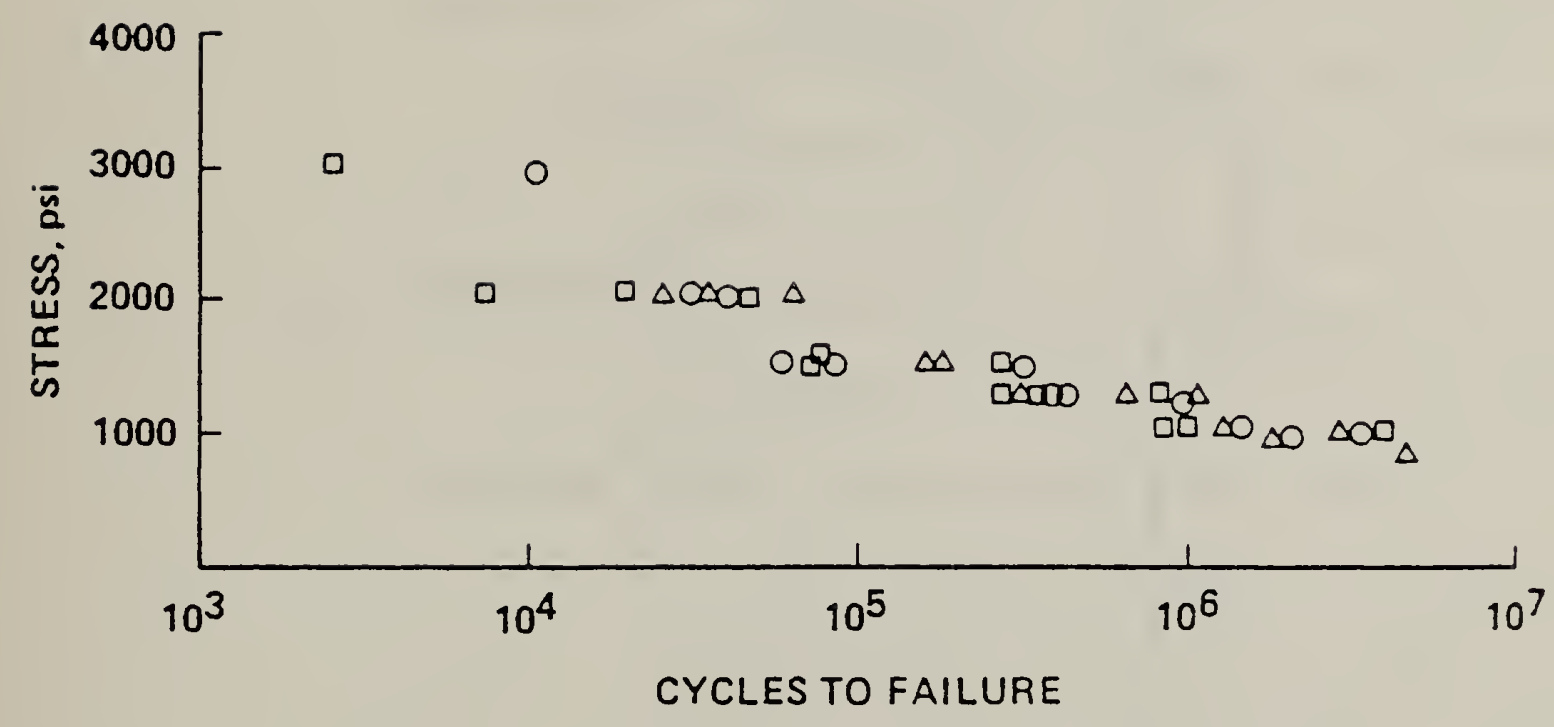

Fig. 3.9 Life comparison of Simplex-P bone cement fabricated at pressures of $(\Delta) 5,(\square) 25$, and $(O) 50$ psi and tested in air at $222^{\circ} \mathrm{C} .[25]$ 


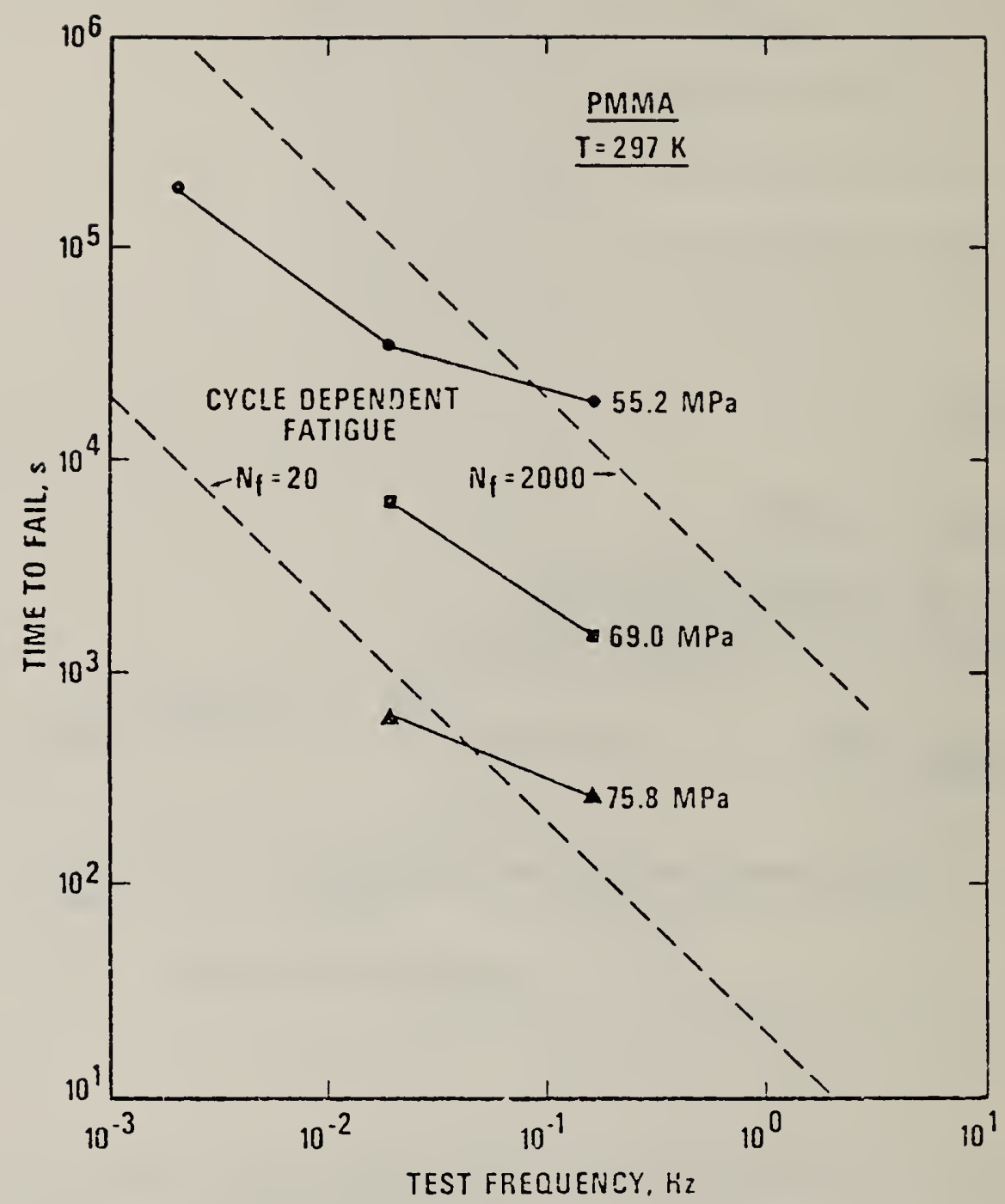

Fig. 3.10 Effect of Test Frequency on the Lifetime of Commerical PrMA Subjected to Zero-Tension Sinusoidal Fatique Loading. [28] 
3.3.3.3.3. Viscoelastic Behavior of Acrylic Bone Cements - PMMA is a material which shows non-linear viscoelastic behavior [12]. Therefore, it should be expected that PMMA bone cements exhibit similar behavior. The effects of various fabrication and cement variables on the viscoelastic properties of the cured cements have been little studied. The most complete work to date is that of Chwirut [31], although other studies have been made $[32,33]$. Figures 3.11 and 3.12 show compressive creep data for various bone cements at $37^{\circ} \mathrm{C}$ and in a norma saline environment. It is of interest to note that (a) in Figure 3.11 , the creep rate is approximately the same for all stress levels, except at the highest stress. Chwirut [31] found that the data fit well to an exponential creep function, $\varepsilon=f(\sigma) t^{n}$; (b) in Figure 3.12 , the amount of creep for different cements varies quite significantly from .006 to .011 for the unreinforced materials. This could be significarit and may be due to differences in porosity, molecular weights or particle sizes of the cements. Certainily more work is required to fulty characterize the behavior of the cements. 
An interesting finding in reference [31] is that, at long times and stresses which are in the range to be expected for implanted bone cements, microcracking occurs in the cements. This is important and may be related to "in vivo" failure of cements. 


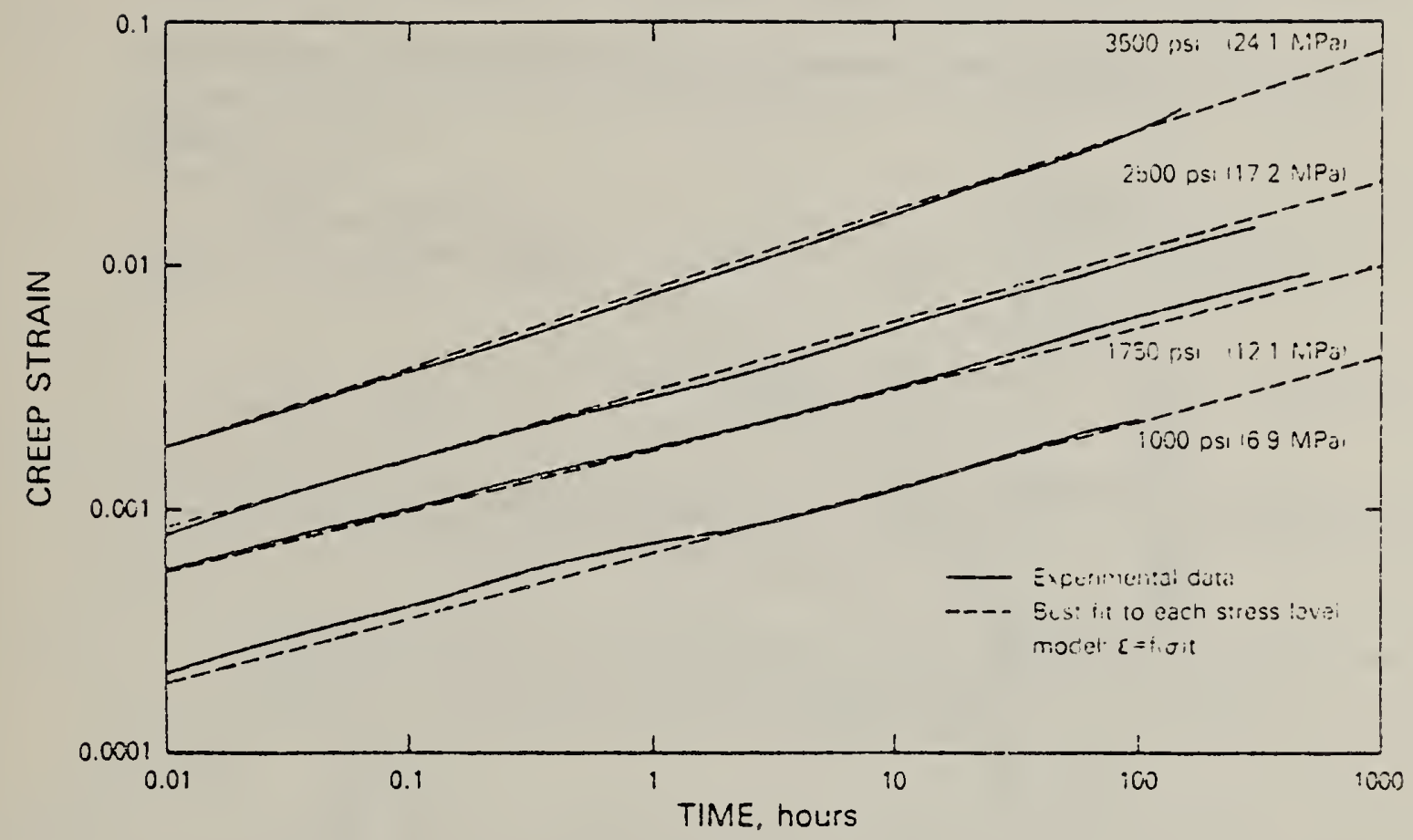

Fig. 3.11 Creep of Zimmer Regular Bone Cement at $37^{\circ} \mathrm{C}$ in Normal Saline Solution. [31] 


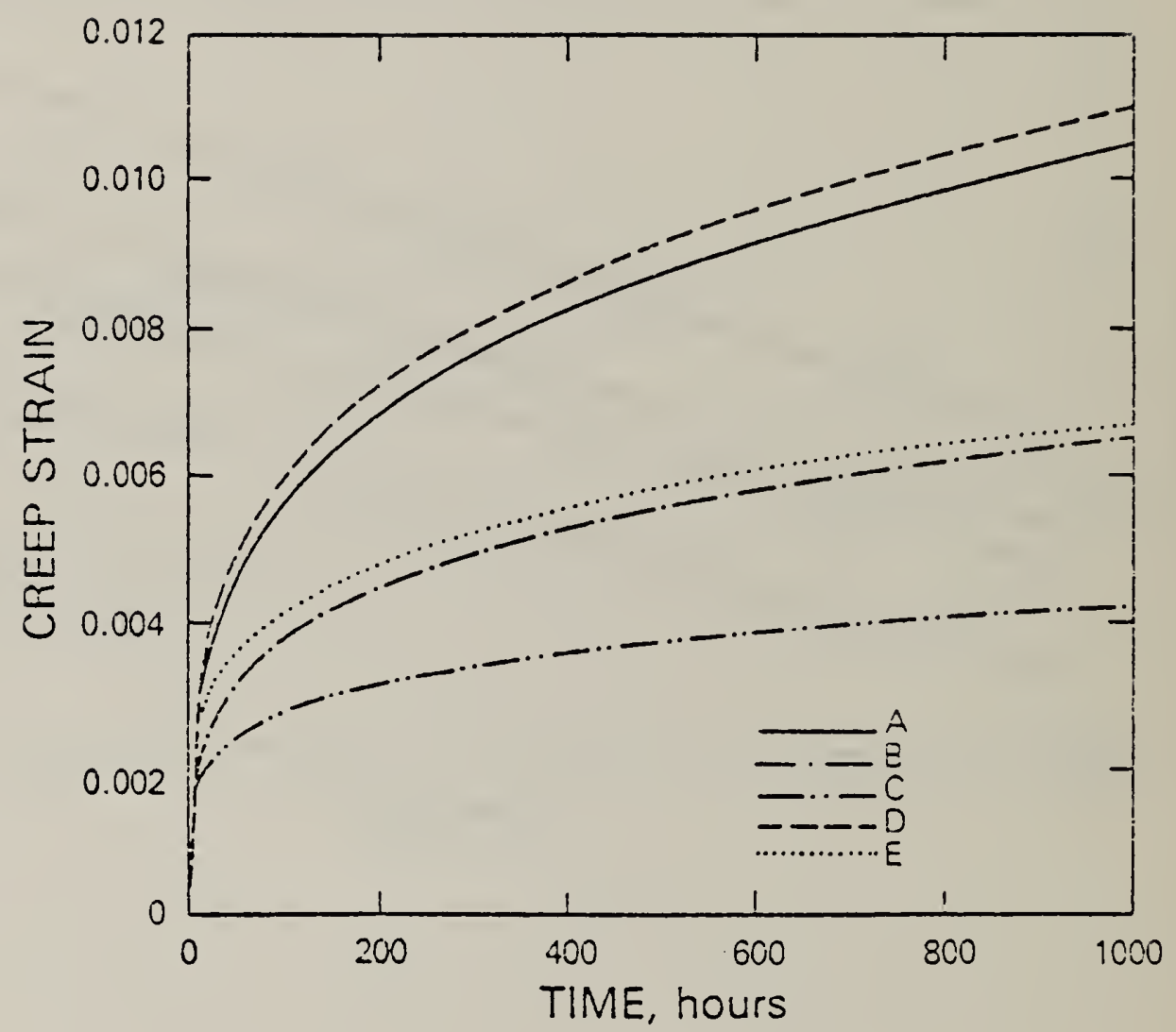

Fig. 3.12 Compressive Creep of Bone Cement at $37^{\circ} \mathrm{C}$ in Normal Saline Solution. Stress $=12.1 \mathrm{MPa}$. A. Zimmer Regular Cement. B. Zimmer Low Viscosity Cement. C. Zimmer Carbon Fiber Reinforced Cement. D. Omniplastic Cement. E. Surgical Simplex P. [31] 
1. Annual Book of ASTM STANDARDS published by the American Society for Testing and Materials, 1916 Race Street, Philadelphia, PA. 19103, 1982 edition, Part 46.

2. U.S. Pharmacopeia, Revision 19, Mack Publishing Co., Easton, Pa., 1975, pp 593-599.

3. D. F. Williams and R. Roaf, Implants in Surgery, W. B. Saunders Company, Ltd, Philadelphia (1973).

4. G. M. Brauer, D. J. Termini and G. Dickson, "Analysis of the Ingredients and Determination of the Residual Components of Acrylic Bone Cements", J. Biomed. Mater. Res., 11, 577-607 (1977).

5. S. S. Haas, G. M. Brauer and G. Dickson, "A Characterization of Polymethylmethacrylate Bone Cement", J. Bone Joint Surg., 57-A, 380-391 (1975).

6. S. S. Haas, G. Dickson and G. M. Brauer, "A Proposed Specification for Acrylic Bone Cement", J. Biomed. Mater. Res. Symposium, 6 , $105-117(1975)$.

7. R. P. Kusy "Characterization of Self-Curing Acrylic Bone Cements", J. Biomed. Mater. Res., 12, 271-305 (1978).

8. S. C. Bayne, E. P. Lautenschlager, C. L. Compere and R. Wi Tdes, "Degree of Polymerization of Acrylic Bone Cement", J. Biomed. Mater. Res., 9, 27-34 (1975).

9. E. P. Lautenschlager, G. W. Marsha11, K. E. Marks, J. Schwartz and C. L. Nelson, "Mechanical Strength of Acrylic Bone Cements Impregnated with Antibiotics", J. Biomed. Mater. Res., 10, 837-845 $(1976)$.

10. R. C. Nelson, R. O. Hoffman and T. A. Burton, "The Effect of Antibiotic Additions on the Mechanical Properties of Acrylic Cement", J. Biomed. Mater. Res., 12, 473-490 (1978).

11. A. B. Welch, "Antibiotics in Acrylic Bone Cement. In Vivo Studies", J. Biomed. Mater. Res., 12, 843-855 (1978).

12. G. B. McKenna and L. J. Zapas "Non-linear Viscoelastic Behavior of Poly(methyl methacrylate) in Torsion", J. Rheology, 23, 151-166 (1979).

13. R. C. Turner, P. E. Atkins, M. A. Ackley and J. B. Park, "Molecular and Macroscopic Properties of PMMA Bone Cement: Free Radica 1 Generation and Temperature Change Versus Mixing Ratio", J. Biomed. Mater. Research, 15, 425-432 (1981).

14. H. B. Lee and D. T. Turner, "Temperature Control of a Bone Cement by Addition of a Crystalline Monomer", J. Biomed. Mater. Res., 11, $671-676$ (1977). 
15. ASTM 0638-76 "Standard Test Method for Tensile Properties of Plastics", Annual Book of ASTM Standards, published by the American Society for Testing and Materials, Philadelphia, (1977) part 35 .

16. ASTM 0695-69 "Compressive Properties of Rigid Plastics" Annual Book of ASTM Standards, published by the American Society for Testing and Materials, Philadelphia, (1977), part 35.

17. American Dental Association, Guide to Dental Materials and Devices, Ed. 6, p. 201, American Denta1 Assn., Chicago, 1972.

18. E. P. Lautenschlager, J. J. Jacobs, G. W. Marshall and P. R. Meyer, Jr. "Mechanical Properties of Bone Cements Containing Large Doses of Antibiotic Powders", J. Biomed. Mater. Res., 10, 929-938 (1976).

19. A.J.C. Lee, R. S. M. Ling and S. S. Vangala, "The Mechanical Properties of Bone Cements", J. Med. Eng. Techno1., 2, 137-140, (1977).

20. W. Rostoker, P. Lereim and J. O. Galante, "Effect of 'In Vivo' Environment on the Strength of Bone Cement", J. Biomed. Mater. Res., 13, 365-370 (1979).

21. A. J. Kinloch and R. J. Young, Fracture Behavior of Polymers, Applied Science, New York, 1983.

22. T. A. Freitag and S. L. Cannon, "Fracture Characteristics of Acrylic Bone Cements", J. Biomed Mater. Res., 10, 805-828 (1976).

23. P.W.R. Beaumont and R. J. Young "Slow Crack Growth in Acrylic Bone Cement", J. Biomed Mater. Res., 9, 423-439 (1975).

24. G. C. Sih and A. T. Berman, "Fracture Toughness Concept Applied to methyl methacrylate", J. Biomed. Mate. Res., 14, 311-324 (1980).

25. T. A. Freitag and S. L. Cannon "Fracture Characteristics of Acrylic Bone Cements. II. Fatigue", J. Biomed. Mater. Res., 11, 609-624 (1977).

26. R. M. Pilliar, R. Blackwel1, I. MacNab and H.U. Cameron, "Carbon Fiber Reinforced Bone Cement in Orthopedic Surgery", J. Biomed. Mater. Res., 10, 893-906 (1976).

27. C. F. Stark, "Fracture and Fatigue Characteristics of Bone Cements", J. Biomed. Mater. Res., 13, 339-342 (1979).

28. G. B. McKenna and R. W. Penn, "Time Dependent Failure in Poly(methyl methacrylate) and Polyethylene", Polymer, 21, 213-220 (1980).

29. G. B. McKenna and R. W. Penn, "Time Dependent Failure of a Polyolefin Rubber Candidate Material for Blood Pump Aoolications", J. Biomed. Mater. Res., 14, 689-703 (1980). 
30. G. B. McKenna, J. M. Crissman and F. A. Khoury, "The Relationship Between Morphology and Mechanical Properties of UItra High Molecular Weight Polyethylene", Second Annual Report to the Bureau of Medical Devices, Food and Drug Administration, NBS-BMD Interagency Agreement, Task No. 80.01, October, 1981.

31. D. J. Chwirut, "Long-Term Compressive Creep Deformation and Damage in Acrylic Bone Cements", J. Biomed. Mater. Res., In Press (1983).

32. R. W. Treharne and N. Brown, "Factors Influencing the Creep Behavior of Poly (methyl methacrylate) Cements", J. Biomed. Mater. Res. Symposium, $\underline{6}, 81-88$ (1975).

33. S. Pal and S. Saha, "Stress Relaxation and Creep Behavior of Normal and Carbon Fibre Reinforced Acrylic Bone Cement", Biomaterials, 3 , 93-96 (1982). 

NBS-114A (REV. 2.8C)

\begin{tabular}{|c|c|c|c|}
\hline $\begin{array}{l}\text { U.S. OEPT. OF COMM. } \\
\text { BIBLLOGRAPHIC DATA } \\
\text { SHEET (See in structions) }\end{array}$ & $\begin{array}{l}\text { 1. PUBLICATION OR } \\
\text { REPORT NO. } \\
\text { NBSIR } 84-2820\end{array}$ & 2. Performing Organ. Report No. & $\begin{array}{l}\text { 3. Publication Dare } \\
\text { January } 1984\end{array}$ \\
\hline
\end{tabular}

Information on Polymeric Materials Used in Orthopedic Devices

5. $A \cup T H O R(S)$

J. M. Crissman and G. B. McKenna

6. PERFORMING ORGANIZATION (If joint or other than NBS, see instructions)

7. Contract Grant No.

NATIONAL BUREAU OF STANDARDS

DEPARTMENT OF COMMERCE

WASHINGTON, D.C. 20234

9. SPONSORING ORGANIZATION NAME AINO COMFLETE ADORESS (STTEL. CiLY. STUTE, ZIF)

Food and Drug Administration

Bureau of Medical Devices

8257 Georgia Ave., Silver Spring, MD 20910

10. SUPPLEMENTARY NOTES

Document describes a computer program; SF-185. FIPS Software Summary, is attached.

11. ABSTRACT (A 200-word or less factual summary of most significant information. If document includes a significant bibliography or literature survey. mention it here)

This report provides information on the two polymeric matërials most commonly used in the fabrication of orthopedic implants. The work was done as part of Task 80-01 NBS-FDA/BMD Interagency Agreement. The two materials described are ultra high molecular weight polyethylene UHMWPE and polymethylmethacrylate (PMMA) bone cement: The report contains information on such subjects as specifications (ASTM), raw materials characterization, processing, morphology, mechanical properties, and wear.

12. KEY WORDS (Six to twelve entries; alphabetical order; capitalize only pioder names; and sedara:e key words ty semicolons) Acrylic; bone cement; mechanical properties; morphology; orthopedic implant; poly(methyl methacrylate); processing; ultra high molecular weight polyethylene.

13. AVAILABILITY

【X Unlimited

For Official Distribution. Do Not Release to NTIS

Order From Superintendent of Documents, U.S. Government Printing Office, Washıngion, O.C. 20402.

¿X Order From National Technical Information Service (NTIS), Springfield, VA. 2216I
14. NO. OF

PRINTED PAGES

129

15. Prize

$\$ 14.50$ 



\section{.}


